\title{
NBSIR 77-1254
}

\section{Transportation, Handling and Field Service Loads for Air Mobility Shelter Systems}

C. W. C. Yancey

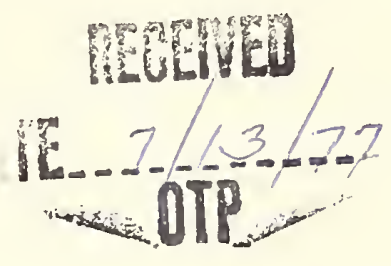

Center for Building Technology Institute for Applied Technology National Bureau of Standards

Washington, D. C. 20234

July 1977

Final Report

Prepared for

Civil \& Environmental Engineering Development Agency Tyndall Air Force Base, Florida 32401 



\section{TRANSPORTATION, HANDLING AND \\ FIELD SERVICE LOADS FOR AIR \\ MOBILITY SHELTER SYSTEMS}

C. W. Yancey

Center for Building Technology Institute for Applied Technology National Bureau of Standards

Washington, D. C. 20234

July 1977

Final Report

Prepared for

Civil \& Environmental Engineering Development Agency

Tyndall Air Force Base, Florida 32401

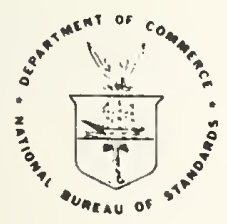

U.S. DEPARTMENT OF COMMERCE, Juanita M. Kreps, Secretary Dr. Sidney Harman, Under Secretary Jordan J. Baruch, Assistant Secretary for Science and Technology NATIONAL BUREAU OF STANDARDS, Ennest Ambler, Acting Director 

PREFACE

ABSTRACT

SI CONVERSION UNITS

1. INTRODUCTION. . . . . . . . . . . . . . . . . . . . . . . . . . . . . 1

1.1 Background. . . . . . . . . . . . . . . . . . . . . . . . . 1

1.2 Objectives and Approach . . . . . . . . . . . . . . . . . . . . . 1

1.2 .1 Objectives . . . . . . . . . . . . . . . . . . . . . . 1

1.2 .2 Approach . . . . . . . . . . . . . . . . . . . . . 1

1.3 Description of Information in the Literature. . . . . . . . . . . . . . . 4

1.4 Organization of Report. . . . . . . . . . . . . . . . . . . . . . 7

2. RAILROAD ENVIRONMENT . . . . . . . . . . . . . . . . . . . . . . . 8

2.1 Over-The-Rail-Transport . . . . . . . . . . . . . . . . . . 8

2.1.1 Random Vibration Excitation. . . . . . . . . . . . . . . . . 11

2.1.2 In-Transit Shock Excitation. . . . . . . . . . . . . . . . . . 15

2.2 Coupling Operations in Switching Yards. . . . . . . . . . . . . . . . . . 17

3. ROAD ENVIRONMENT. • . . . . . . . . . . . . . . . . . . . . . . . 27

4. AIR ENVIRONMENT . . . . . . . . . . . . . . . . . . . . . . . . . . . 37

4.1 Airplane Transport of Cargo . . . . . . . . . . . . . . . . . . . 37

4.1.1 Propeller-Driven Airplanes . . . . . . . . . . . . . . . . . 37

4.1 .2 Turbojet Airplanes . . . . . . . . . . . . . . . . . . . . 42

4.2 Helicopter Transport of Cargo . . . . . . . . . . . . . . . . . . . 44

4.2.1 Cargo Transported Inside Helicopters . . . . . . . . . . . . . . . 44

4.2.2 Cargo Transported Outside Helicopters. . . . . . . . . . . . . . . 50

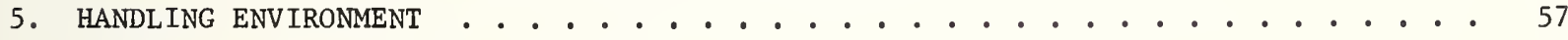

5.1 Normal Handling Excitations . . . . . . . . . . . . . . . . . . . . 57

5.1 .1 Lifting Inputs . . . . . . . . . . . . . . . . . . . 57

5.1 .2 Placement During Stacking. . . . . . . . . . . . . . . . . 57

5.1.3 Short Transport by Handling Devices. . . . . . . . . . . . . . . . 58

5.2 Abnormal Handling Excitations . . . . . . . . . . . . . . . . . 58

6. FIELD SERVICE LOADS . . . . . . . . . . . . . . . . . . . . . . . 60

6.1 Gravity Loads . . . . . . . . . . . . . . . . . . . . . . . . 60

6.2 Snow and Ice Loads. . . . . . . . . . . . . . . . . . . . 60

6.3 Wind Loads. . . . . . . . . . . . . . . . . . . . . . 60 60

6.4 Thermal Loads . . . . . . . . . . . . . . . . . . . . . . 61

6.5 Combination of Field Service Loads. . . . . . . . . . . . . . . . . . 62

7. SUMMARY AND CONCLUSIONS . . . . . . . . . . . . . . . . . . . . . . 63

7.1 Areas of Sufficient Data. . . . . . . . . . . . . . . . . . 63

7.2 Areas of Insufficient Data. . . . . . . . . . . . . . . . . . . . . 64

8. LIST OF REFERENCES . . . . . . . . . . . . . . . . . . . . . . . 66 
This report was prepared by the Structures Section, Center for Building Technology, Institute for Applied Technology, National Bureau of Standards, Washington, D. C. for the Air Force Clvil \& Environmental Engineering Development Agency, Tyndall Air Force Base, Florida. The preceeding Interim Report identified the deficiencies in the current design procedure for military shelters. This report is an expansion of the Interim Report and its purpose is to present some of the dynamic load information--incident to transportation--needed to improve the design procedure for shelters. 
To fulfill one of the prerequisites for establishing design criteria for milltary fleld shelters, transportation, handling and field service load data are presented. An extensive literature search was conducted to determine the magnitude and frequencies of shock and vibration responses produced by railroad, road and air cargo vehicles and by devices commonly used in handling fleld shelters. Summary data, extracted from field study reports, are presented in the form of acceleration versus frequency diagrams. The acceleration values can be used to compute an Equivalent Static Force input for the design and analysis of shelter models. The probabilities of occurrence of the acceleration amplitudes generated by the three transportation modes are indicated in cases where data reduction included statistical analyses. Sources of the dynamic load data included flatbed trucks, propeller and jet airplanes, helicopters, ra1lroad flatcars and forklift trucks. Where possible, the shock and vibration data used in presenting the sumary diagrams were restricted to that obtained from tests involving military vehicles commonly used to transport shelters. Recommendations are presented for the selection of static design loads to account for gravity, snow, 1ce and wind effects.

Key Words: Acceleration; airplanes; cargo, dynamic loads; equivalent static force; gravity load; handling devices; handling loads; military field shelters; probability distributions; shocks, snow load; static load; trains; transportation; trucks; vibrations; wind load. 


\section{SI Conversion Units}

In view of the present accepted practice in this country for building technology, common U.S. units of measurement have been used throughout this publication. In recognition of the position of the United States as a signatory to the General Conference on Weights and Measures, which gave official status to the metric SI system of units in 1960, appropriate conversion factors have been provided in the table below. The reader interested in making further use of the coherent system of SI units is referred to:

NBS SP 330, 1972 Edition, "The International System of Units"

ASTM E380-75/IEEE Std. 268-1976 ASTM/IEEE Standard Metric Practice

Table of Conversion Factors to Metric (S.I.) Units

\begin{tabular}{|c|c|c|c|}
\hline Physical Quantity & To Convert From & To & Multiply By \\
\hline \multirow{2}{*}{ Length } & inch (in) & meter $(\mathrm{m})^{\mathrm{a}}$ & $2.540 \times 10^{-2} *$ \\
\hline & foot $(f t)$ & meter (m) & $3.048 \times 10^{-1} *$ \\
\hline \multirow[t]{2}{*}{ Area } & inch $^{2}$ & meter ${ }^{2}\left(m^{2}\right)$ & $6.4516 \times 10^{-4} *$ \\
\hline & foot $^{2}$ & meter $^{2}\left(m^{2}\right)$ & $9.290 \times 10^{-2}$ \\
\hline \multirow[t]{2}{*}{ Volume } & inch $^{3}$ & meter ${ }^{3}\left(\mathrm{~m}^{3}\right)$ & $1.639 \times 10^{-5}$ \\
\hline & foot $^{3}$ & méter ${ }^{3}\left(\mathrm{~m}^{3}\right)$ & $2.832 \times 10^{-2}$ \\
\hline \multirow[t]{2}{*}{ Force } & pound (1bf) & newton (N) & 4.448 \\
\hline & kilogram (kgf) & newton $(\mathrm{N})$ & 9.807 \\
\hline Pressure, Stress & psi & $\begin{array}{l}\text { Pascals (pa) or } \\
\text { newton/meter }{ }^{2}\left(\mathrm{~N} / \mathrm{m}^{2}\right)\end{array}$ & $6.894 \times 10^{3}$ \\
\hline \multirow[t]{2}{*}{ Energy } & inch-pound (in-lbf) & joule (J) & 1.130. $\times 10^{-1}$ \\
\hline & foot-pound (ft-1bf) & joule $(\mathrm{J})$ & $13.558 \times 10^{-1}$ \\
\hline Weight, Mass & pound $(1 \mathrm{bm})$ & kilogram (kg) & $4.536 \times 10^{-1}$ \\
\hline Unit Weight & $\mathrm{pef}$ & kilogram/meter ${ }^{3}\left(\mathrm{~kg} / \mathrm{m}^{3}\right)$ & 16.018 \\
\hline Velocity & foot/sec (fps) & meter/sec $(\mathrm{m} / \mathrm{s})$ & $3.048 \times 10^{-1} *$ \\
\hline Acceleration & foot $/ \sec ^{2}$ & meter $/ \sec ^{2}\left(\mathrm{~m} / \mathrm{s}^{2}\right)$ & $3.048 \times 10^{-1}$ \\
\hline
\end{tabular}

Meter may be subdivided. A centimeter $(\mathrm{cm})$ is $1 / 100$ and a millimeter $(\mathrm{mm})$ is $1 / 1000 \mathrm{~m}$. *Exact. 


\section{INTRODUCTION}

1.1 Background - The dynamic environment generated during the Lransportation and handling of cargo consists of randomly occurring dynamic forces. These forces have characteristics which are categorized as periodic, transient or random. Combinations of these types of dynamic forces result from transportation and handling events. In general, the forcing function input to the cargo is complex in nature; furthermore, forcing functions are difficult to describe for some events because of a scarcity of recorded data upon which to base a definition.

The right hand side of figure 1.1 illustrates the point that dynamic loads can be defined at several interfaces within a given transportation or handling mode. From an analytical standpoint, it is desirable to describe the loads at the point of attachment of the shelter to the support or tiedown system (i.e. interface $\underline{A}$ in figure 1.1). The dynamic loads so described would become the applied forces needed to analyze the shelter as a structural system. The desired condition notwithstanding, forcing functions usually have not been defined at the attachment point interface in test programs. Thus, the dynamic loads to be applied to shelters must be derived from dynamic response measurements made at other, more convenient interfaces. For the various transportation modes documented in the literature, dynamic response has usually been described in terms of shocks and vibrations on the cargo loadbed at locations directly adjacent to (e.g. fore and aft) the cargo.

In view of the fact that mobile shelters are placed into service in many parts of the world and are transported by various modes, it is necessary to establish a set of design/ analysis criteria. Predicting transportation and handling loads is one of the prerequisites to establishing criteria. The description of the design loads must be compatible with the available methods for analyzing structures such as shelters. While there have been several efforts to gather and summarize transportation load data, no existing compilation fulfills the objective of translating the data into a common format which can be used in developing a design criteria.

\subsection{Objectives and Approach}

1.2.1 Objectives - This study was conducted to establish design loads for mobile shelters, which are incident to three modes of cargo transportation: railcar, truck and aircraft. To provide the basis for a comprehensive design criteria, the study also sought to define load inputs induced by handling operations and field service. The format for presenting the load data was to be consistent with an equivalent static force analysis of typical shelter conformations. The formulation of load combinations and the development of design criteria were not within the scope of this study.

1.2.2 Approach - As shown in figure 1.2, a cycle of shelter use may involve loads incident to transportation, handling and field service. The transportation and 
I HELO SHELTER

2 TIEDOWN FIXTURE
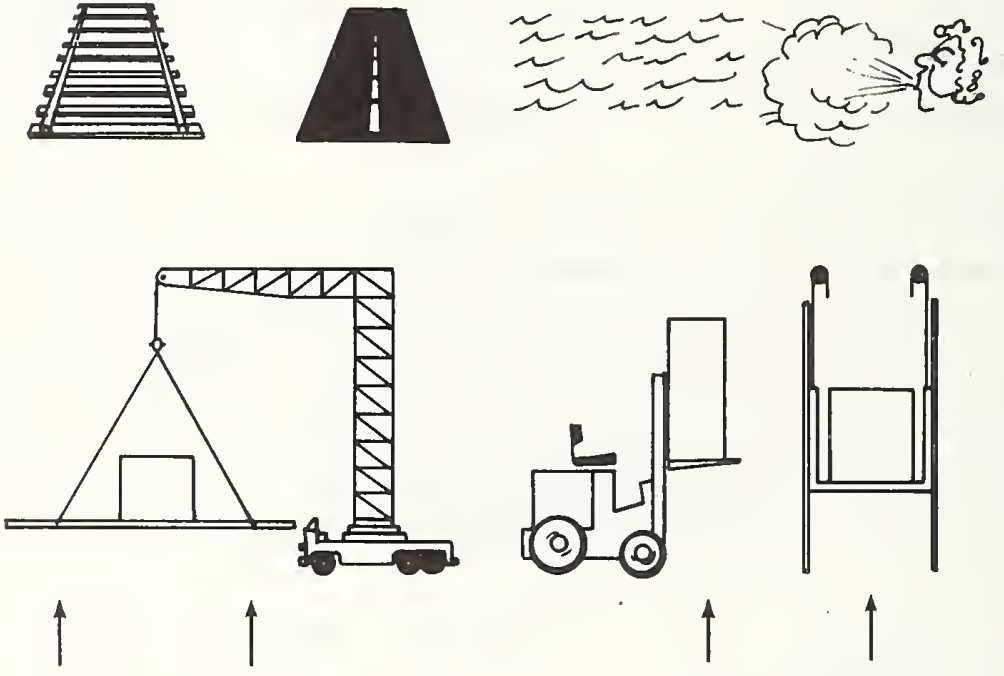

D
3 TRANSPORTATION MODE IIRAIN. TRUCK, BOAT AIRPLANE, HELICOPTER)

4 TRANSPORTATION MEOIUM (RAIL, ROAD, WATER, AIR)
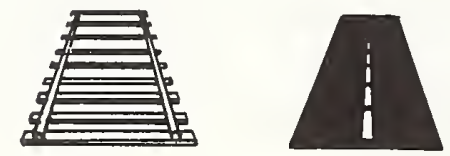

B
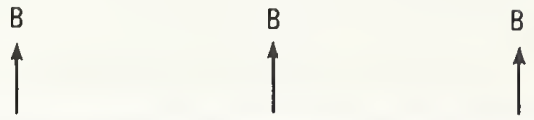

5 HANDLING OEVICES (CRANE, FORKLIFT, ELEVATOR, ETC.)

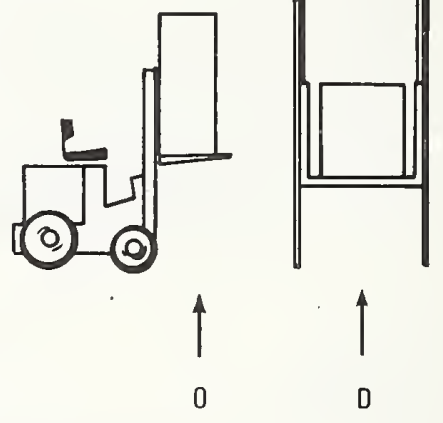

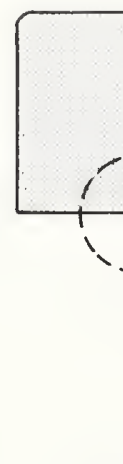

$c$
1

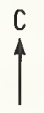

1

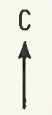

B LOAOS AT LOADBED OF TRANSPORT VEHICLE
A LOAO INPUT TO SHELTER

C FORCING FUNCTION INPUT FROM TRANSPORTATION MEOIUM

D LOAOS FROM HANOLING OEVICES 


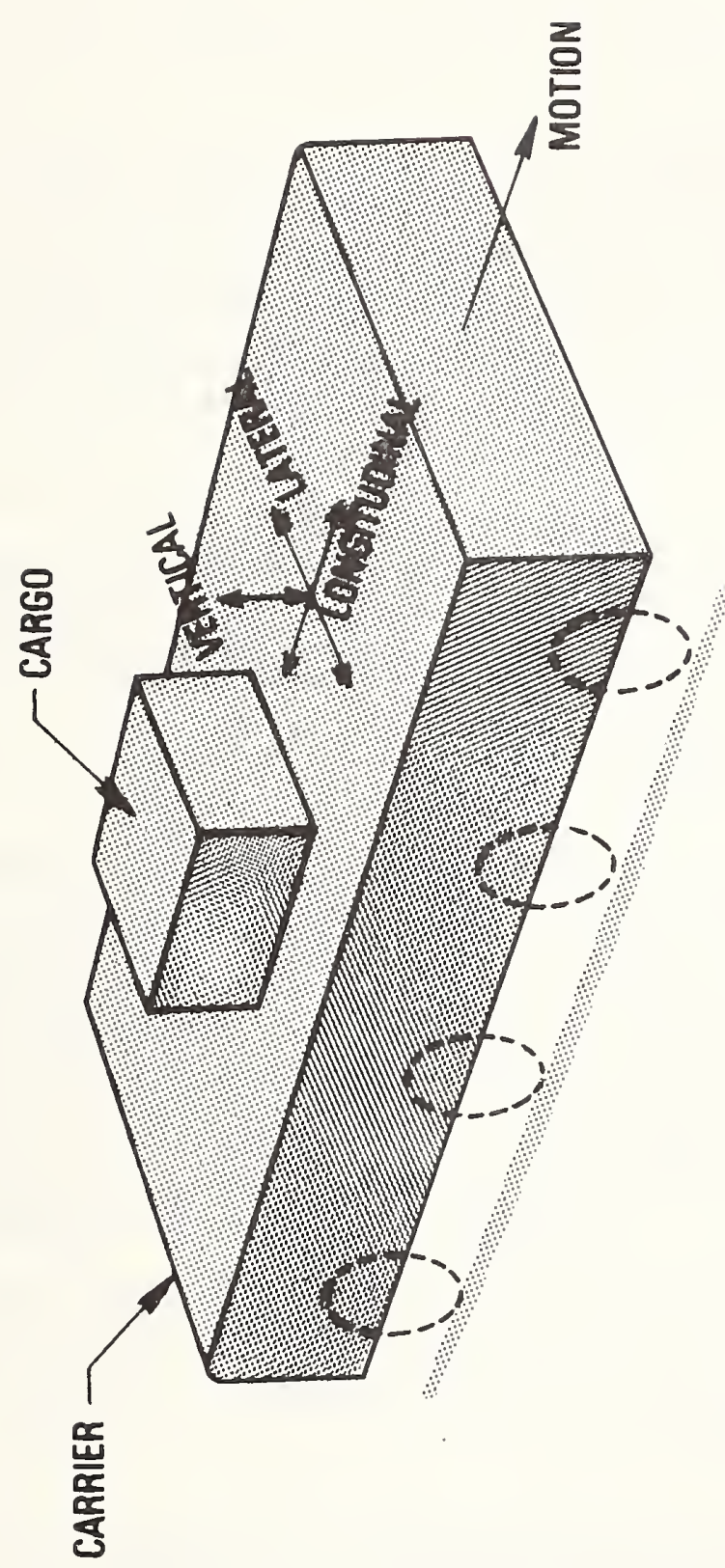

0
5
0
0
0
5
है
0
0

0
s
0

0

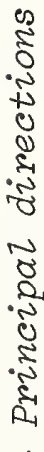

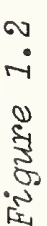

$\frac{c}{\frac{c}{c c}}$ 
handling loads are primarj.ly dynamic inputs. They are discussed in this report as two separate categories of dynamic loading. The transportation loads are subdivided according to the type of carrier: railcar, truck, fixed-wing aircraft and rotarywing aircraft. Activities such as lifting, short transport and stacking are the sources of handling loads. Field services loads due to snow, gravity, wind and thermal gradient are treated separately because they are virtually static in nature and they may be applied to different shelter configurations than exist during transportation and handling operations. It should be noted that the temporary storage of shelters in a stacked configuration is considered a field service condition in that the same static loads are considered. On the other hand, the stacking operation - involving lifting and placement - is considered a handling activity in that it involves dynamic loads.

Each source of loading which may affect the design/analysis of field shelters is discussed independently; the selection of the applicable transportation and handling modes is considered a design decision. The dynamic load information is presented in the form of acceleration versus frequency diagrams to facilitate its use in an equivalent static force method of analysis.

The design force is to be computed by multiplying the shelter's mass by an acceleration magnitude selected from the appropriate acceleration versus frequency diagram. The design frequency is to be established on the basis of the natural frequency (known or estimated) of the shelter or shelter component. This simplified analytical approach is analagous to the equivalent static force formulation commonly used to analyze the seismic resistance of building structures. Also, the probabilities of occurrence of the various transportation and handling loads are presented when such information is available. Consequently, a risk-oriented design approach is made possible. A typical risk-oriented design decision is as follows: Equipped with the knowledge that a particular high-amplitude acceleration is caused by an event of low probability of occurrence, a design acceleration of lower magnitude may be selected, consistent with. the stated risk of damage.

\subsection{Description of Information in the Literature - A comprehensive literature search was} conducted to determine the magnitude of dynamic loads generated by railroad, road and air transportation vehicles and by devices typically used to handle field shelters. Complete transportation and handling load information must, in addition to quantifying the dynamic loads, establish frequencies at which the loads occur and indicate the probability of occurrence of the loads. Toward the objective of establishing reliable statistical load information for the above mentioned transportation and handling media, applicable data have been extracted from reports of several extensive field measurement programs. These studies were conducted to quantify the shock and vibration loads experienced by the cargo floor of railroad flatcars, tractor-trailer combinations, flatbed trucks, airplanes and helicopters. Where possible, the load information presented herein is based on data 
obtained from the loadbed of military vehicles commonly used to transport cargo such as field shelters. Data from commercial vehicle counterparts have also been included in some cases. The load information is presented in both graphical and tabular formats to facilitate its use in an analysis of a shelter in its shipping configuration.

The loadbed dynamic response data are usually presented in the form of acceleration versus frequency diagrams. The acceleration ordinates indicate either zero-to-peak acceleration, root-mean-square (rms) response, or mean-square acceleration per frequency band. The approach used to reduce the data is largely dependent on the type of vibration excitation caused by the events, the relative amount of data collected and its intended use. For example, random vibrations are commonly analyzed by passing the electrical analog of the vibration measurements through a series of narrow bandpass filters (i.e. a spectrum analyzer). The filtered data then essentially become single frequency sinusoidal vibrations whose amplitudes are random variables. The output from each bandpass is the mean-square value, from which the mean power spectral density can be obtained. The complete power spectral density distribution then is determined by changing the frequency bandpass.

An alternate format used in some recent reports of random vibration data employs the concept of a cumulative probability distribution. This approach usually involves the filtering of the vibration measurements into narrow frequency bands and counting the number of occurrences of various amplitudes. Thus, the fraction of time (i.e. the probability) that a given amplitude will be below a specified value is computed within the frequency band or across the entire frequency spectrum. Such an analysis can be performed for each transportation event included in the study and for each of the three principle directions (see fig. 1.3). This statistical method of data reduction requires a relatively large volume of data and usually requires the aid of a computer. Berause of these requirements, this method has had limited use in transportation studies until recently.

For those transportation and handling events which cause shock response $1 /$ (e.g. railcar coupling or humping), the data are usually presented in the form of shock spectra. Thus, the accelerations experienced by a series of single-degree-of-freedom dynamic systems with different natural frequencies, are given. The damping ratio $\left(c / c_{c}\right)$ is varied to generate different spectra. This format gives information on the energy levels associated with various frequencies and indicates the relative damage potential of different transient inputs. To derive "worst-case" data, shock spectra obtained for several transportation events (e.g. a truck crossing railroad tracks, cattle guards and rough road) and accelerometer locations are enveloped. The envelope curve is comprised of the maximum accelerations obtained for each frequency. Therefore, the envelope is not a continuous curve, but rather is a number of data points connected by straight lines. This type of curve accounts for the combined effects of various operating conditions, traveling speeds, accelerometer

1/ Shock is defined as a sudden and severe transient excitation of an object. 


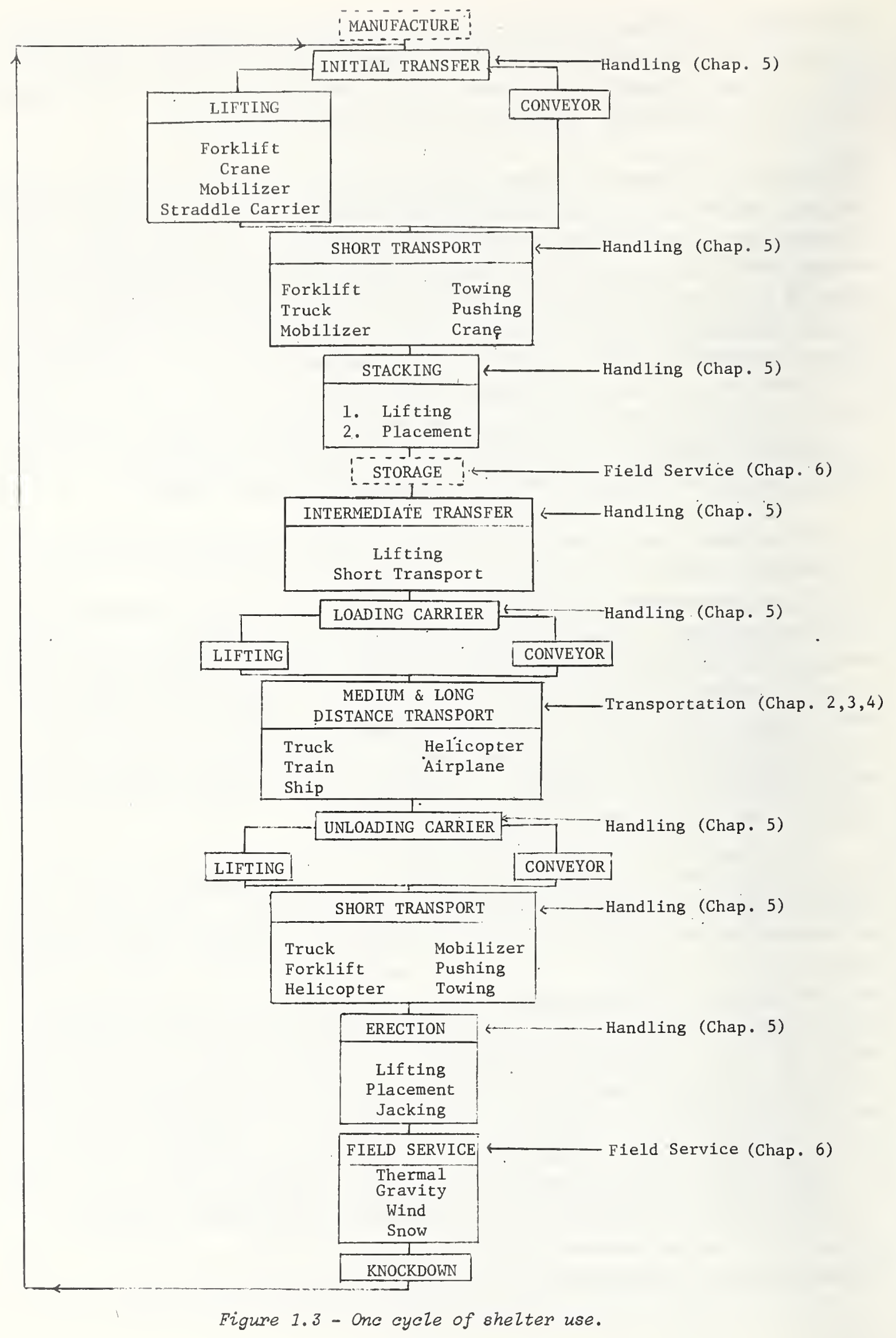


locations, welght of the carrler and the cargo weight. In some reports, the envelope curves represent the absolute worst case in that directional effects are also combined. Al1 of the above-mentioned forms of data presentation w111 be exhibited in the remaining chapters of this report.

1.4 Organization of Report - The remainder of the report is organized as follows. Both over-the-rall and rallroad switching yard environments are discussed in chapter 2 . The normal events comprising the over-the-rail environment are described and the critical frequency spectra are presented for these events. Also, data are presented to show the probability of occurrence of various coupling speeds. Shock spectra are presented for speeds having a low probability of occurrency and for those having a high probability of occurrence.

Chapter 3 presents data helpful in predicting the environment assoclated with medium and long distance truck transportation. Vibration measurements obtained from the deck of a flatbed truck, operating under "normal" and "abnormal" road conditions provide the bases for the description.

The dynamic loads experienced in the cargo areas of typical military cargo aircraft are discussed in chapter 4. The shocks and vibrations are separated into two classes: (1) those caused by propeller-driven and turbojet airplanes (1.e. fixed-wing aircraft) and (2) those produced by helicopters (1.e. rotary-wing aircraft). Recognizing that cargo may be transported elther Inside or outside a helicopter, both of these air transport modes are discussed.

Handling excitations are discussed in chapter 5. The primary operations of interest to shelter handling are: (1) lifting by forklifts, cranes, etc. (2) stacking for storage purposes and (3) short transport by forklifts, mobilizers, cranes, etc. Normal and abnormal handling events are discussed only briefly due to the insufficlent amount of available information.

Loads occurring during field service are discussed in Chapter 6. Static design loads are presented to account for the effects of snow, ice, wind and gravity.

Chapter 7 presents Summary and Conclusions. 
The dynamic environment assoclated with rail transport of cargo stems from two distinctly different operational sources: (1) over-the-rail transport and (2) coupling or humping operations in switching yards. The cargo floor of a rallcar is subjected to both continuous and transient vibrations during over-the-rail transport. The transient excitations usually in the form of shocks - are of two types: (1) recurrent or repetitious and (2) intermittent (i.e. etther single occurrence or irregular occurrence) [1]. 2/

Some of the causes of the shocks and vibrations comprising the railroad dynamic environment are listed in table 1. The lists of events and sources are not exhaustive, but they include the causes of the most severe accelerations reported to date. Also shown in table 1 are the predominant directions and the type of dynamic excitation caused by each event. Although shock response may occur on the cargo floor as a result of such events as starting, stopping and slack run-ins/outs and from track irregularities, the most severe shocks are caused by the coupling of railcars in switching yards. Dynamic loads measured during both over-therail and switching events are described in the following sections of this chapter. The load data are intended to provide the basis for predicting design forces which are to be resisted by field shelters.

2.1 Over-The-Rail-Transport - Although data have been obtained for both conventional

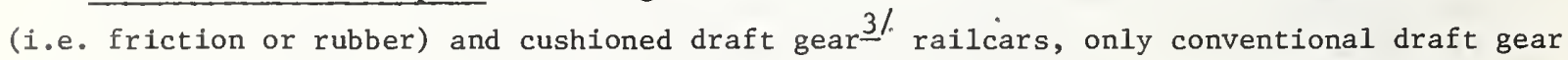
data are presented here. This somewhat conservative approach is based on the assumption that shelters are usually transported by railcars with standard draft gear. Furthermore, the continuous and transient vibrations measured aboard railcars with standard draft gear are generally more severe than those measured on cushioned draft gear cars. The draft gears included in the standard category are $18000 \mathrm{ft}-1 \mathrm{bf}$ (24404 J), $36000 \mathrm{ft}-1 \mathrm{bf}$ (48809 J) and $60000 \mathrm{ft}-1 \mathrm{bf}$ (81349 J) Association of American Railroads (A.A.R.) types. The range of predominant frequencies for typical A.A.R. 1915 truck springs are shown in figure 2.1 [2]. The range of frequencies is seen to extend from about 4 to $8 \mathrm{~Hz}$. According to Foley [1], the railcar frame will produce cargo floor excitations in the $60 \mathrm{Ho} 100 \mathrm{~Hz}$ range, while traversing rail joints produces accelerations in the frequency range of 10 to $30 \mathrm{~Hz}$.

Foley [1] and Gens [2] have described the over-the-rail environment as generally consisting of low-level random vibrations upon which are superimposed recurrent transient accelerations. The dynamic characteristics differ depending upon whether the frequency range is above or

2/ The numbers in parenthesis indicate references which are listed in Section 8.

3/ A draft gear is a mechanical device used to isolate shock, in the longitudinal direction in railcars. It is installed between the coupler and the car body to reduce the shock that is transmitted through it to the freight car. 
TABLE 1 -- Events Which Cause Railroad Dynamic Excitations

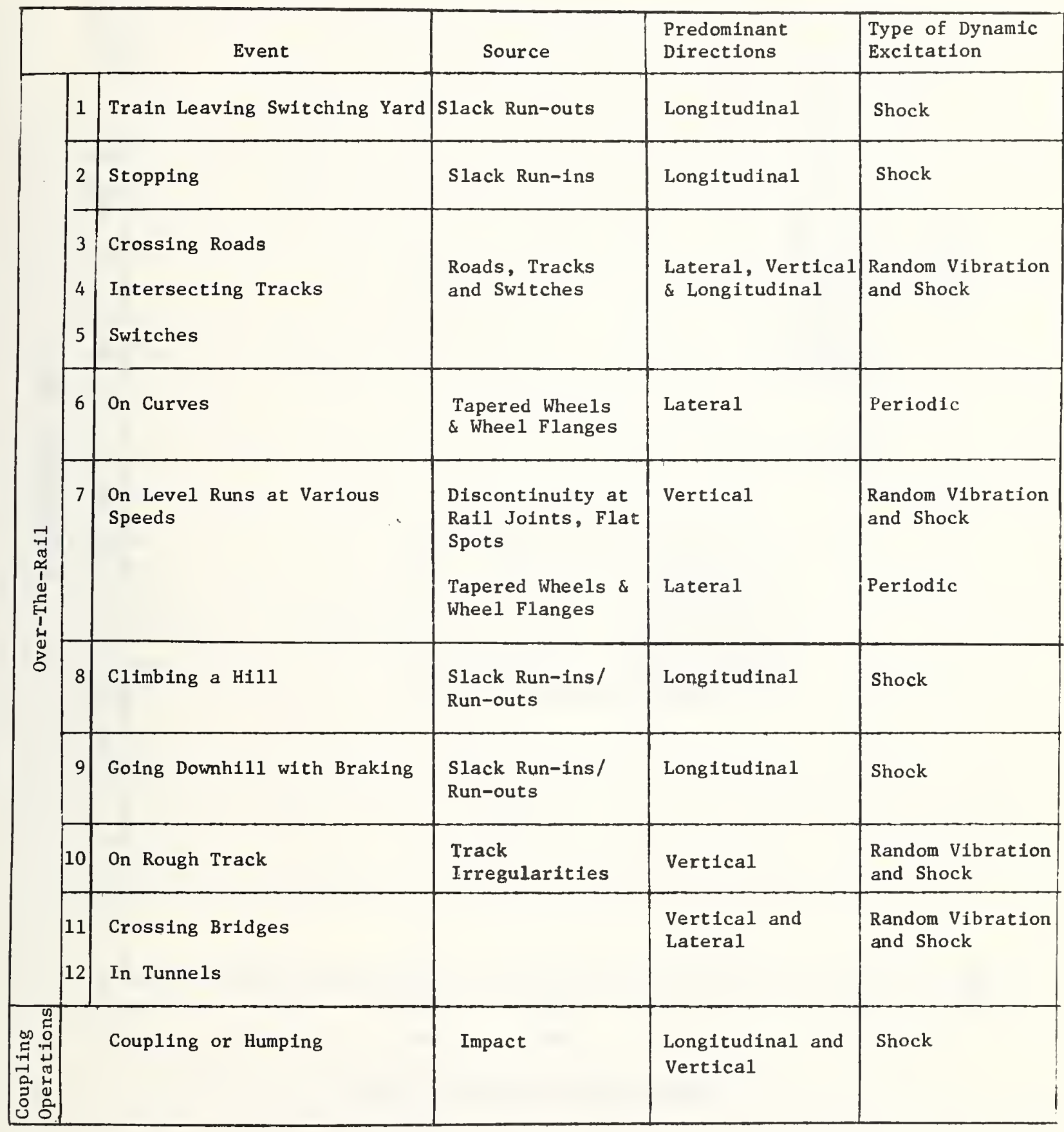



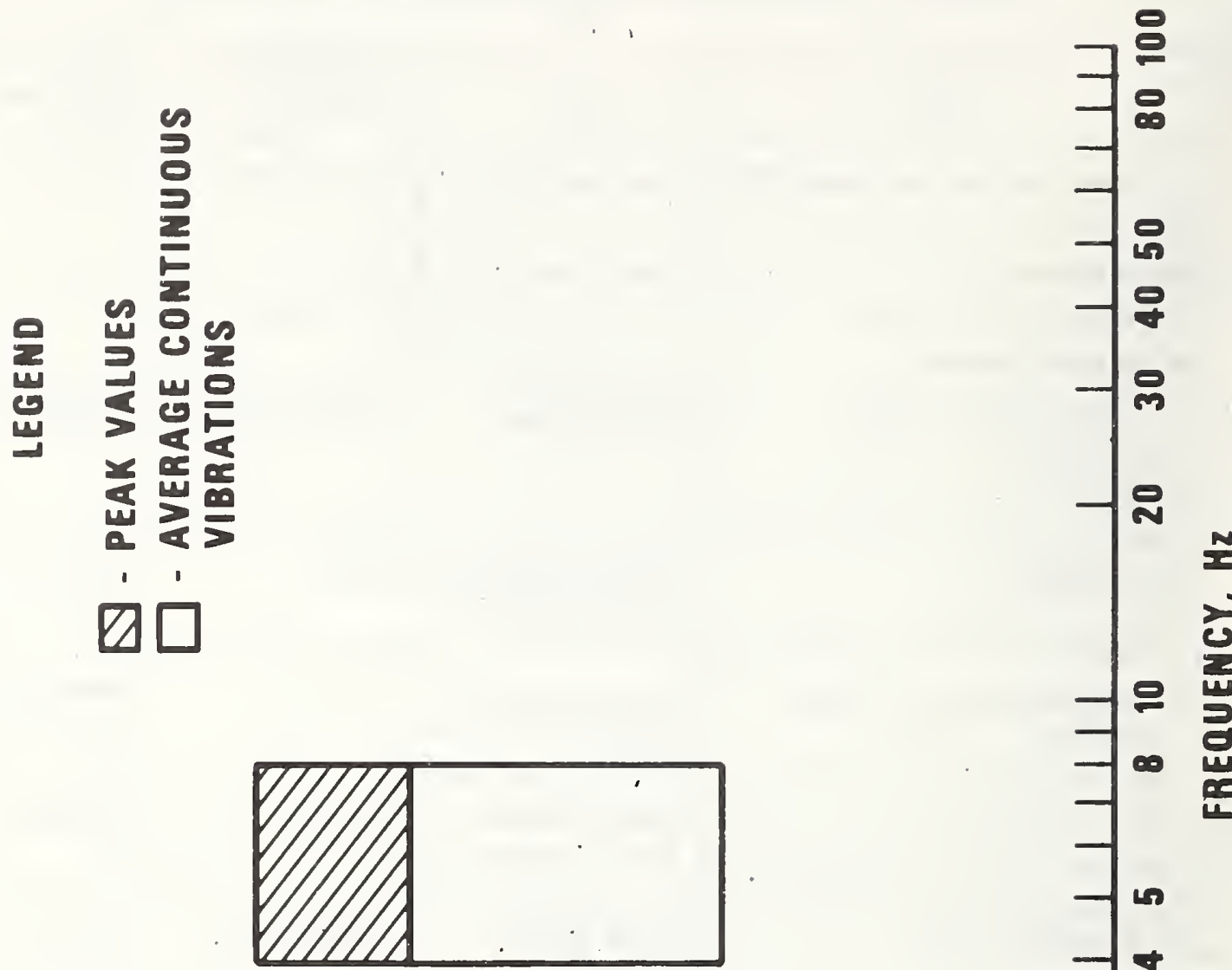

ㅍ

$\frac{5}{2}$

पू क.

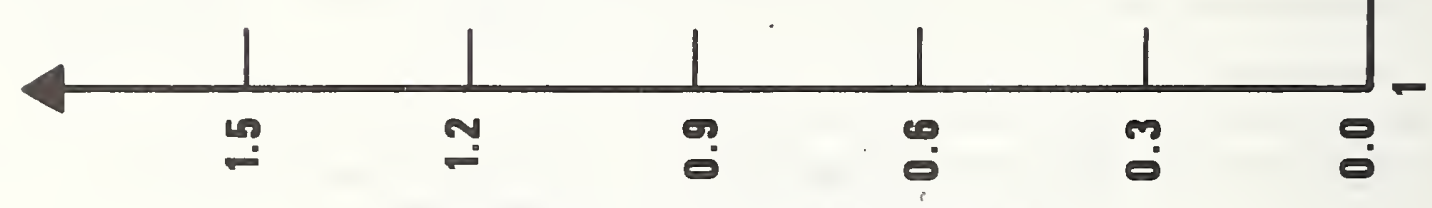

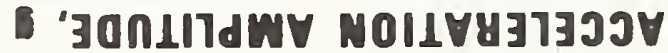


below $10 \mathrm{~Hz}$. Below $10 \mathrm{~Hz}$, the accelerations are almost entirely of the repetitive shock type, while above $10 \mathrm{~Hz}$ the rail environment consists of intermittent transient accelerations superimposed on broad band random excitation.

2.1.1 Random Vibration Excitation - Measurements of accelerations experienced by the cargo floor of a flatcar with standard draft gear have been made by Sandia Laboratories [3]. The $66200 \mathrm{lb}(30028 \mathrm{~kg})$ flatcar had a wood deck and was equipped with side and end stake pockets. It was used to transport a "radioactive fuel element shipping cask" over a distance of approximately $500 \mathrm{mi}(804 \mathrm{~km})$. The purpose of the shipment was to provide an in-transit test of the cask tiedown system. The flatcar was attached to regularly scheduled trains varying in length from 65 to 120 cars. The data gathering activity consisted of obtaining acceleration time-histories in the vertical, lateral and longitudinal directions at various locations on the deck. The predetermined sampling events were selected to essentially encompass the over-therail sources of vibrations. Accelerometer measurements were recorded for 11 typical events. All of the sampled events are listed in table 1. Crossing roads (item 3) was not included as an event for sampling. Although no reason was stated for omitting this event, the effect was the elimination of some transient responses that would have been recorded. To obtain the test results, the time-histories were passed through a series of narrow-bandpass filters and the number of acceleration peaks within each bandpass were counted. Thus, having obtained the distribution of acceleration peaks within each bandpass, cumulative probability distributions were computed. The probability distributions, so obtained for each event, were combined to obtain a composite distribution for all of the sampled events. Test results were presented by Gens [3] and Ostrem [4]. Directional composite frequency spectra obtained from the test run are presented in figures 2.2, 2.3, and 2.4 [4]. The three figures summarize the data obtained for the 11 over-the-rail events. The data were plotted at the center frequency within each bandpass. The statistical-based format discussed in section 1.3 was used in presenting these acceleration versus frequency curves. In addition to a distribution curve showing Peak $4 /$ accelerations, curves of constant probability are presented for probabilities of 90, 95, 98, 99 and 99.5 percent.

The results indicate that the most severe accelerations occurred in the low frequency domain (i.e. $<10 \mathrm{~Hz}$ ). Because the results are presented as composite diagrams, it is not known which events contributed to this phenomenon. It was also observed that in all bandpasses the peak acceleration magnitudes were highest in the vertical direction. Generally, the lateral direction Peaks were next highest; the longitudinal vibrations are concluded to be insignificant for the over-the-rail environment. Further examination of figures 2.2-2.4 shows that above $10 \mathrm{~Hz}$ the Peak accelerations were below $0.72 \mathrm{~g}$, irrespective of direction.

4/ When the word "peak" is capitalized in this report, it is referring to an absolute maximum acceleration measured during the stipulated event(s). 


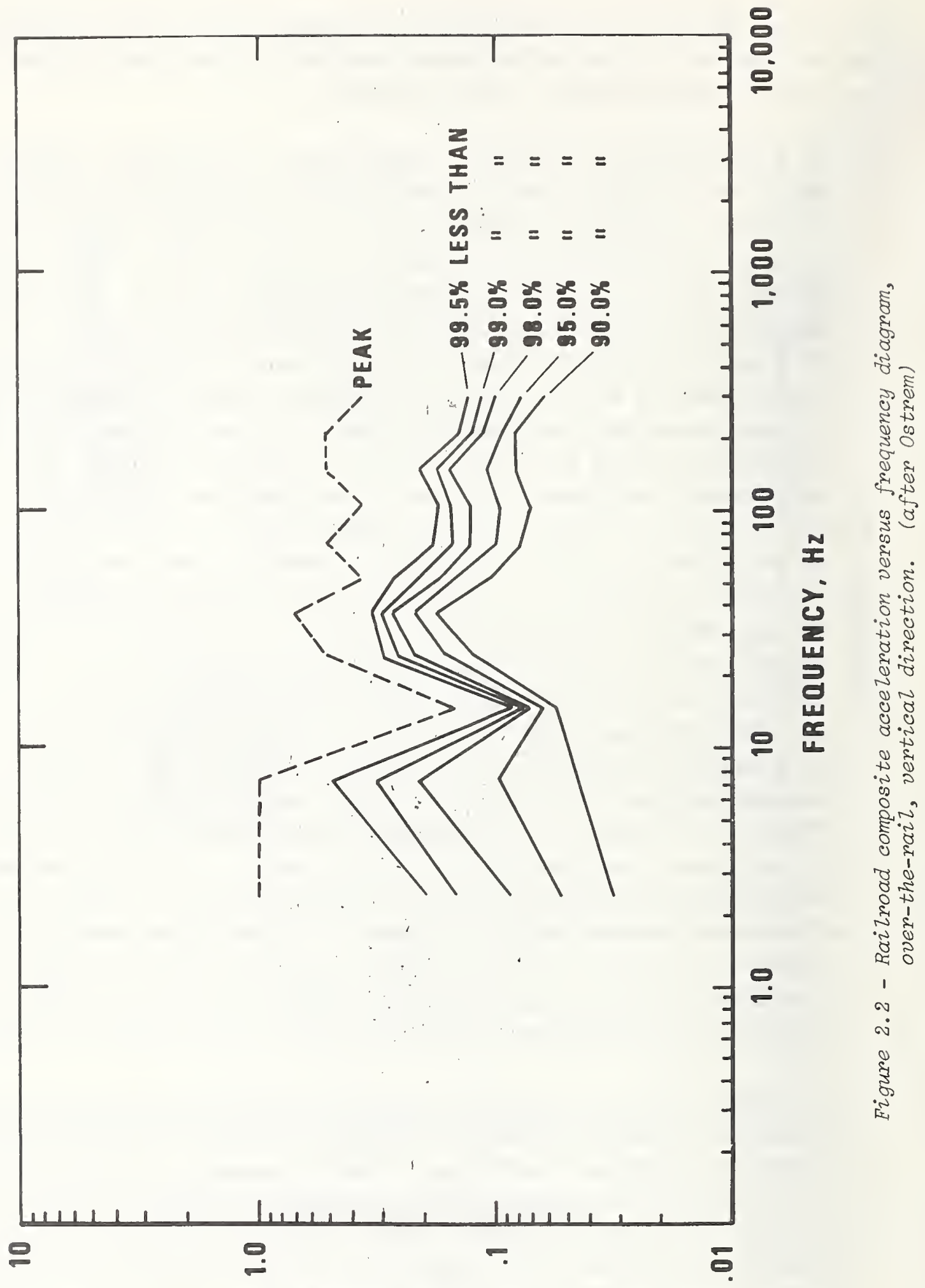

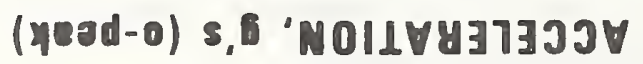




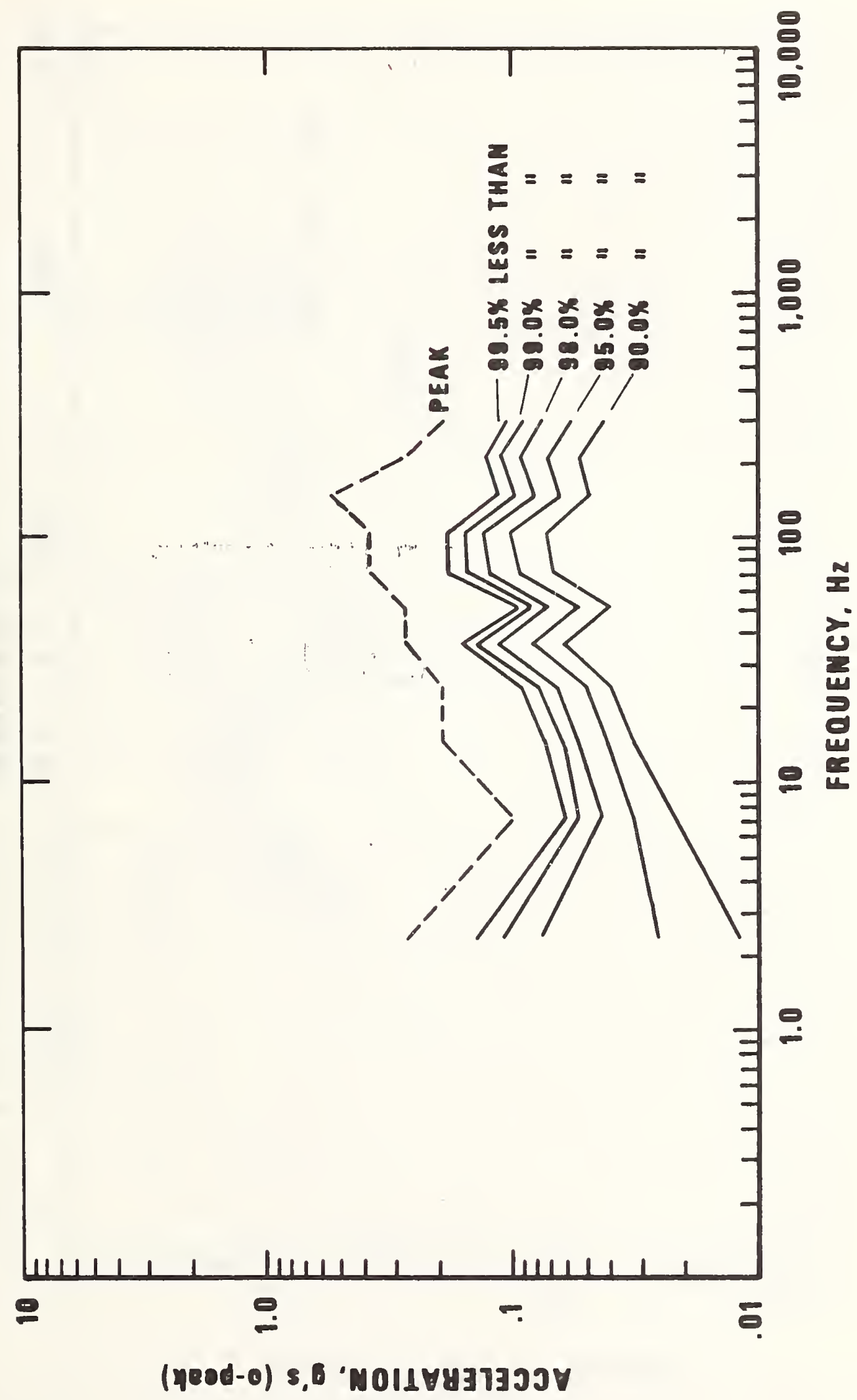

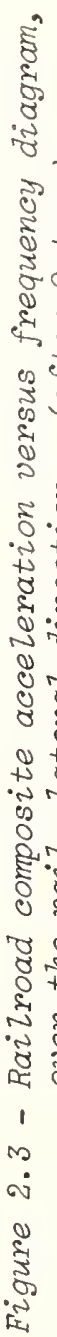




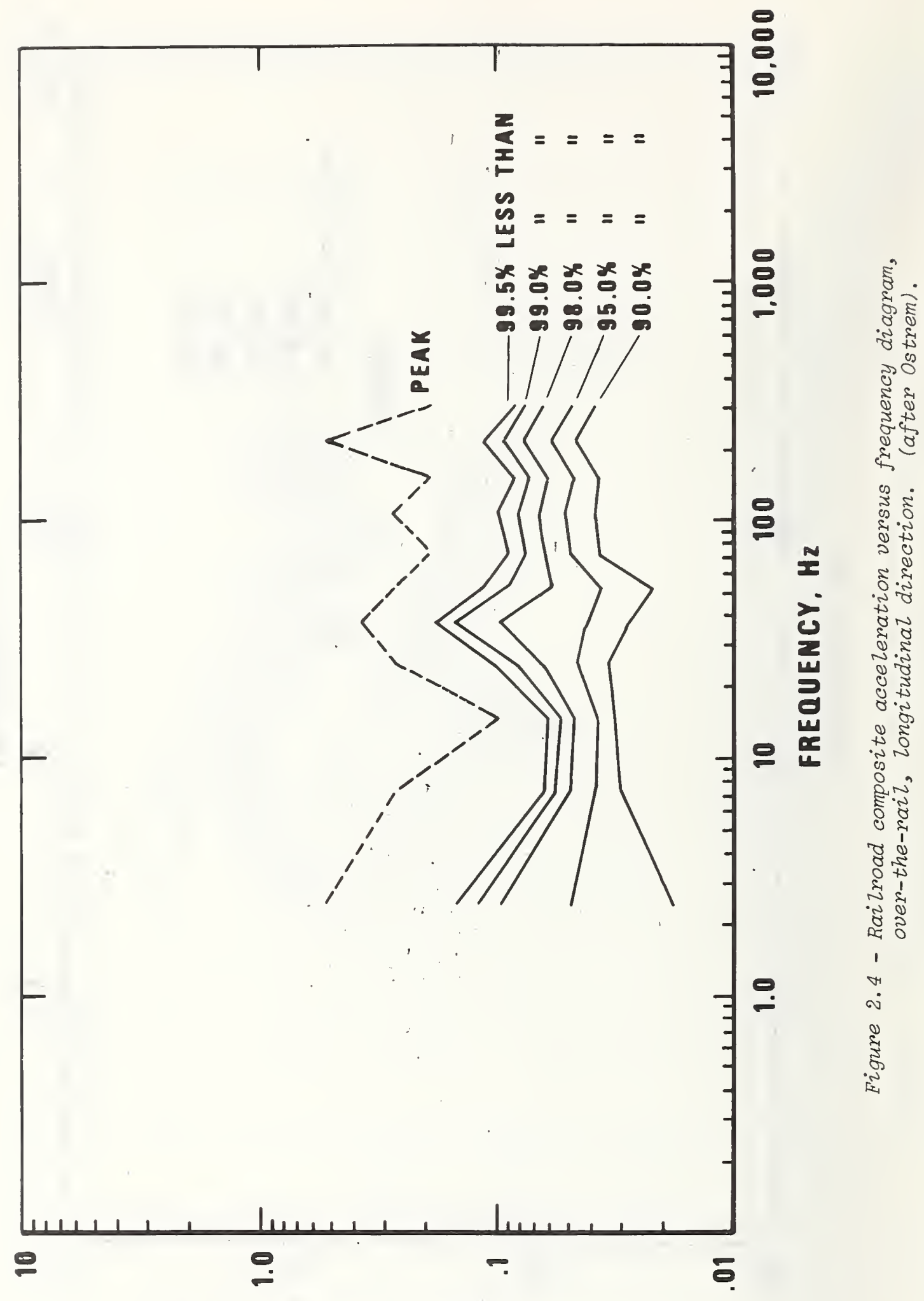

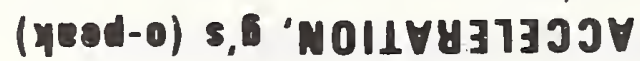


Because the 500-mi (804-km) trip involved most of the over-the-rall-events which are sources of dynamic excitations, it is concluded that the above-mentioned test events are representative of the over-the-rail environment experienced by standard-draftgear flatcars transporting cargo. With respect to transportation design loads for shelters, the data shown in figures 2.2, 2.3, and 2.4 are recommended as bases for predicting dynamic loads for over-the-rail transport. When a "worst case" design approach is used, the Peak acceleration ordinates can be selected for the specified frequency level. In cases where a risk-oriented design philosophy is used, lower design accelerations can be obtained based on the level of probability specified. Generally speaking, the accelerations caused by over-the-rail transport will not govern the design of shelters. In fact, Foley [1] states that "the continuous excitation experienced during rail transportation is somewhat lower in amplitude than that experienced in road travel." The data presented above will be useful input to a reliability-based design analysis of shelters.

\subsubsection{In-Transit Shock Excitation - In the over-the-rail dynamic environment,} shocks are caused by slack run-ins/outs in the coupling system, starts, stops, and various track conditions (see table 1). Here, shock excitation refers to the sudden, severe, non-periodic excitation of the cargo deck. The most common format for describing transportation-borne shock is the shock spectra $a^{5 /}$. Data presented in this format provide an indication of the frequencies at which the most severe accelerations occur as well as giving the magnitude of the critical accelerations.

Shock spectra envelopes for accelerations caused by slack run-ins/outs are shown in figure 2.5 [3]. The composite curves were obtained by enveloping spectra for a number of occurrences of these operations. Accelerometer measurements were made aboard a flatcar equipped with standard draft gear. At various times during the 500-mi $(804-\mathrm{km})$ trip, the test car was part of three different train lengths, varying from 65 to 120 cars. The three curves in figure 2.5 reflect measurements taken in three orthogonal directions. Note that the damping ratio $\left(\mathrm{C} / \mathrm{C}_{c}\right)$ used in computing the shock spectra was 0.03 . According to ostrem [4], the ratio is commonly used for cargo which are not provided with shock isolation systems. Examination of figure 2.5 shows that the highest accelerations occur in the longitudinal direction for frequencies below $20 \mathrm{~Hz}$. The maximum acceleration magnitude in this frequency range is approximately $1 \mathrm{~g}$. Above $20 \mathrm{~Hz}$, the highest accelerations occur in the vertical direction. The maximum acceleration, occurring at about $100 \mathrm{~Hz}$, is approximately $3.5 \mathrm{~g}$. Directional shock spectra envelopes for inputs resulting from road crossings, intersecting

5/ A shock spectra is defined as the response of a series of single-degree-of-freedom dynamic systems to shock excitation. Thus, shock spectra differs from frequency spectra such as shown in figures 2.2 - 2.4; here the frequency and damping ratio have to be assumed prior to determining response, and only one degree of freedom is assumed. 


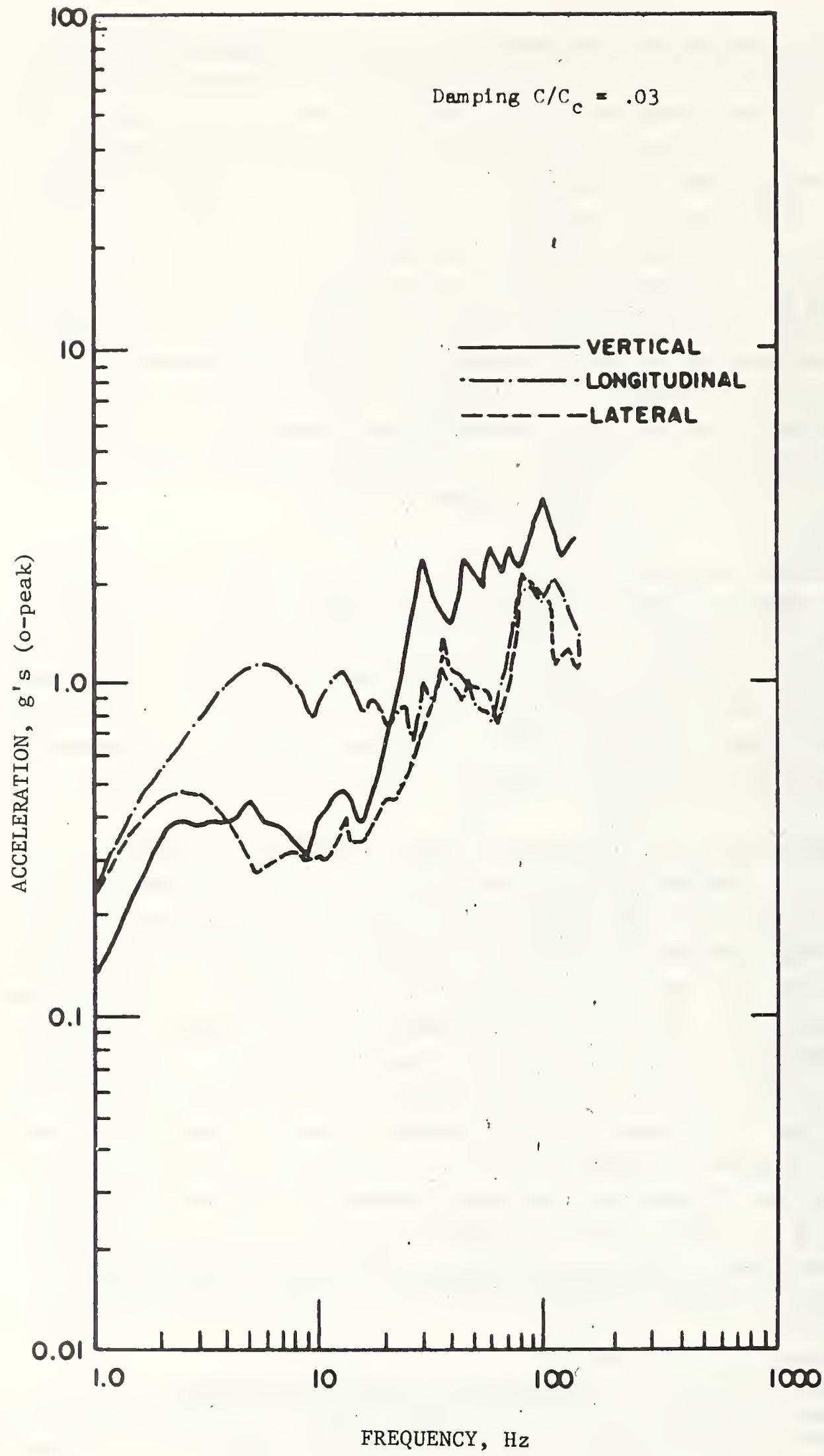

Figure 2.5 - Railroad shock spectra envelopes, slack mun ins/outs, directional. (after Ostrem) 
tracks (at right angles) and switch crossings are shown in figure 2.6 [4]. It is shown that in the low frequency range ( 1 .e. up to $10 \mathrm{~Hz}$ ) that the maximum acceleration is about $1 \mathrm{~g}$. The most severe shocks in this range occur in the vertical direction. It is interesting to note that Gens [2] Indicates that over-the-rail shocks seldom exceed $1 \mathrm{~g}$.

Considering the data presented in figures 2.5 and 2.6 as being typical of the overthe-rail shock environment, it is concluded that the design acceleration for shelters with natural frequencies less than $20 \mathrm{~Hz}$, is $1 \mathrm{~g}$ in the vertical and longitudinal direction. In the lateral direction, the design acceleration for the same natural frequency range is $0.5 \mathrm{~g}$.

As is shown in section 2.2, the shock response cause by the above-mentioned events will not govern shelter design for the raflroad dynamic environment.

2.2 Coupling Operations in Switching Yards - Rallcar couplers have an automatic actuator feature which makes it necessary for the cars to be impacted together to effect coupling. Several factors (1.e. equipment and operators) cause a wi.de varlation in the coupling speeds. The literature contains several reports of studies conducted to determine the range and frequency of occurrence of coupling speeds in switching yards. Sufficient fleld data have been collected to derive a statistically-based prediction of coupling speeds. Curve A in figure 2.7 shows a cumulative probability distribution curve that was plotted from data presented in table 2 of Ref. 5 and table 2-1 of Ref. 6. The probability distribution is cut off at $2 \mathrm{mph}(0.89 \mathrm{~m} / \mathrm{s})$ because it requires a speed of this magnitude to actuate the coupling systems. Thus, the approximate range of coupling speeds is from $2 \mathrm{mph}(0.89 \mathrm{~m} / \mathrm{s})$ to $11 \mathrm{mph}(4.92 \mathrm{~m} / \mathrm{s})$. It is noted that the curve is dashed for speeds below $5 \mathrm{mph}(2.24 \mathrm{~m} / \mathrm{s})$ because there were no specific data presented for the lower speeds. Inspection of the histogram from which curve A in figure 2.7 was derived, shows that the coupling speed distribution has positive skewness. The fact that the 50 percentile value lies on the left side of the speed range also indicates positive skewness. The probability distribution represented by curve A differs somewhat from that presented by Ostrem et al $[3,7]$. For comparative purposes, 0strem's probability distribution is shown as curve B in figure 2.7. Examination of two probability distributions shows that while $5 \mathrm{mph}(2.24$ $\mathrm{m} / \mathrm{s}$ ) is the 70 percentile speed on curve $A$, it is the 50 percentile speed on Ostrem's curve. Likewlse $8 \mathrm{mph}(3.58 \mathrm{~m} / \mathrm{s})$ is the 90 percentile value on Ostrem's curve, while curve A indicates 97 percentile for $8 \mathrm{mph}(3.58 \mathrm{~m} / \mathrm{s})$. The specific source of 0 strem's probability distribution was not indicated and therefore the differences have not been resolved. Because curve $A$ is based on data sources which are referenced, it will be used in subsequent discussion of coupling speeds.

The benefit in determining the probability distribution of coupling speeds is that a basis is established for determining the likelihood that different shock levels will 


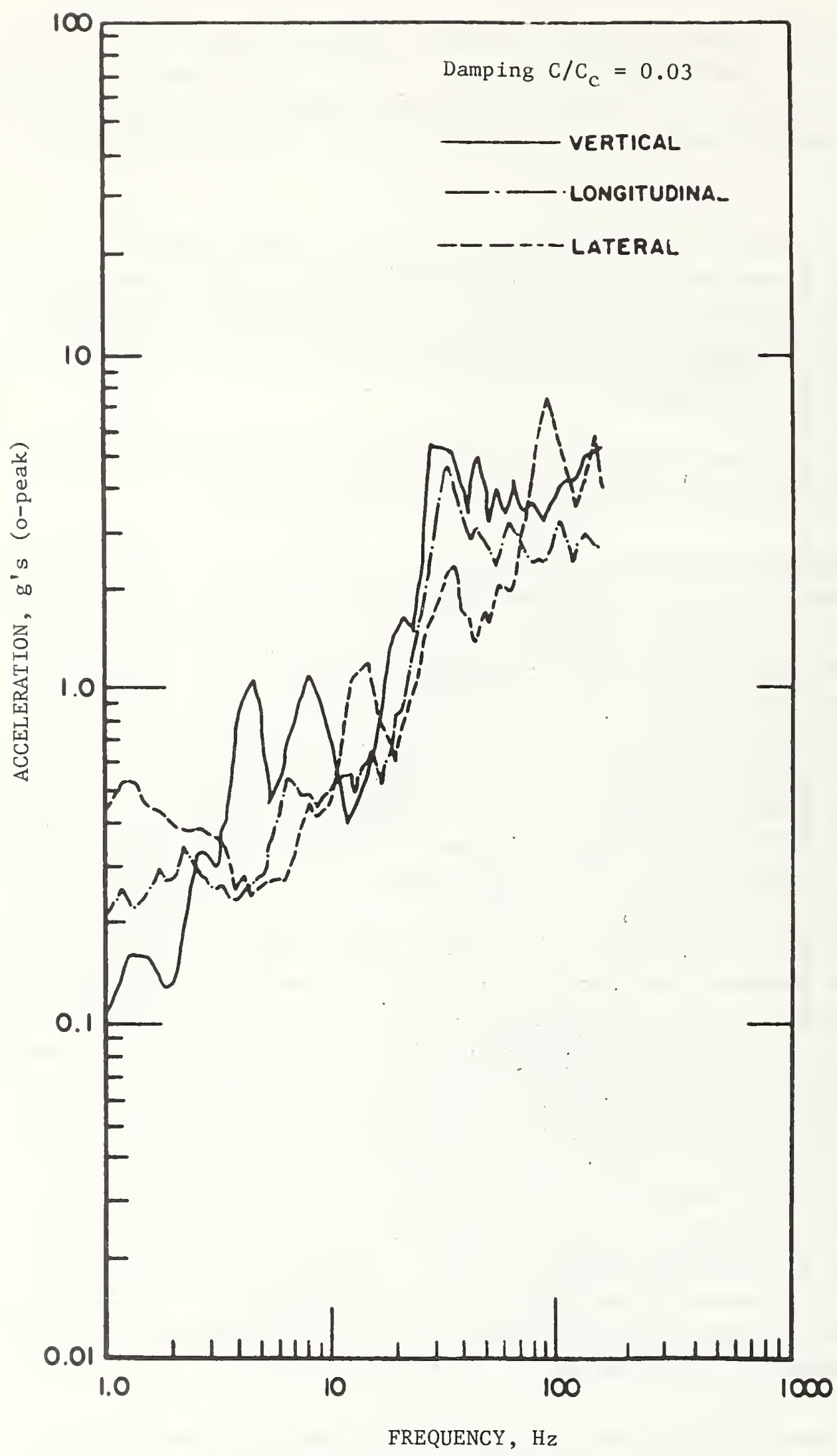

Figure 2.6 - Railroad shock envelopes, road crossings, intersecting track and switches, directional. (after Ostrem) 
occur for rallroad cargo, and in particular. for shelters. A coupling speed distribution such as presented in figure 2.7 makes it possible to predict the probability of not exceeding a given coupling speed as a function of the number of switching yards traversed by a flatcar. This exercise is important in that freight cars generally traverse more than one switching yard. Table 2 presents the probability of not exceeding specific speeds for $1-6$ switching yards. $\underline{6}$

Table 3 presents the complimentary probabilities: namely, the probabilities of exceeding specific coupling speeds. To obtain a probabilistic design approach for the dynamic environment caused by coupling, it is necessary to have railcar response data for the full range of coupling speeds.

The response of railcars to coupling impact is usually described in terms of shock spectra for each of the three principal directions. The directional spectra are obtained by using the time-histories from accelerometers located on the cargo deck as forcing functions for the single-degree-of-freedom systems. Then, analyses, using either analog or digital techniques, are performed for particular natural frequencies and damping ratios. Representative shock spectra data are presented herein for coupling speeds with a relatively high probability of occurrence and for those with a relatively low probability of occurrence. Curve A in figure 2.7 indicates that about $70 \%$ of all observed impacts have occurred at speeds no greater than $5 \mathrm{mph}(2.24 \mathrm{~m} / \mathrm{s})$. Envelopes of shock spectra for a coupling speed of

6/ The coupling speed is regarded as a random variable and the headings of the five righthand columns of table 2 indicate the event of the random variable being $\leq$ the specified speed (1.e. $5 \mathrm{mph}, 6 \mathrm{mph}$, etc.). The probabilities of the five events are shown in the first row. The left-hand column indicates the number ( $n$ ) of switching yards traversed by a particular railcar. An underlying assumption is that exactly one coupling impact occurs in each yard. The probability entries for $n=2, \ldots$, , were obtained by treating the switching events as a serles of independent repeated Bernoulli trials. A Bernoulli trial is one which has only two possible outcomes, "success" or "failure." Here, obtaining a coupling speed $\leq$ a specified value (e.g. $5 \mathrm{mph}$ ) constitutes success. Conversely, obtaining a speed greater than the statue value is called failure. The Binomial Law can be used to express the probability, denoted by $b(k ; n, p)$, that $n$ Independent repeated Bernoulli trials, with probabilities $p$ of success and $q(=1-p)$ of failure, will result in exactly $k$ successes and $n-k$ failures (in which $k=0$, 1 , ., ., n). The formulation of the Binomial Law is as follows:

$$
\mathrm{b}(\mathrm{k} ; \mathrm{n}, \mathrm{p})=\frac{\mathrm{n} !}{(\mathrm{n}-\mathrm{k}) ! \mathrm{k} !} \mathrm{p}^{\mathrm{k}} \mathrm{q}^{\mathrm{n}-\mathrm{k}}
$$

The entries in table 2 were computed for the outcome, $k=n$, where $n=1,2,3,4,5,6$. The physical significant of $k=n$ is that if $n$ couplings occur all $n$ of them will be $\leq 5 \mathrm{mph}(2.24 \mathrm{~m} / \mathrm{s})$ etc. Equation 1 reduces to:

$$
b(k ; n, p)=p^{n}
$$

The values of $p$ are shown in the first row of table 2 . The values for the remaining rows were obtained by using the corresponding value of $n$ in equation 2 . The values in table 3 are complements of those in table 2; they represent the probabilities of there being one or more coupling impacts--within the $n$ trails--at greater than the specified speed. 


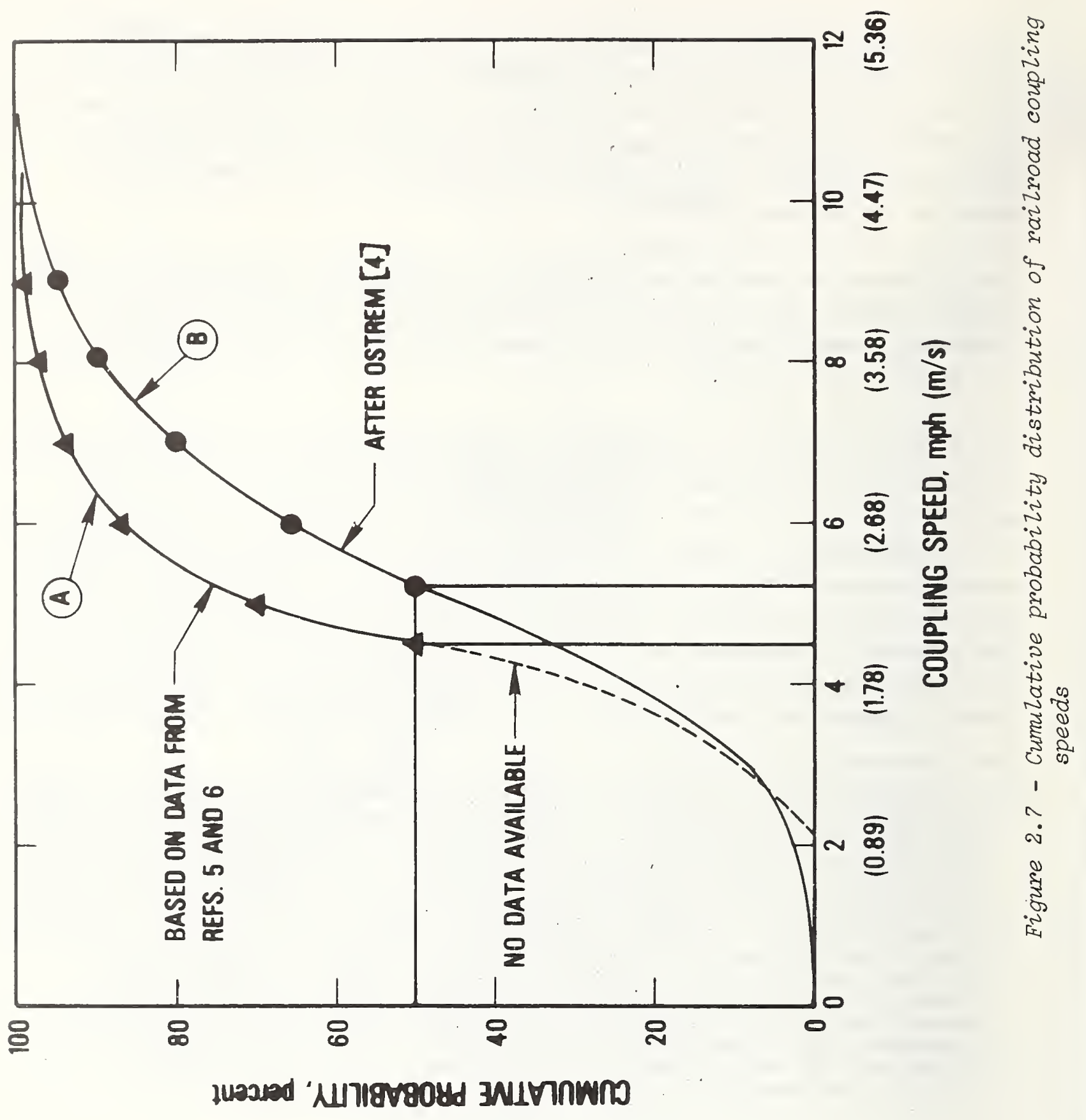


TABLE 2 -- Probability of Not Exceeding a Given Coupling Speed

\begin{tabular}{|c|c|c|c|c|c|}
\hline $\begin{array}{l}\text { Number } \\
\text { of Yards }\end{array}$ & $\begin{array}{c}\leq 5 \mathrm{mph} \\
2.24 \mathrm{~m} / \mathrm{s}\end{array}$ & $\begin{array}{l}\leq 6 \mathrm{mph} \\
2.68 \mathrm{~m} / \mathrm{s}\end{array}$ & $\begin{array}{l}\leq 7 \mathrm{mph} \\
3.13 \mathrm{~m} / \mathrm{s}\end{array}$ & $\begin{array}{l}\leq 8 \mathrm{mph} \\
3.58 \mathrm{~m} / \mathrm{s}\end{array}$ & $\begin{array}{c}\leq 9 \mathrm{mph} \\
4.02 \mathrm{~m} / \mathrm{s}\end{array}$ \\
\hline 2 & 0.700 & 0.874 & 0.934 & 0.965 & 0.988 \\
3 & 0.490 & 0.764 & 0.872 & 0.931 & 0.976 \\
4 & 0.343 & 0.668 & 0.814 & 0.898 & 0.964 \\
5 & 0.240 & 0.584 & 0.761 & 0.867 & 0.952 \\
6 & 0.168 & 0.510 & 0.711 & 0.836 & 0.941 \\
& 0.118 & 0.445 & 0.664 & 0.806 & 0.930 \\
\hline
\end{tabular}

Example: If a railcar has impacts in 3 switching yards, the probability of all $\underline{3}$ coupling speeds being $\leq 6 \mathrm{mph}$ is $0.66 \overline{8}$.

TABLE 3 -- Probability of Exceeding A Given Coupling Speed

\begin{tabular}{|c|c|c|c|c|c|}
\hline $\begin{array}{l}\text { Number } \\
\text { of Yards }\end{array}$ & $\begin{array}{c}>5 \mathrm{mph} \\
2.24 \mathrm{~m} / \mathrm{s}\end{array}$ & $\begin{array}{c}>6 \mathrm{mph} \\
2.68 \mathrm{~m} / \mathrm{s}\end{array}$ & $\begin{array}{c}>7 \mathrm{mph} \\
3.13 \mathrm{~m} / \mathrm{s}\end{array}$ & $\begin{array}{c}>8 \mathrm{mph} \\
3.58 \mathrm{~m} / \mathrm{s}\end{array}$ & $\begin{array}{c}>9 \mathrm{mph} \\
4.02 \mathrm{~m} / \mathrm{s}\end{array}$ \\
\hline 1 & 0.300 & 0.126 & 0.066 & 0.035 & 0.012 \\
2 & 0.510 & 0.236 & 0.128 & 0.069 & 0.024 \\
3 & 0.657 & 0.332 & 0.186 & 0.102 & 0.036 \\
4 & 0.760 & 0.416 & 0.239 & 0.133 & 0.048 \\
5 & 0.832 & 0.490 & 0.289 & 0.164 & 0.059 \\
6 & 0.882 & 0.555 & 0.336 & 0.194 & 0.070 \\
\hline
\end{tabular}

Example: If a railcar has impacts in 3 switching yards, the probability of 1 or more coupling speeds exceeding 6 mph is 0.332 . 
approximately $3 \mathrm{mph}(1.34 \mathrm{~m} / \mathrm{s})$ are shown in figure 2.8 [4]. The envelopes were obtained in the same field study discussed in section 2.1.1. Acceleration time-histories were obtained by Gens [3] during the low-speed coupling phase with the test car coupled to the switching engine. The test car then struck a stationary, loaded gondola car at an estimated speed of $3 \mathrm{mph}(1.34 \mathrm{~m} / \mathrm{s})$. Figure 2.8 shows that the most severe shocks occurred in the longitudinal direction up to $20 \mathrm{~Hz}$. The maximum acceleration in the $1-20 \mathrm{~Hz}$ range was about $3.5 \mathrm{~g}$. The vertical acceleration magnitude was a close second over most of this frequency range. Above $20 \mathrm{~Hz}$, shocks in the vertical direction were the most severe. Lateral and longitudinal shocks were of approximately equal magnitude over the 20-150 $\mathrm{Hz}$ range. The maximum acceleration--in the vertical direction--was approximately $30 \mathrm{~g}$.

Probability distribution curve A in figure 2.7 indicates that approximately $98 \%$ of all coupling impacts occur at speeds less than or equal to $11 \mathrm{mph}(4.92 \mathrm{~m} / \mathrm{s})$. With this statistical basis, $11 \mathrm{mph}(4.92 \mathrm{~m} / \mathrm{s})$, is commonly regarded as the "worst case" coupling speed in regard to potential shipping damage. Several impact test programs have been conducted in which the maximum coupling speed is either $10 \mathrm{mph}(4.47 \mathrm{~m} / \mathrm{s})$ or $11 \mathrm{mph}(4.92$ $\mathrm{m} / \mathrm{s}$ ). It is noted that in Procedure VI of MIL-STD-810C [8], a maximum coupling speed of $10 \mathrm{mph}(4.47 \mathrm{~m} / \mathrm{s})$ is specified in the rail impact test. Thus, it is concluded that shock spectra data for coupling speeds of 10 or $11 \mathrm{mph}(4.47$ or $4.92 \mathrm{~m} / \mathrm{s})$ would indicate the upper limit in damage potential for shelters shipped by rail. Directional shock spectra envelopes are presented in figure 2.9 [4] for $11 \mathrm{mph}(4.92 \mathrm{~m} / \mathrm{s})$ coupling speed. The results were obtained with the use of the same standard draft gear flat car mentioned in section 2.1.1. For the high-speed coupling tests, acceleration time-histories were obtained for such events as (1) an engine striking the standing test car and (2) an engine striking the test car in motion. The resulting shock spectra were combined to form the composite envelopes shown in figure 2.9. The response curves are presented for $\mathrm{C} / \mathrm{C}_{\mathrm{c}}=0.03$, which according to Ostrem [3] and Foley [9] is indicative of non-shockisolated cargo. In essence, the three curves are predictions of how cargo with various natural frequencies may respond to acceleration time-histories at the coupling speed of $11 \mathrm{mph}(4.92 \mathrm{~m} / \mathrm{s})$. For example, a non-shock-isolated shelter with a natural frequency (in each direction) of $10 \mathrm{~Hz}$ will experience a shock of approximately $2 \mathrm{~g}$ in both the longitudinal and vertical direction. A shelter with a natural frequency of $20 \mathrm{~Hz}$ will experience about $4.5 \mathrm{~g}$ longitudinally and $3.0 \mathrm{~g}$ vertically.

Several reports [3], [4], have shown a shock spectra envelope for a coupling speed of 11 $\mathrm{mph}(4.92 \mathrm{~m} / \mathrm{s})$ and $\mathrm{C} / \mathrm{C}_{\mathrm{c}}=0$; figure 2.10 shows the envelope as presented in Ref. 4. Ostrem [4] refers to this curve as the "upper limit of shock spectra" with regard to the railroad coupling environment. In comparing the shock spectra curves in figs. 2.9 and 2.10 it is observed that the ordinates in the latter figure are in general, an order of magnitude greater than the corresponding maximum values in the former figure. For example, the maximum acceleration at $10 \mathrm{~Hz}$ is about $2 \mathrm{~g}$ for $\mathrm{C} / \mathrm{C}_{\mathrm{c}}=0.03$ while the envelope curve 


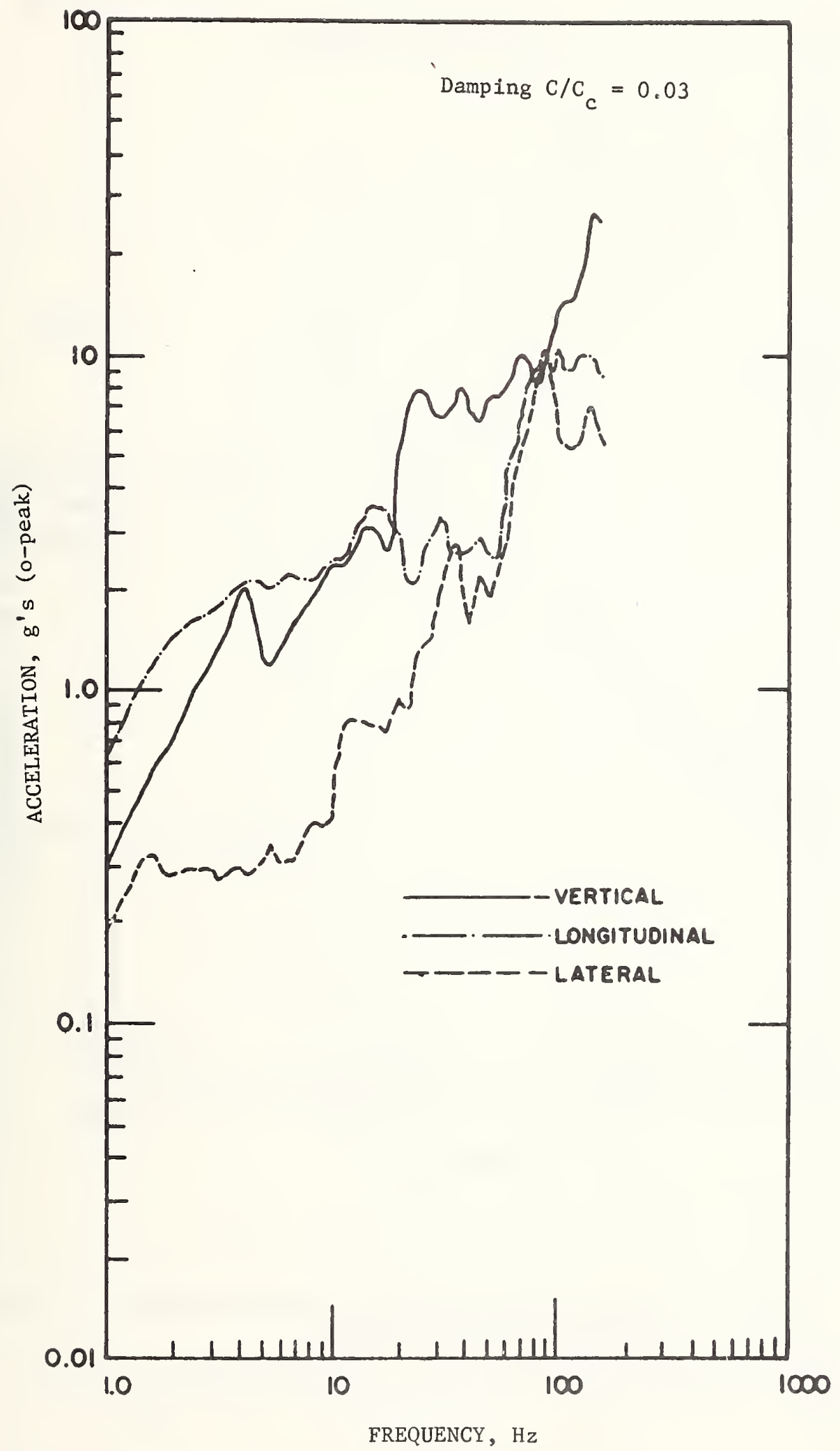

Figure 2.8 - Shock spectra envelopes, railroad coupling (2 - 5 mph), directional. (after Ostrem) 


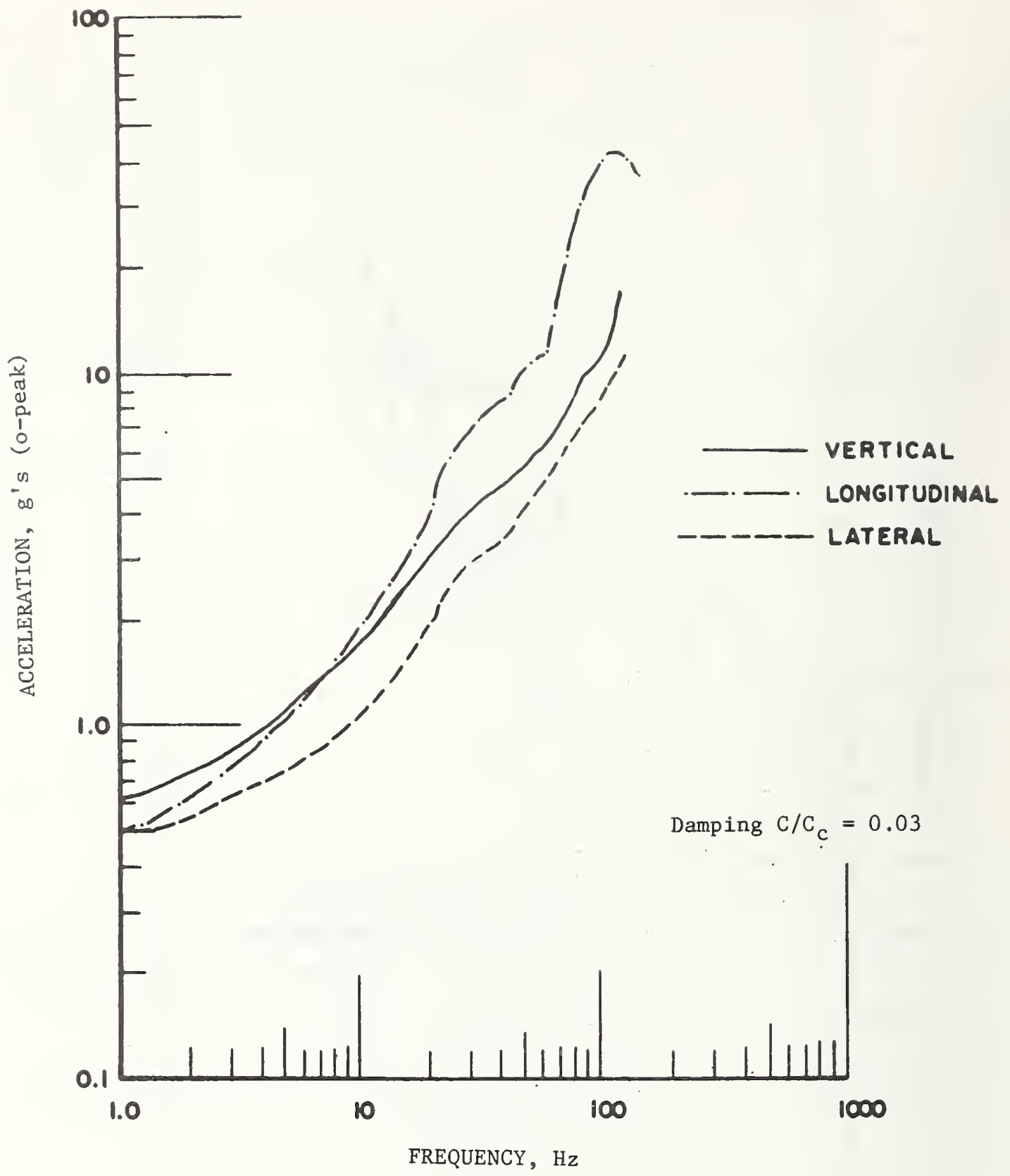
Figure 2.9 - Shock spectra envelopes, railroad coupling (11 mph),
directional (after Ostrem) 


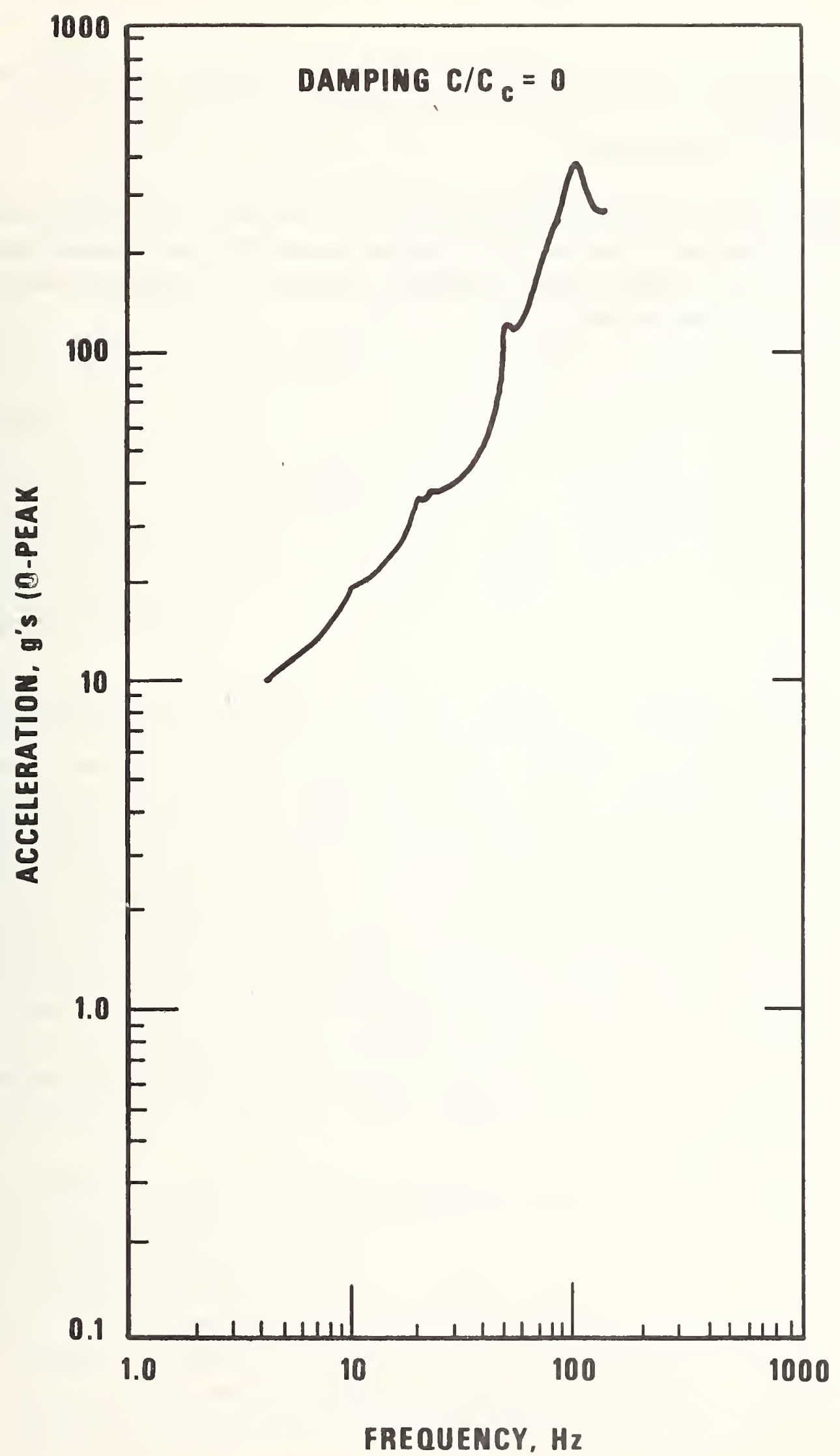

Figure 2.10 - Maximum shock spectra envelope, railroad coupling
(11 mph). (after Ostrem) 
for $\mathrm{C} / \mathrm{C}_{\mathrm{C}}=0$ indicates a response of about $20 \mathrm{~g}$ at the same frequency. The upper $11 \mathrm{mit}$ spectra envelope in figure 2.10 is presented for 1llustrative purposes, but is not recommended for selecting design accelerations.

Structural damping has a mitigating effect on the maximum acceleration amplitudes and 1 ts neglect results in an overly conservative design requirement. The Importance of damping emphasizes the need for additional data with which to refine the estimates of damping used in shelter design and analysis. 


\section{ROAD ENVIRONMENT}

In road vehicles, shock and vibration excitations are functions primarily of vehicle dynamics and road irregularities. Occastonally, wind gusts are also a factor in the highway dynamic environment. Internal excltations may be caused by the engine, transmission and drive assembly, wheel unbalance and shimmy. Such excitations are usually of low amplitude, as a result of good engineering design and maintenance. Normal over-the-road events which cause the more critical excitations include (1) crossing railroad tracks, (2) traversing roads made rough by potholes and dips, and (3) crossing cattle guards. A study of the vibration response of a 2 1/2-ton (907-kg) flatbed truck, [10,11], identified some "abnormal conditions" affecting the cargo's dynamic environment. The abnormal conditions include driving with two wheels on the shoulder, driving completely on the shoulder and driving on a dirt road. The environment, caused by the normal and abnormal over-the-road conditions, consists principally of a low level random vibration upon which is superimposed a large number of repetitive shock inputs [12]. Frequency spectra and shock spectra data for typical events encountered by a 2 1/2-ton (907-kg) flatbed truck will be presented in the following paragraphs.

Two and One-Half Ton Flatbed Truck - Typically, shelters are transported over-theroad in such military vehicles as $M-35, M-55$ and M-36 trucks. These are all flatbed cargo trucks with steel cargo bodies and dual rear axles. Ideally, a description of dynamic environment for truck transport of shelters would be based on vibration measurements on the cargo floor of these vehicles. The vibration studies would involve both normal and abnormal road conditions. A search of the literature on over-the-road truck studies revealed very little applicable data for military cargo vehicles. However, it was found that extensive vibration measurements had been taken on the deck of a commercial 2 1/2-ton (907-kg) flatbed truck, under both normal and abnormal conditions. The truck was loaded with cargo which consisted of a "distributed-mass dummy" mounted on an isolated pallet. The cargo was rigidly tied down to the deck and accelerometers were located fore and aft of the pallet/deck interface. The rear accelerometers were located over the rear wheels. The events comprising the category of normal conditions were:

1. Backing up to a loading dock across railroad tracks,

2. Driving to a weighing station across a series of railroad tracks,

3. Going into a dip at low speed,

4. Driving from a low, level road to a raised road,

5. Driving onto a bad overpass,

6. Driving onto a heavily patched asphalt highway at $50 \mathrm{mph}(22.4 \mathrm{~m} / \mathrm{s})$,

7. Driving on an access road parallel to an interstate highway,

8. Driving on a smooth blacktop, four-lane highway at 50,55 and $35 \mathrm{mph}(22.4,24.6$ and $15.6 \mathrm{~m} / \mathrm{s}$ ), 
9. Driving in a paved construction zone at 45 and $55 \mathrm{mph}(20.1$ and $24.6 \mathrm{~m} / \mathrm{s})$, and 10. Driving on rough blacktop at $60 \mathrm{mph}(26.8 \mathrm{~m} / \mathrm{s})$.

The events in the abnormal condition category included:

1. Driving with two wheels on the shoulder of the road at $45 \mathrm{mph}(20.1 \mathrm{~m} / \mathrm{s})$,

2. Driving completely on the shoulder of the road at $45 \mathrm{mph}(20.1 \mathrm{~m} / \mathrm{s})$,

3. Colliding with a loading dock,

4. Driving off the road in desert brush,

5. Driving onto the median of an interstate highway,

6. Driving on a dirt road at $45 \mathrm{mph}(20.1 \mathrm{~m} / \mathrm{s})$,

7. Driving into a dip at $50 \mathrm{mph}(22.4 \mathrm{~m} / \mathrm{s})$,

8. Hitting holes in a truck stop at 45 to $50 \mathrm{mph}(20.1$ to $22.4 \mathrm{~m} / \mathrm{s})$,

9. Running over a cattle guard at $45 \mathrm{mph}(20.1 \mathrm{~m} / \mathrm{s})$, and

10. Driving over railroad tracks at 45 and $50 \mathrm{mph}(20.1$ and $22.4 \mathrm{~m} / \mathrm{s})$.

The measurements obtained from sampling the cargo deck response to these Events were reduced in one of two ways depending upon the characteristics of the vibrations.

In the first method, long-duration random vibrations were analyzed with narrow-band spectrum analyzers. The acceleration peaks were counted within each frequency bandpass for both the fore and aft accelerometers. The data were combined into a composite probability distribution description for each event. Then, the results from all normal events that caused long-duration continuous vibrations were combined to. form a composite description of the dynamic environment for normal road conditions.

Nine of the ten normal events produced long-duration vibrations. Data were reduced for the vertical direction only because it was the observed direction in which maximum acceleration levels occurred. Six of the ten abnormal events also produced vibrations which were analyzed in the manner described above. Composite response curves for long-duration vibrations caused by the nine normal events and six abnormal events are presented in figures 3.1 and 3.2 respectively [4]. In addition to the Peak accelerations (i.e. the absolute maximum acce1.) curves are shown for 99.5, 99.0, 98.0,95.0 and 90.0 percentile accelerations. Comparison of the two sets of curves will show that the respective ordinates are in relatively close agreement. No explanation is offered in the source documents for the closeness of results for the two categories. It is concluded from figures 3.1 and 3.2 that the continuous excitation experienced during truck transportation has a Peak amplitude of about $2 \mathrm{~g}$ in the vertical direction. It is notelorthy that the 99 percentile amplitudes are less than $0.5 \mathrm{~g}$ for all frequency bands. 


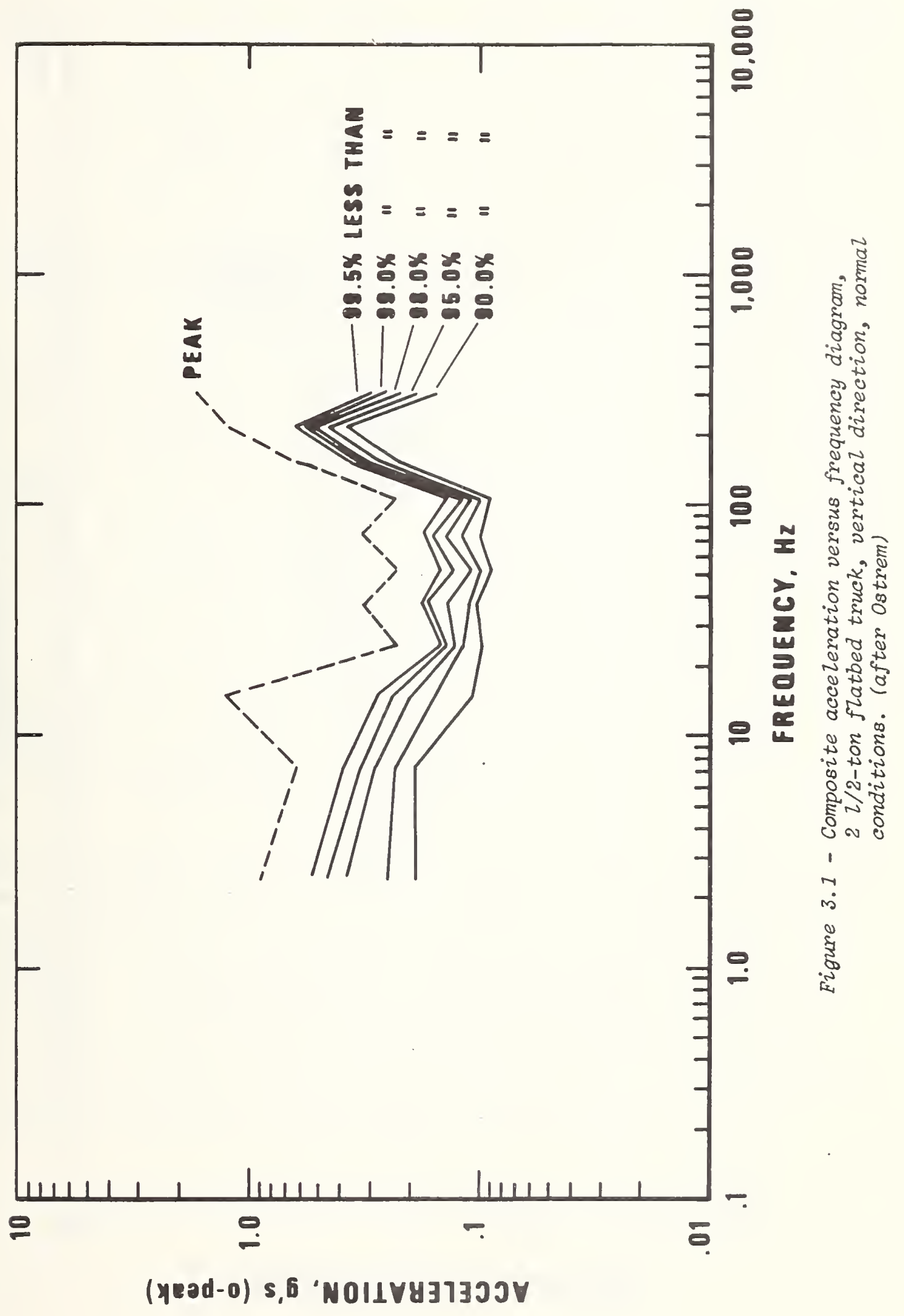




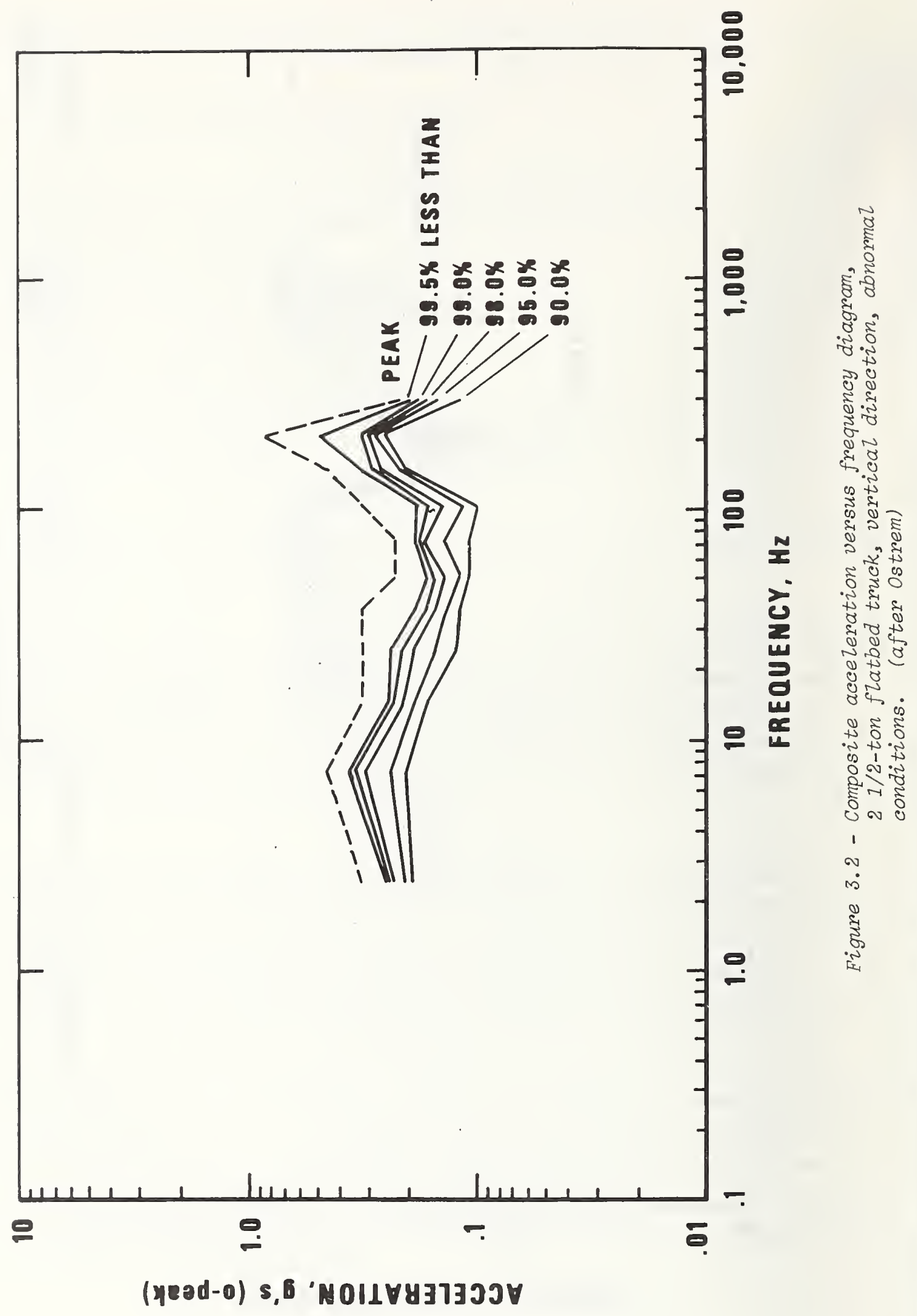


The second method of data reduction was applied to transient vibration measurements. Shock spectra were derived to describe the transient response caused by both normal and abnormal events. Only one normal event, driving across a series of railroad tracks at low speed (event No. 2), caused shock excitations. On the other hand, four abnormal events resulted in shock excitations. Figures 3.3, 3.4, 3.6 and 3.7 [4] present the shock spectra for the five events. It should be noted that the two curves in figure 3.4 show shock spectra resulting from one normal event (1.e., crossing railroad tracks at a slow speed) and one abnormal event ( $1 . e .$, crossing railroad tracks at $45 \mathrm{mph}(20.1 \mathrm{~m} / \mathrm{s}$ )). The acceleration time-histories from which the two spectra curves in figure 3.4 were derived are shown in figures 3.5.1 and 3.5.2 The time histories were used as the applied forcing functions. Then the equivalent static acceleration (1.e. maximum dynamic response) was computed for single-degree-of-freedom systems with particular natural frequencies and damping ratios. Although spectra were obtained for damping ratios of $0,0.03$ and 0.10 , only those obtained for $\mathrm{C} / \mathrm{C}_{\mathrm{c}}=0.03$ are presented. As stated previously, the spectrum for 0.03 damping ratio is regarded as an estimate of the response severity produced on non-1solated cargo systems. Except for figure 3.7, the response curves present maximum accelerations for the vertical direction only. This approach is due to the test observation that the severest cargo deck excitations occurred in the vertical direction. As would be expected, colliding with a loading dock (figure 3.7) produces a higher longitudinal than vertical shock excitation over most of the frequency range. Examination of figures 3.3 through 3.6 shows that, in general, driving over potholes (figure 3.3) causes the severest shock excitation experienced in the road environment. It is noted that relatively high amplitudes exists over most of the frequency range. For frequencles less than $100 \mathrm{~Hz}$, the severest acceleration, $8 \mathrm{~g}$, occurs at about $3 \mathrm{~Hz}$. According to Foley, et al [1], truck suspension systems provide the relatively high intermittent transient inputs at 3 to $6 \mathrm{~Hz}$.

With regard to the design of shelters for truck transport the data in figures 3.3 - 3.7 are suggested as belng representative of the shock environment. Thus, vertical accelerations can generally be selected from fig. 3.3 while horizontal accelerations are selected from figure 3.7. The shock spectra can be used in an equivalent static force design in the following manner. An acceleration value is selected that corresponds to the estimated natural frequency of the shelter (or shelter component). This acceleration is used to compute an equivalent static force, which is to be applied to the shelter to account for dynamic effects. The shelter is then analyzed for maximum stresses or deflections. The maximum stresses and deflections are then compared to allowable values. 


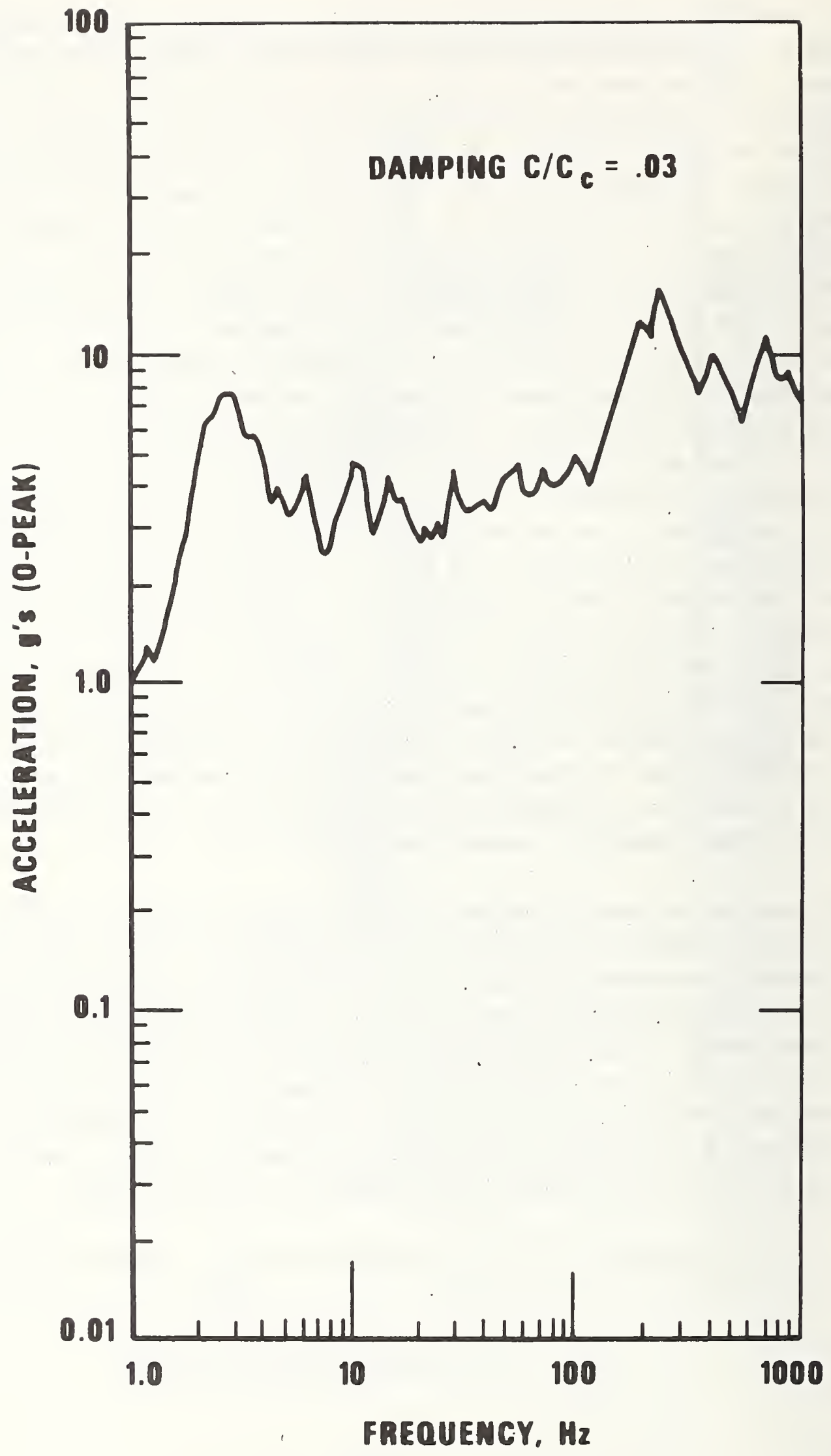

Figure 3.3 - Maximom shock spectra, 2 1/2-ton flatbed truck, vertical direction, potholes at truck stop. (after Ostrem) 


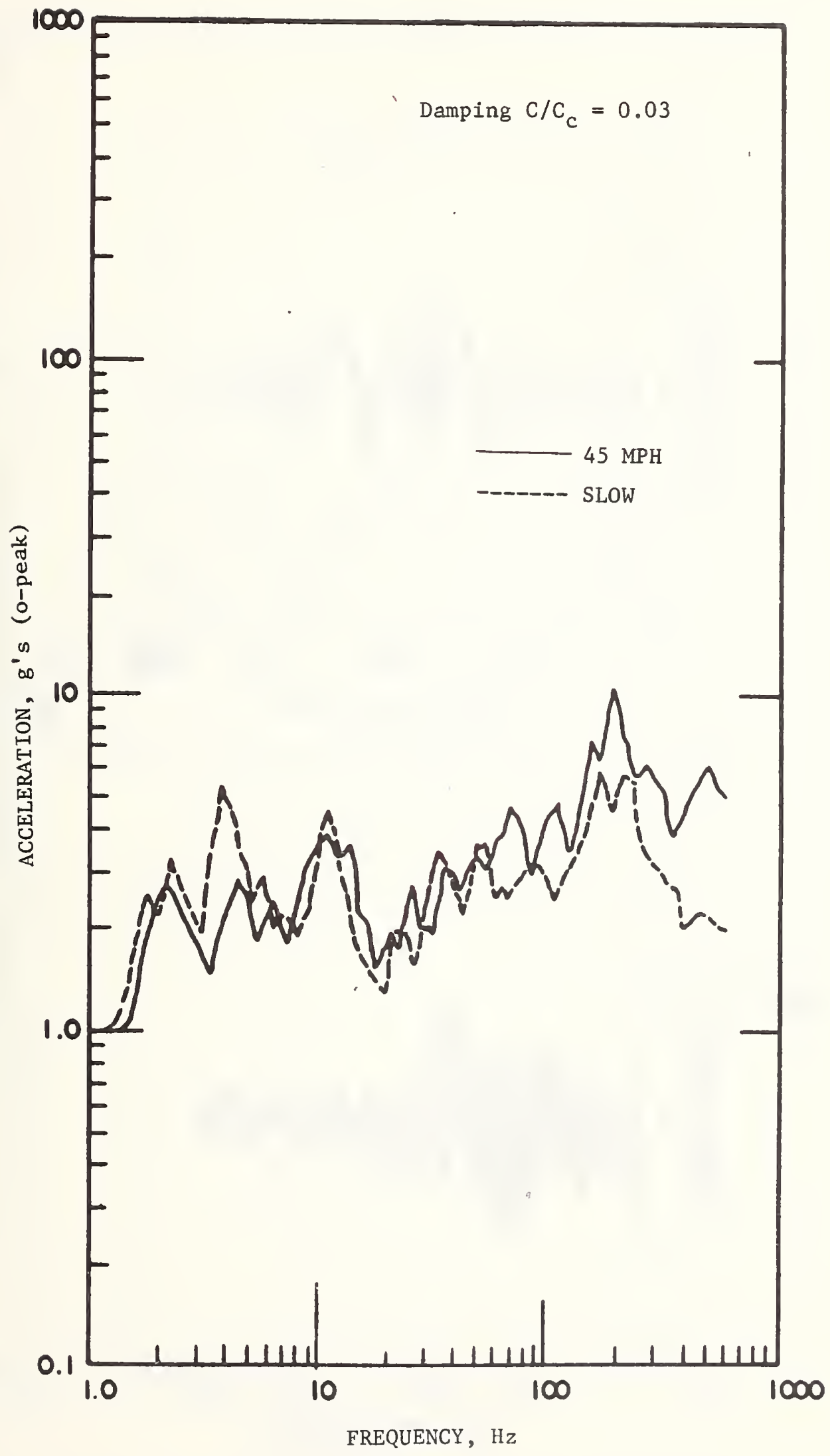

Figure 3.4 - Maximum shock spectra, 2 1/2-ton flatbed tmuck, vertical direction, railroad crossings. (after Ostrem) 

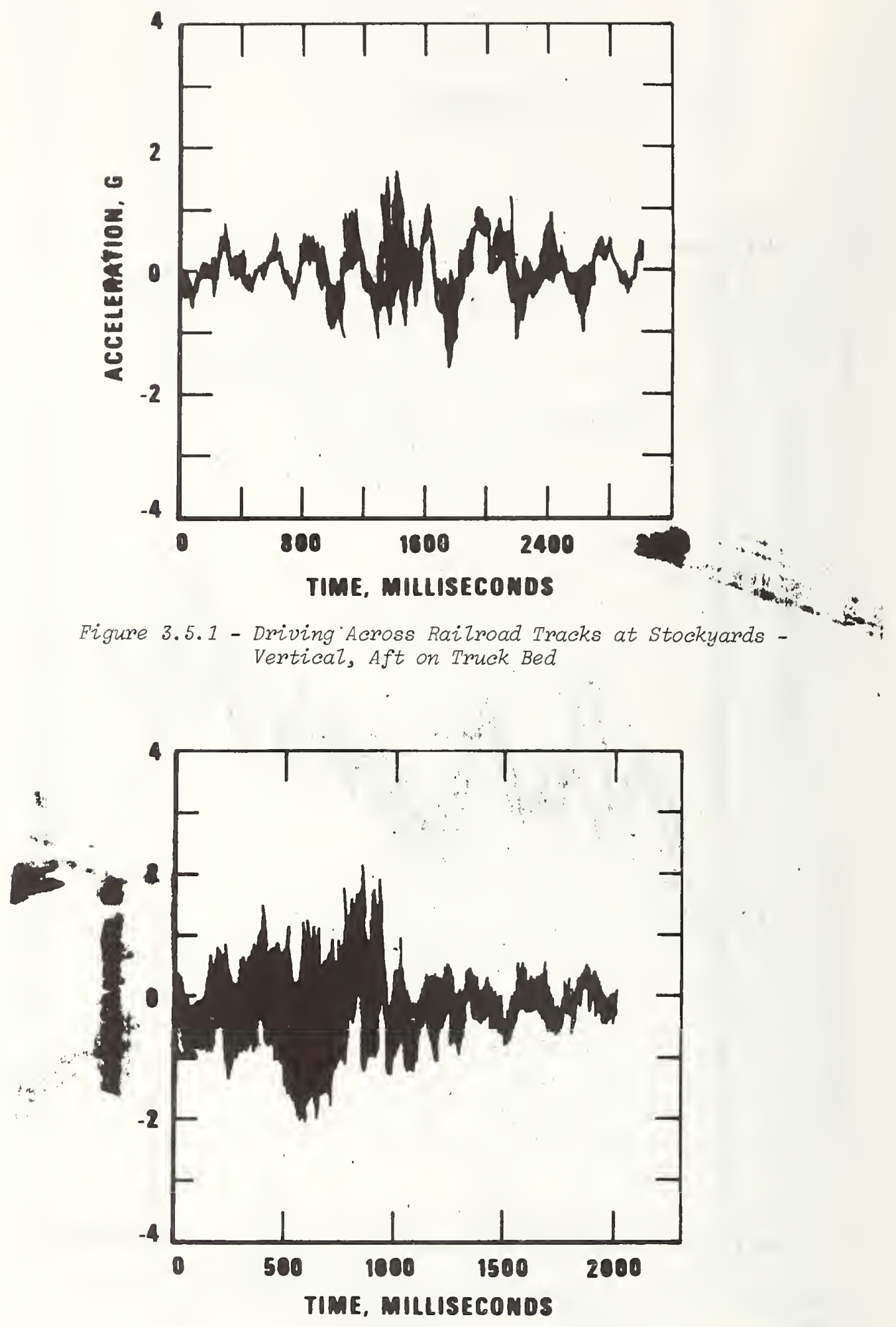

Figure 3.5.2 - Driving Across Railroad Tracks at $\simeq 45 \mathrm{mph}$ Vertical, Aft on Truck Bed. 


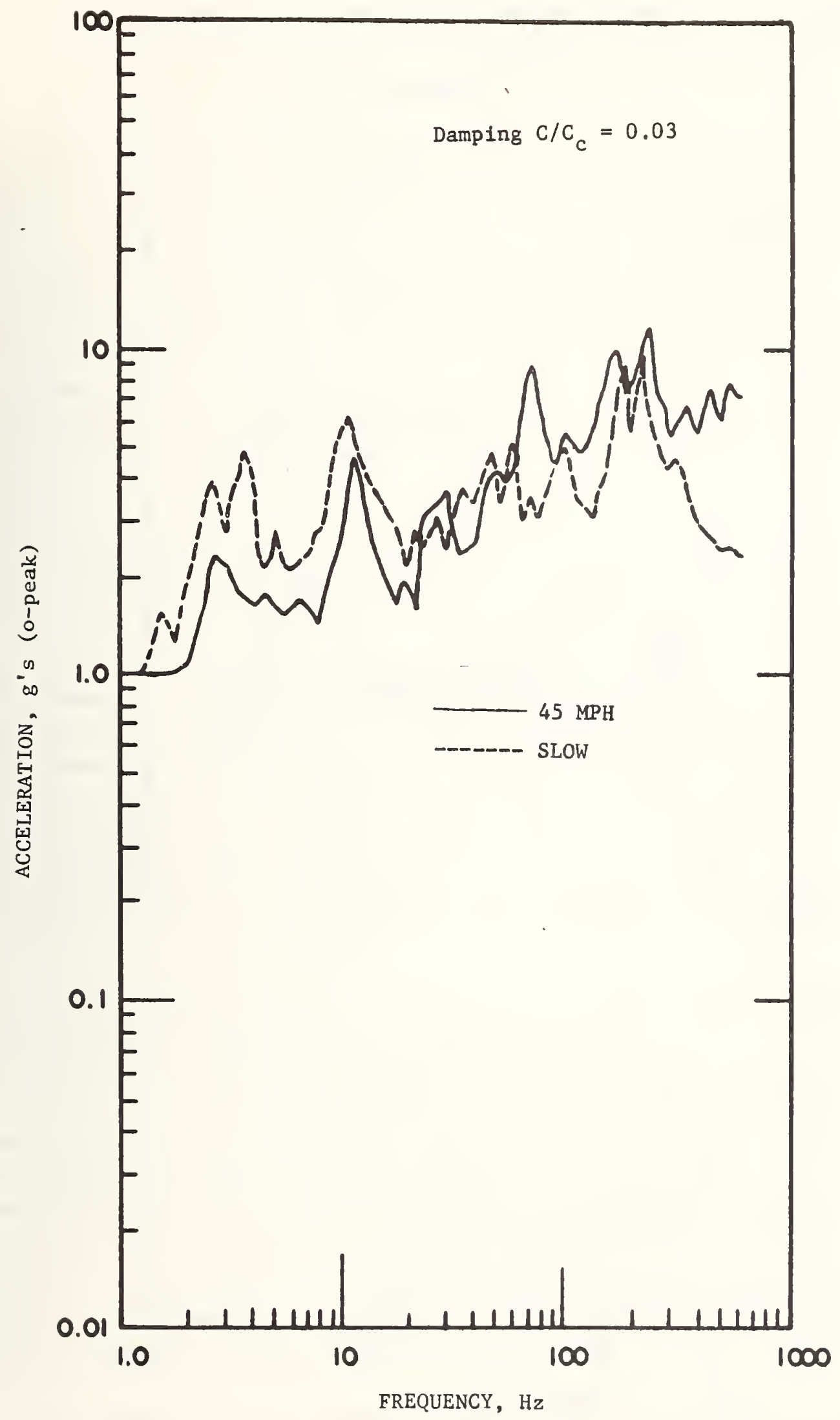

Figure 3.6 - Maximum shock spectra, 2"1/2-ton flatbed truck, vertical direction, driving across cattle guards. (after Ostrem) 


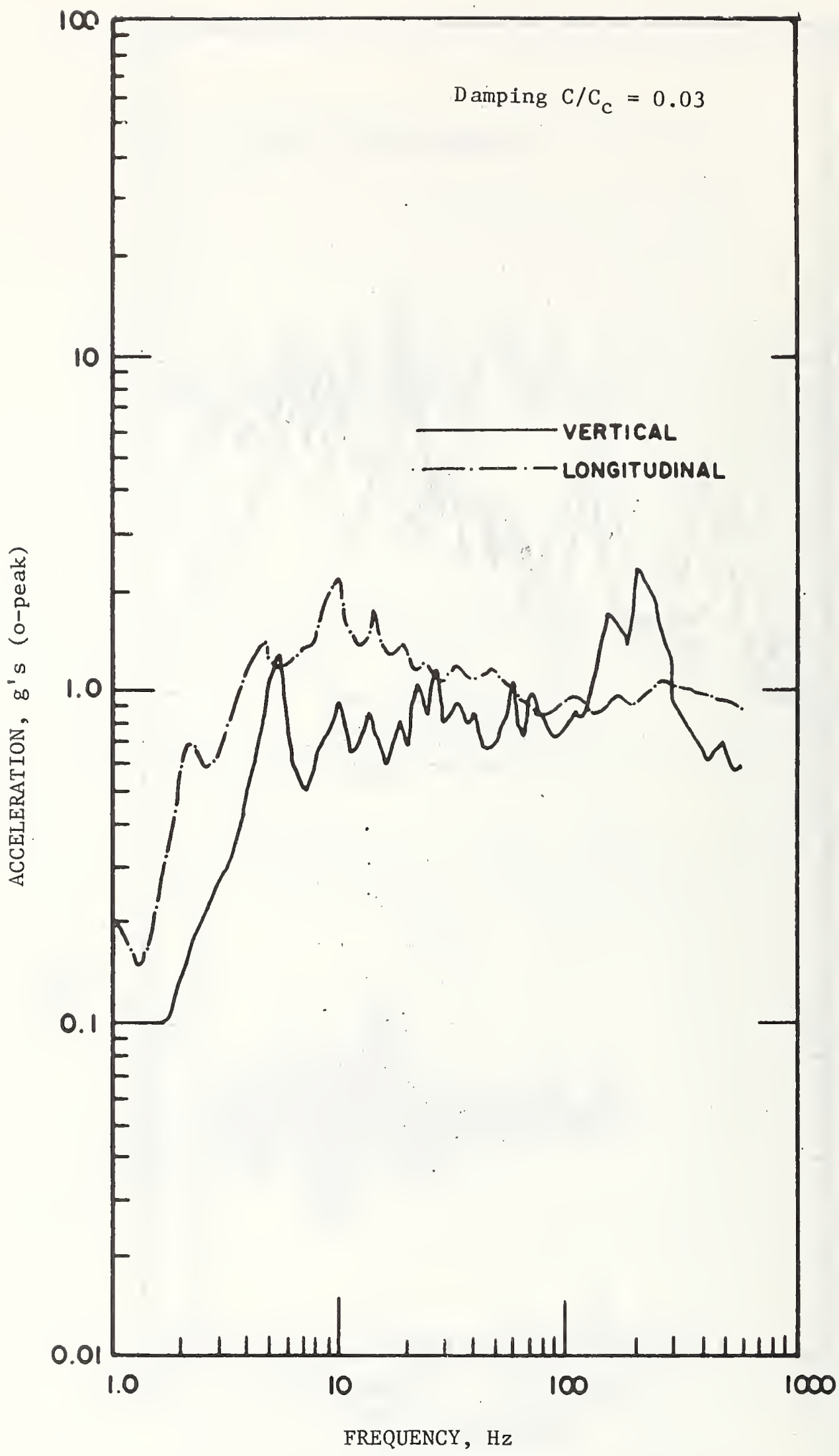

Eigure 3.7 - Maximum shock spectra, 2 1/2-ton flatbed truck, Zongitudinal direction, backing into loading docks. (after ostrem) 


\section{AIR ENVIRONMENT}

The vehicles used to transport shelters through the air are airplanes - either propeller or turbojet - and helicopters. Propeller-driven airplanes are separated into two categories: reciprocating engine and turboprop aircraft. The dynamic environment caused by the fixedwing and rotary-wing classes of aircraft are different although they have in common several normal service conditions. Vibrations in aircraft result from such factors as runway roughness, propulsion dynamics, propeller and rotor unbalance, aerodynamic forces and acoustical fluctuations. Air turbulence around the aircraft will also induce vibrations. The air has vertical components of velocity which impart vertical accelerations to the aircraft [4]. The dynamic effects of these factors on the cargo deck have been measured for all the classes of aircraft mentioned above.

Most of the available vibration data related to air transport of cargo have been obtained from measurements made aboard military cargo aircraft. For example, acceleration timehistories have been obtained from the cargo floor of the C-130 which is a cargo plane commonly used for transporting shelters. While there are sufficient data with which to predict the in-flight environment of airplanes and helicopters, there is a scarcity of information pertaining to the dynamic environment during landing. This shortcoming is probably inconsequential to transport by modern turbojet airplanes since recent studies of the shocks experienced during landing operations [12] indicate a relatively low probability (10 $0^{-3}$ ) of exceeding $1 \mathrm{~g}$. There is no evidence given in the literature to suggest that helicopter landing produces severe environments when the cargo is transported inside the aircraft. The environment caused by the "landing" of cargo which is transported while suspended beneath a helicopter is one of concern to shelter designers. However, applicable test data are not available at this time.

4.1 Airplane Transport of Cargo - Shock and vibration measurements have been made on the cargo floor of both turbojet and propeller airplanes $[1,4,7,14]$. Acceleration timehistories were obtained on these aircraft during normal service operations such as: taxilng, ground run-up, take-off, climbing, cruising, turning and descending. The accelerometers were oriented to obtain measurements in the vertical, lateral and longitudinal directions. The dynamic environment for fixed-wing alrcraft is generally characterized by broad-band random excitations upon which are superimposed continuous single-frequency excitation [1]. The most severe accelerations are produced during the take-off and climb events and while cruising at high altitudes. The take-off and climb events cause relatively high amplitude inputs of short duration. On the other hand, the cruise environment is characterized by moderate amplitudes of considerably longer duration.

4.1.1 Propeller-Driven Airplanes - Figures 4.1 through 4.4 present directional acceleration data obtained for the C-123, 377 PG (Pregnant Guppy), C-130 and 


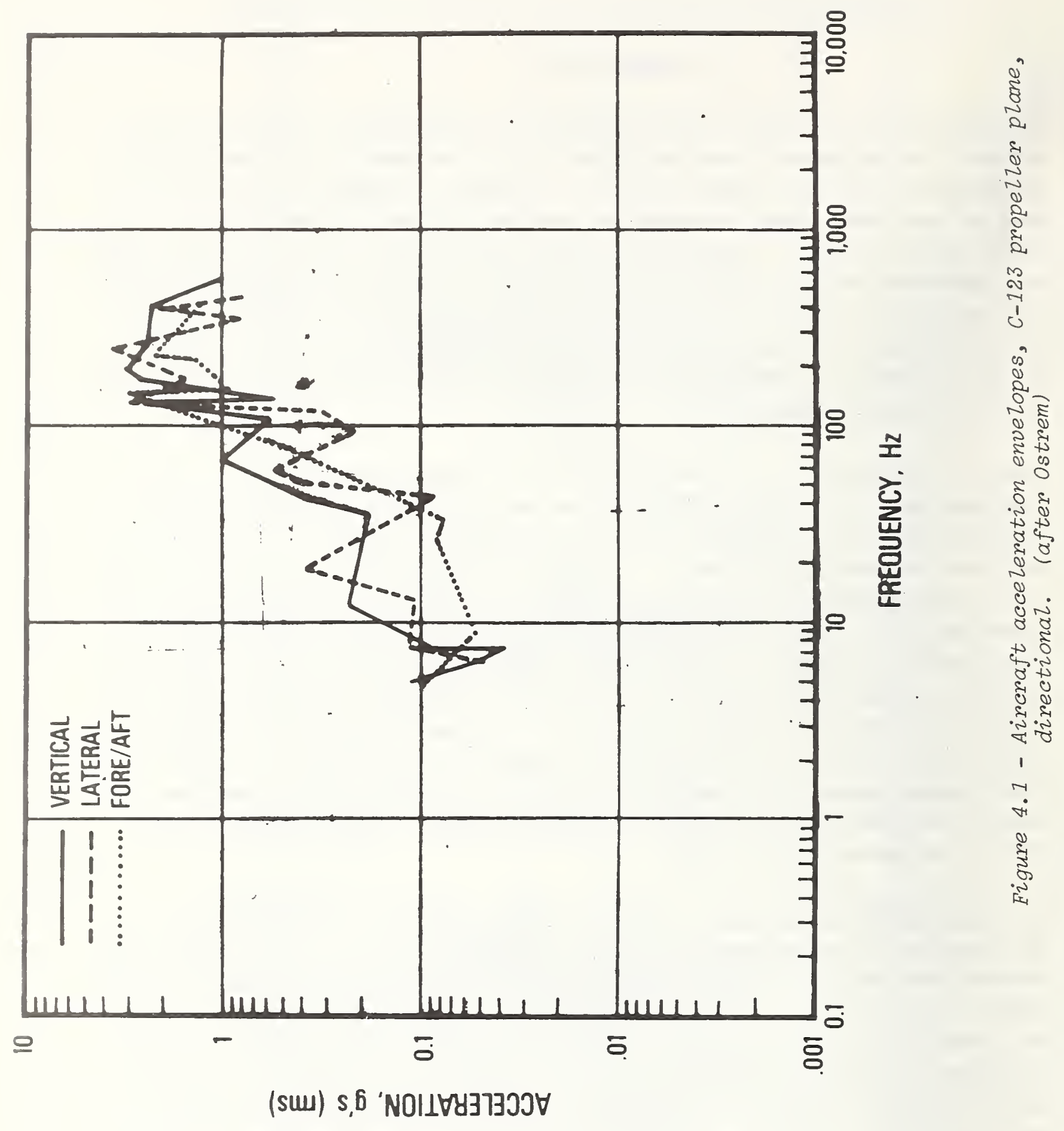




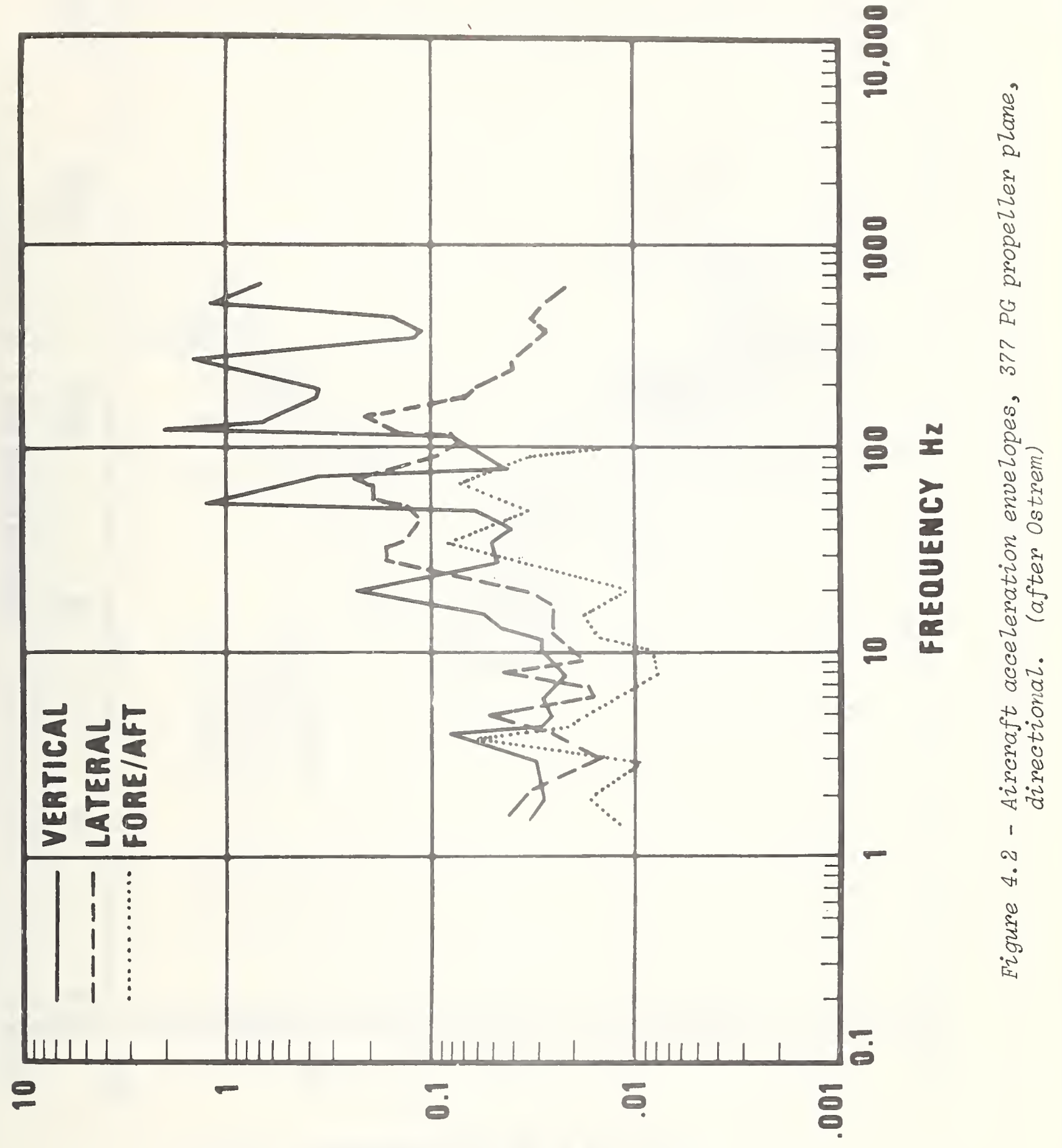

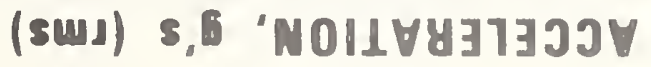




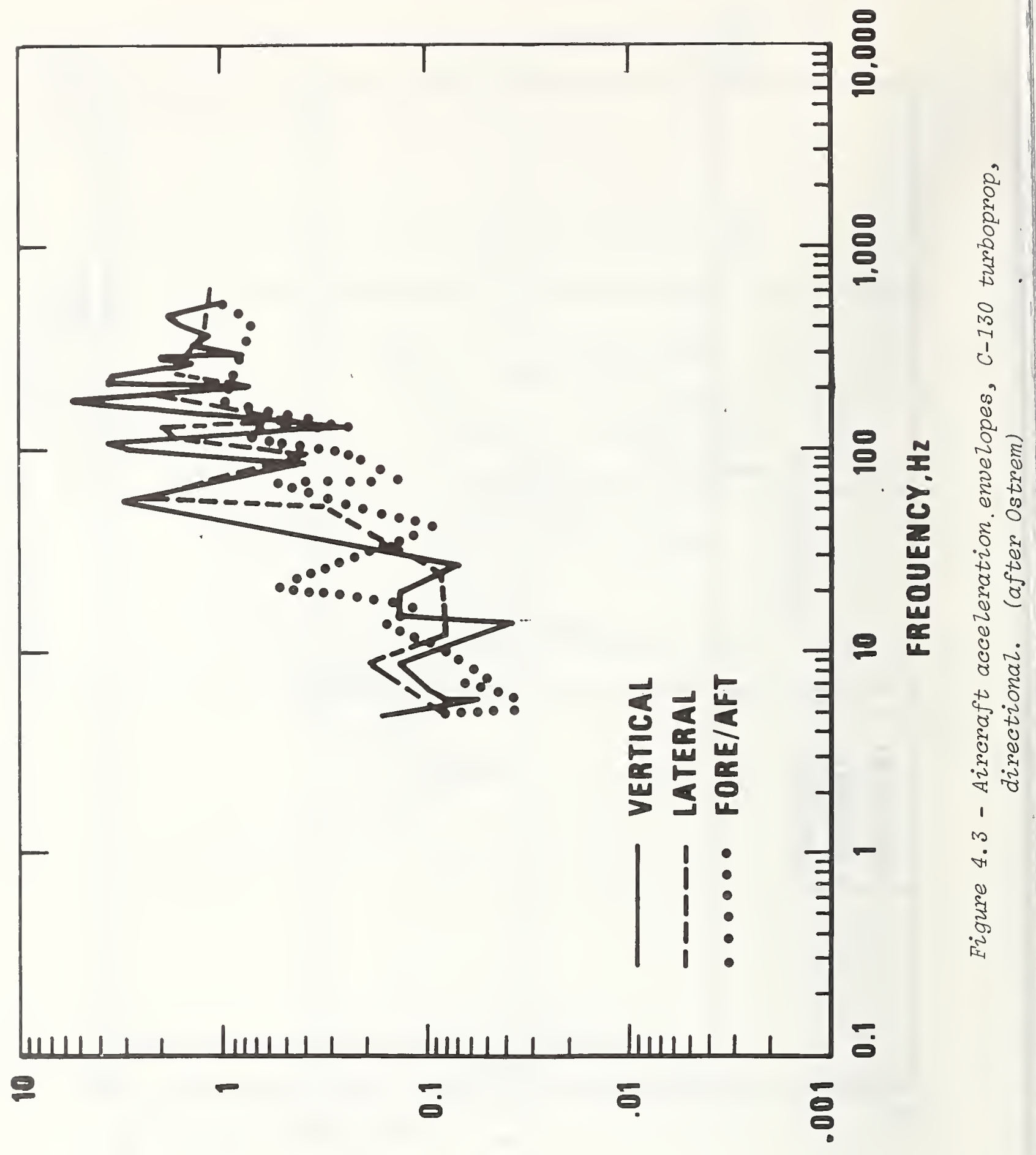

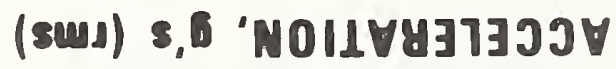




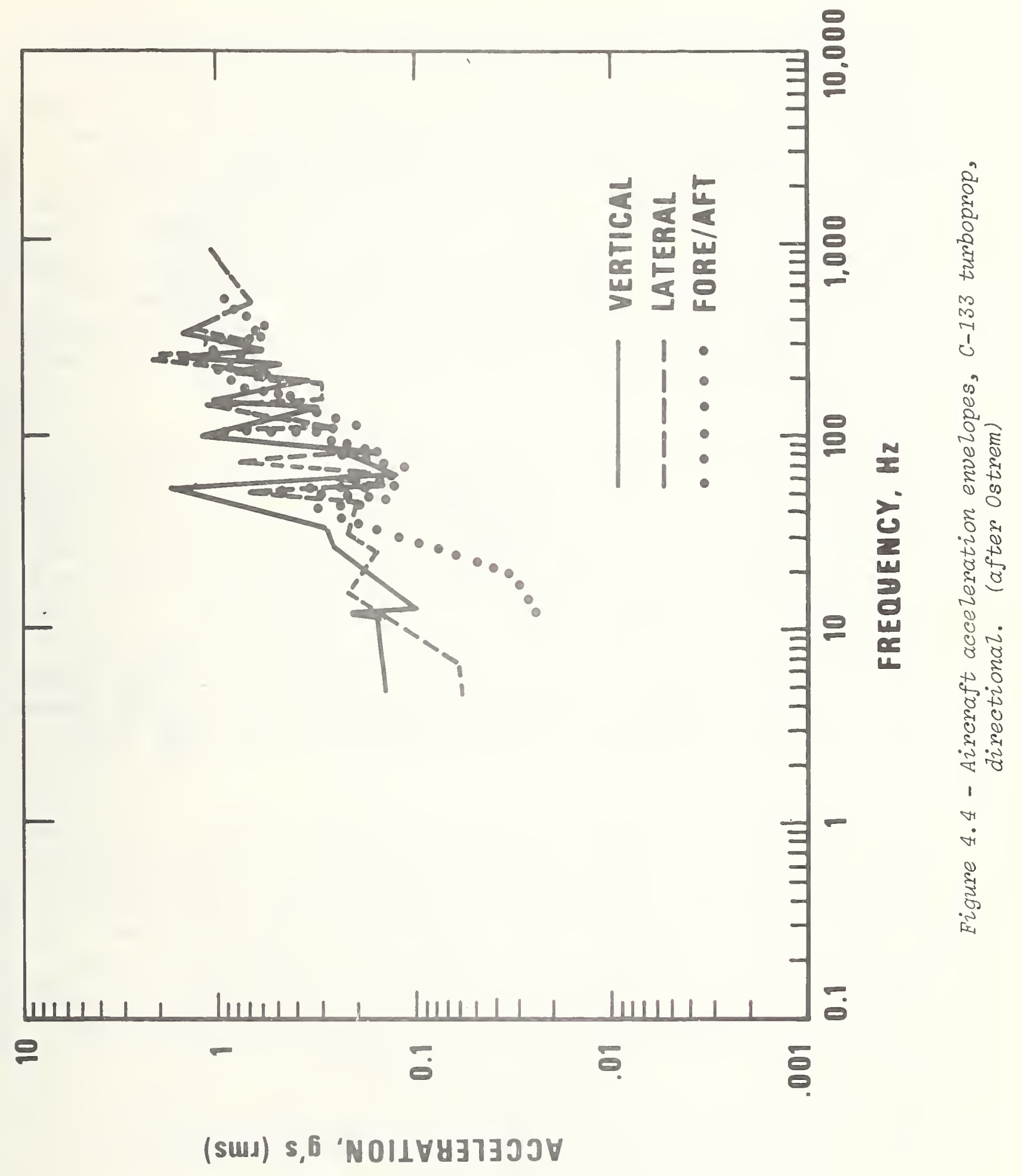


C-133 airplanes respectively [4, 7]. The C-123 and 377 PG are reciprocating engine, military cargo planes. Both the $\mathrm{C}-130$ and $\mathrm{C}-133$ are turboprop planes with four engines and three-bladed propellers. The original data - obtained by the Wright Air Development Division - were presented in the form of power spectral density curves. Subsequently, Ostrem [4, 7] computed the root-mean-square accelerations $\left(g_{\text {rms }}\right)$ for the frequency bandwidths comprising the spectra. Thus, the data were presented in the form of $\mathrm{g}_{\mathrm{rms}}$ versus frequency. As discussed in section 4.3, this format is not compatible with the equivalent static force design approach. It is important to note that the four diagrams are composites of maximum data points obtained for different accelerometer locations and all the normal operating conditions mentioned in section 4.1. Thus, the curves are envelopes encompassing the maximum acceleration level for all flight conditions rather than continuous response spectra.

\subsubsection{Turbojet Airplanes - Turbojet airplanes are commonly used for transporting} military cargo. A search of the literature revealed that data useful in predicting the dynamic environment of this class of fixed-wing airplane is scarce. Furthermore, the methods of data presentation varied according to available instrumentation and intended use of the information. Dynamic load information obtalned from an early version and a more recent version of one type of military turbojet is presented herein. The data are presented in the respective formats used in the source reports. They will serve as a case-in-polnt of the problem of having to use diverse data formats in predicting dynamic loads generated by airplanes. This problem is addressed in section 4.3, where a common basis is established for presenting the acceleration versus frequency data.

In 1958, acceleration measurements were made aboard a KC-135A (military version of the Boeing 707 commercial jet) for the conditions of ground run-up, taxiing, take-off and crulsing. The accelerometer time-histories were passed through a series of narrowbandwidth filters for the purpose of data reduction. The original Boeing report [15] presented the data in the form of power spectral density versus frequency diagrams. Subsequently, Ostrem [7] integrated the spectral densities within each filter bandwidth and computed the mean-square accelerations. The results were then presented in the form of $\mathrm{g}_{\mathrm{rms}}$ versus frequency. The summary response diagram for the KC-135A is presented in figure 4.5 [7]. The three directional-dependent curves are envelopes of the highest values of $\mathrm{g}_{\mathrm{rms}}$ for all observed flight conditions. Thus, the diagram indicates maximum $g_{\text {rms }}$ data points connected by straight lines rather than continuous functions of frequency. The frequency range extends from approximately 10 to $2000 \mathrm{~Hz}$ (the accelerations corresponding to frequencles above about $500 \mathrm{~Hz}$ are probably superfluous for shelter design considerations). Vertical accelerations were generally predominant. This result is to be expected in that Foley et al [1] indicate that the most severe amplitudes are caused by take-off and climbing conditions. Examination of figure 4.5 shows that the maximum value of $\mathrm{g}_{\mathrm{rms}}$ was approximately $2 \mathrm{~g}$ in the vertical and lateral 


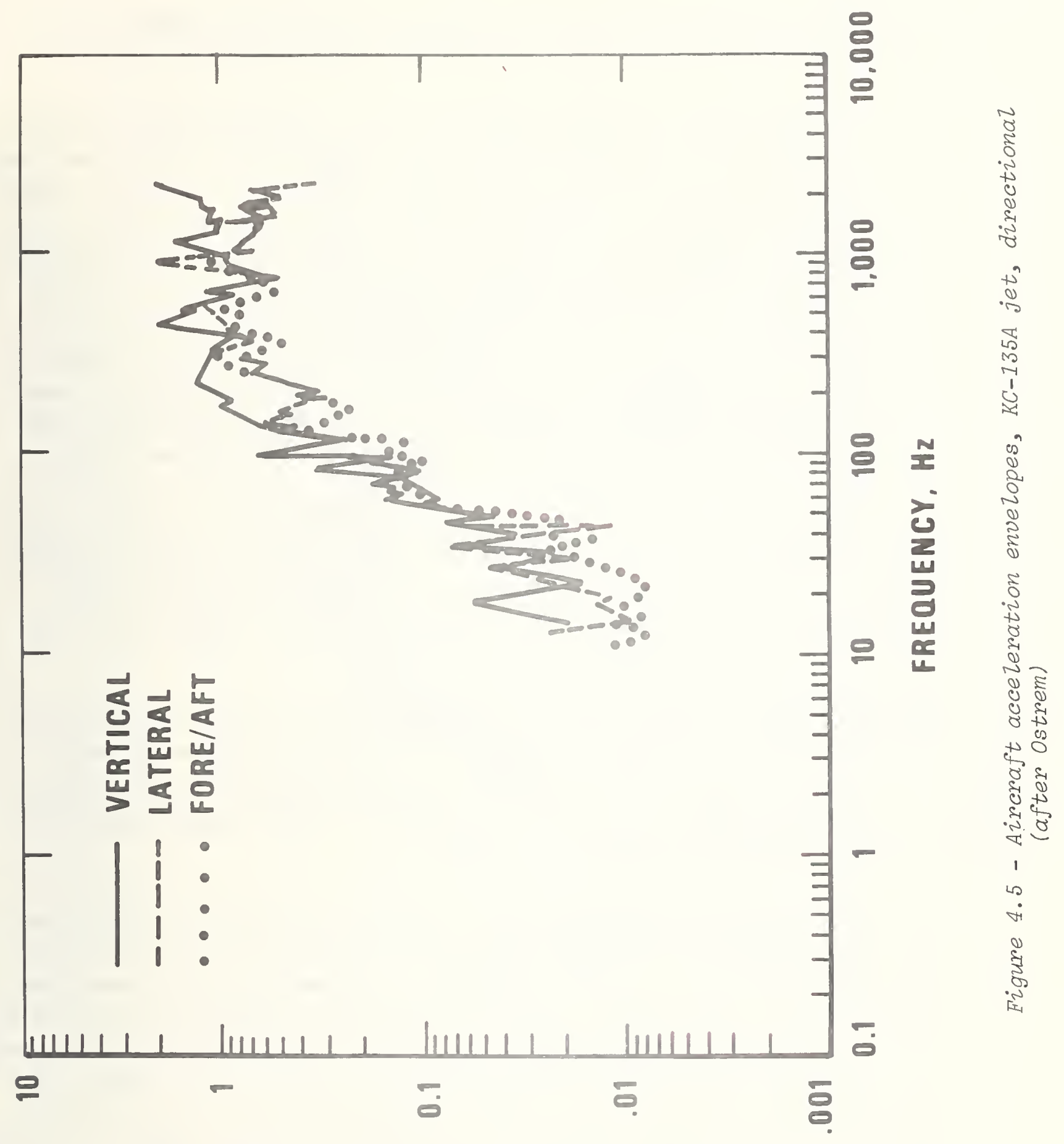

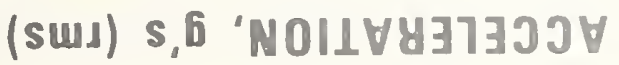


directions. In the longitudinal (i.e. fore and aft) direction, the maximum value of $\mathrm{g}_{\mathrm{rms}}$ was about $1 \mathrm{~g}$.

In a later test program, accelerometer time-histories were obtained aboard a NC-135 (a military version of the commercial 707 jet) for the conditions of: take-off, full power climb, cruising, descent and braking (after landing). Acceleration records were not obtained for the touchdown part of the landing operation. The random vibration timehistories were processed by bandpass analysis (i.e. flltering with narrow bandpasses). In the orfiginal report of this study, Harley [16] presented the data in the form of cumulative probability distributions within each frequency band. This form of data presentation was described in section 1.3. Part of the data is presented in figure 4.6 [4] in terms of the maximum values of peak accelerations and the probability of peaks being less than indicated levels. Of the five test conditions mentioned above, takeoff produced the most severe accelerations in the frequency range of about 2-100 Hz.

Above $100 \mathrm{~Hz}$, the accelerations produced by braking after landing were the most severe. Figure 4.7 [4] shows the maximum values of peak acceleration for the higher frequency range. It is noted that data are presented for the vertical direction only since preliminary review of the acceleration measurements indicated the predominance of the acceleration in this direction.

\subsection{Helicopter Transport of Cargo - Prediction of the dynamic environment for helicopters is important to the design of military field shelters in that it is a convenient mode of short- and medium-haul transportation. Movement of cargo via helicopter involves one of two dynamic environments depending upon. whether the shelters are supported inside the aircraft or are suspended from beneath the aircraft by cables.}

\subsubsection{Cargo Transported Inside Helicopters - The dynamic environment for cargo trans-} ported inside helicopters is primarily influenced by the same factors that affect cargo in fixed-wing aircraft (e.g. propulsion dynamics, rotor unbalance and air turbulance). However, Foley et al [1] indicate that cargo floor responses of helicopters differ from those of airplanes. For example, there is very little difference between the vibrations caused by take-off and those due to cruising in helicopter flight. In contrast, there is a significant difference in accelerations caused by these two events in airplanes. Secondly, the dynamic environment inside cargo helicopters is characterized by continuous single-frequency vibrations, of relatively high amplitude, in the lower frequency range (i.e. up to about $40 \mathrm{~Hz}$ ). No such characteristic has been noted for the time-histories obtained aboard airplanes.

Cargo floor vibrations have been measured in several military helicopters for a variety of operating conditions. About half of the avallable data have been obtained inside 


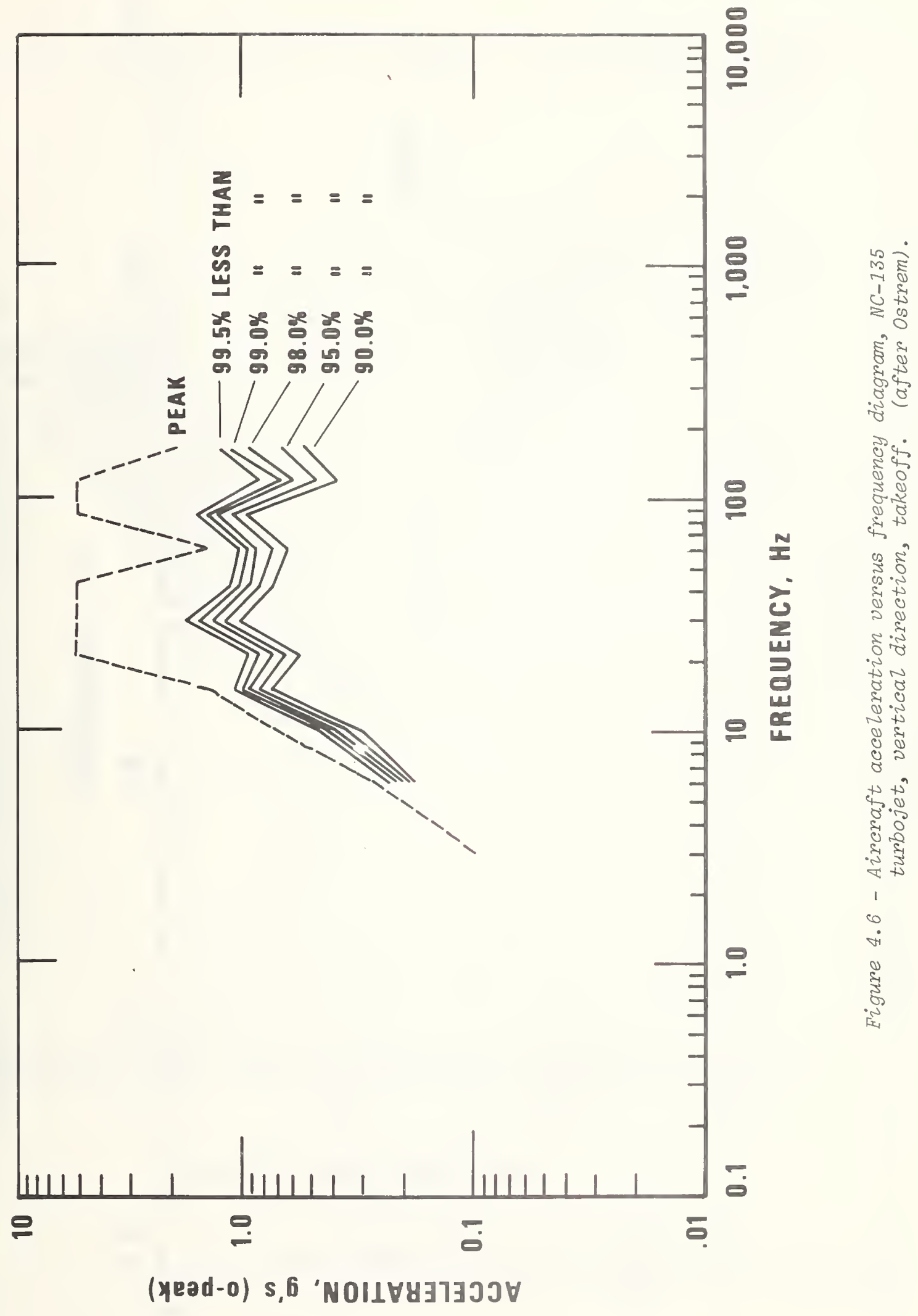




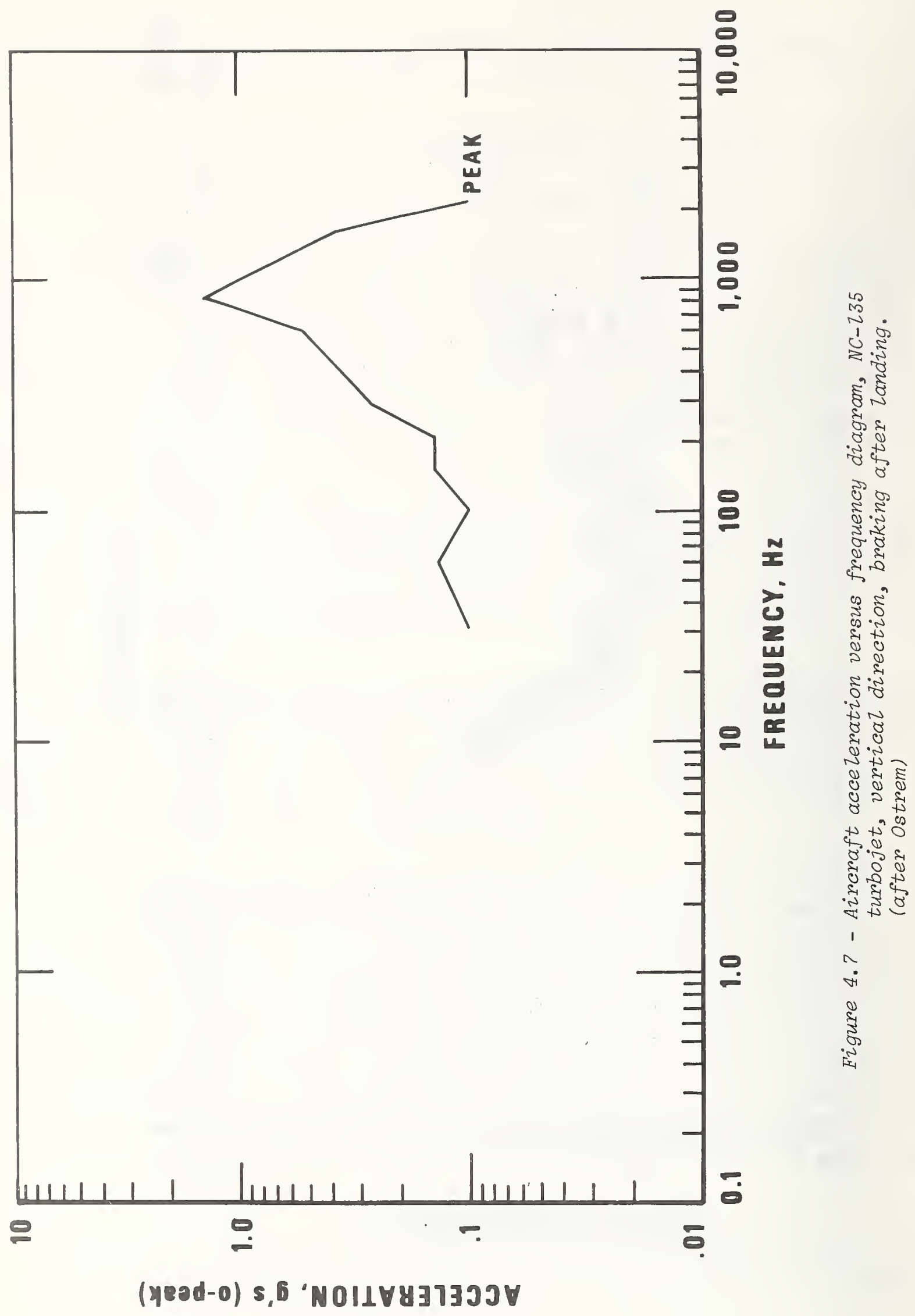




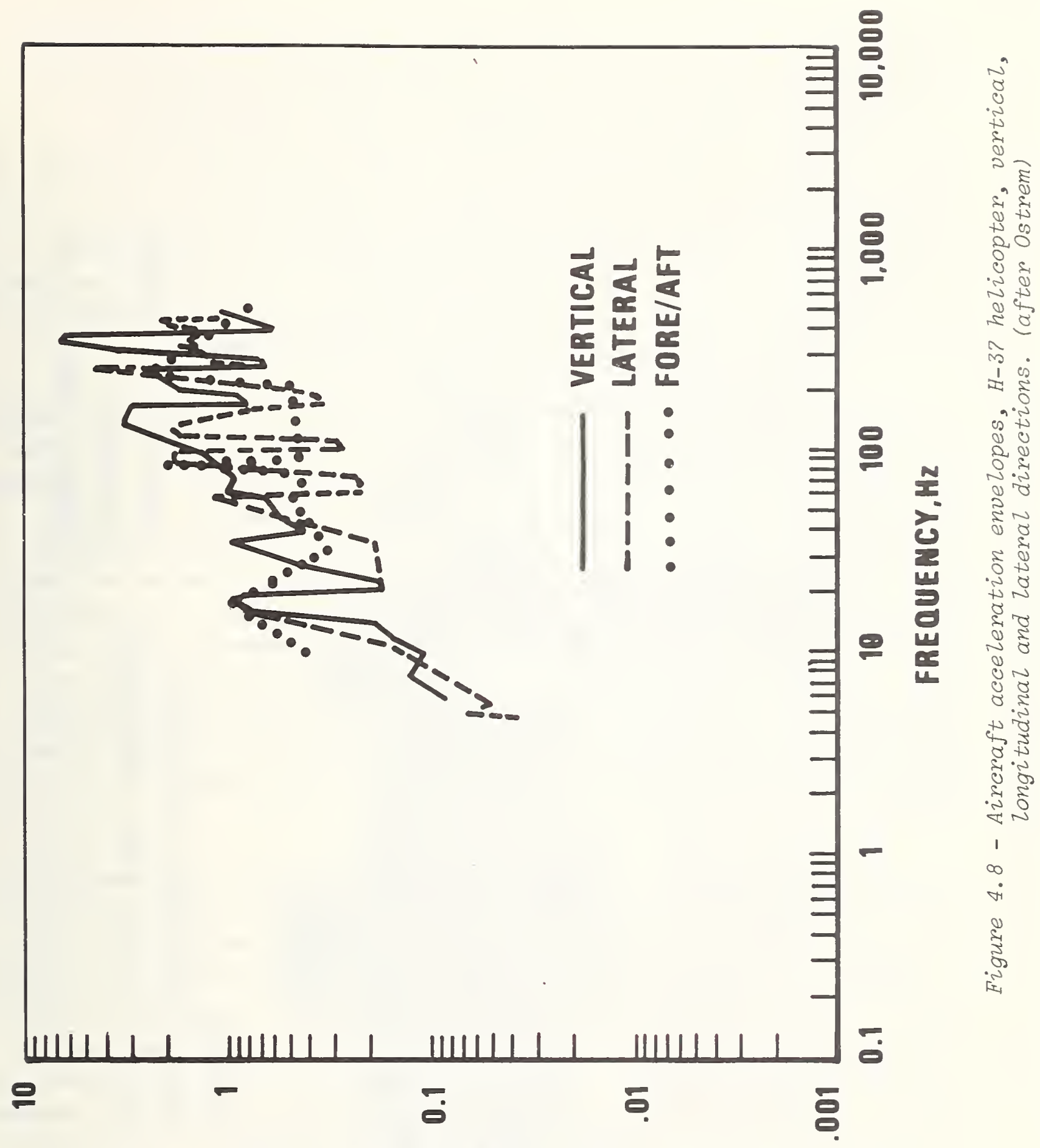

(suد) S,6 'NOIL 
helicopters which are carriers of cargo, including shelters. However, describing the dynamic environment for cargo helicopters is complicated by the presentation of the data in several different formats. Representative dynamic response data are presented below in the format used in the source document. Additional work in this area is necessary to normalize the existing data. Given a common format, the dynamic environment on the cargo floor of helicopters can be more succinctly described. It is important to note that the literature search did not reveal any shock and vibration measurements incident to the landing of rotary-wing aircraft. No explanation was given for the omission of this event from the test programs; the effect of not having test data for landing on existing predictive models is not presently known.

Representative cargo floor vibrations were measured aboard a $\mathrm{H}-37$ helicopter and reported in Reference 7. The $\mathrm{H}-37$ is a cargo helicopter with a single main rotor plus a torquecompensating tail rotor. Vibrations were measured at several locations for the following ground and flight conditions: (1) motor starts, (2) rotor engagement, (3) take-off, (4) hovering, (5) climbing, (6) cruising and (7) descending. A composite diagram of the test results is presented in figure 4.8 [7]. The three curves show the envelopes of $g_{\text {rms }}$ for the vertical, lateral and longitudinal directions. Data points representing the maximum values of $g_{\text {rms }}$ in narrow frequency bands have been connected by straight lines to obtain these composite diagrams. Examination of figure 4.8 shows that the most severe accelerations generally occurred in the vertical direction. The highest value of $g_{\text {rms }}$ was about 7.9 and occurred at approximately $350 \mathrm{~Hz}$. Between the center frequencies of 5 and $80 \mathrm{~Hz}$ the values of $\mathrm{g}_{\mathrm{rms}}$ do not exceed $1 \mathrm{~g}$ irrespective of direction.

Vibration measurements were also obtained from the cargo floors of two cargo helicopters for ten normal ground and flight conditions [17]. The CH46 and CH47 aircrafts were used for these field tests. Both of these carrier types feature contrarotating rotors to compensate for torque applied to the fuselage. The dimensions, weights and performance ratings of these two helicopters are presented in Reference 18 . The primary difference between the two aircraft, for test purposes, is that the CH47 has an isolated floor in the cargo compartment while the $\mathrm{CH} 46$ does not. In the latter aircraft, the airframe structure directly supports the cargo floor. According to Reference 17, the acceleration time-histories consisted of Gaussian random excitations; therefore, they were subjected to narrow bandpass analyses. Mixed with the random components were decaying sinsusoidal excitations of single frequencies. At this writing the complete data from this test program are not available. Shown in figure 4.9 is the diagram for the 99 percentile peak amplitudes, as a function of frequency. It is noted that for the dual rotor types of helicopter the highest levels (about $3 \mathrm{~g}$ ) were obtained in the longitudinal and transverse directions between 350 and $500 \mathrm{~Hz}$. This is the only frequency band in which the accelerations in the vertical direction were not dominant. The highest level in the vertical direction was about $2.5 \mathrm{~g}$. Although no supporting diagrams were presented in Reference 17, it was stated that the absolute peaks were in the $350-500 \mathrm{~Hz}$ band (i.e. $425 \mathrm{~Hz}$ center frequency) at $5.2 \mathrm{~g}$ for a11 axes. 


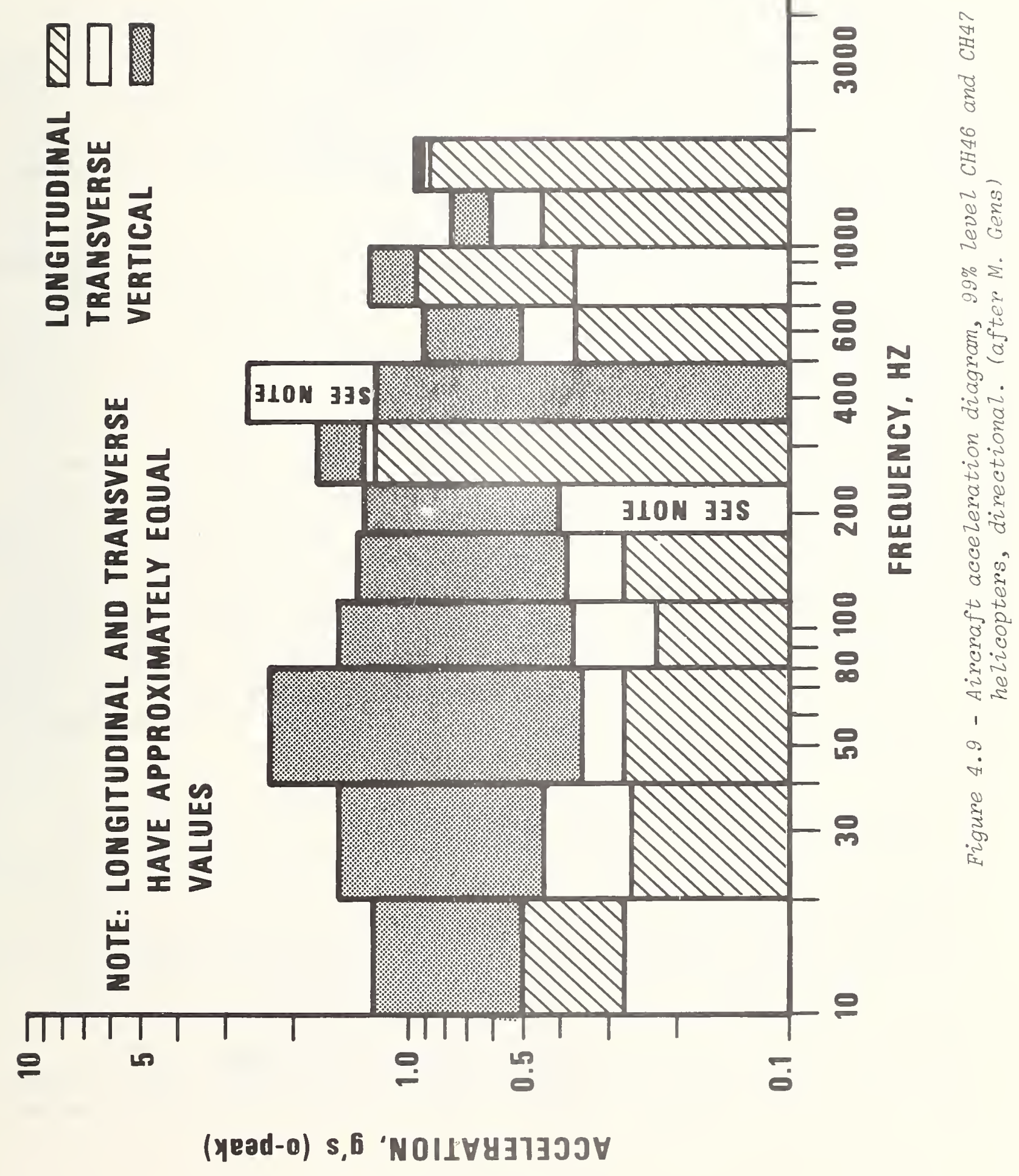


Another acceleration measurement program involved the use of the HH43B helicopter [4, 18]. Familiarly known as the "Huskie," this aircraft is principally a personnel carrier. However, it is constructed similarly to the cargo type carriers with contrarotating rotors. Two sets of accelerometers were placed in the passenger-cargo area and three-directional vibration measurements were obtained for 18 ground and flight conditions. Landing was included as one of the test conditions, but equipment malfunction prevented data collection during the landing event. Figure 4.10 presents a summary diagram for all the data acquired inside the HH43B. In constructing the constant probability curves, weighting factors were assigned to the 17 events to account for the relative frequency of their occurrence. Examination of figure 4.10 shows that the highest Peak occurred in the $350-500 \mathrm{~Hz}$ band (i.e. $425 \mathrm{~Hz}$ center frequency). The absolute maximum magnitude was approximately $2 \mathrm{~g}$. Between 0 and $180 \mathrm{~Hz}$, the maximum zero-to-peak acceleration was $1 \mathrm{~g}$.

4.2.2 Cargo Transported Outside Helicopters - In addition to the factors which influence the dynamic environment of cargo transported inside a helicopter, cargo suspended beneath a helicopter's fuselage is subjected to aerodynamic pressures. In the case of field shelters, such pressures are applied to all exposed surfaces. Qualitatively, the aerodynamic pressures would seem to cause a more severe load application than would be experienced by a shelter supported inside the aircraft. In addition, an externally supported shelter will receive shock excitations when it is "landed" in the field. Shelter design criteria for the air transport mode must account for these sources of design loading. However, no quantitative information has been found to provide a basis for predicting dynamic loads on externally-transported helicopter cargo. The state-ofthe-art consists of directional load factors which are presented in American National Standard MH5.1 [19] for the design of containers. The load factors are applicable to containers supported either inside or outside rotary-wing aircraft. In addition, MH5.1 requires that for externally-supported containers, their end structures and top structure be designed for a uniformly-applied aerodynamic pressure of $80 \mathrm{psf}\left(391 \mathrm{~kg} / \mathrm{m}^{2}\right)$ and 35 psf $\left(171 \mathrm{~kg} / \mathrm{m}^{2}\right)$ respectively.

\subsection{Summary of Air Transport Environment - The air transport dynamic environment is} produced by three classes of aircraft: propeller-driven airplanes, jet airplanes and helicopters. Test programs involving the measurement of vibrations aboard military cargo and personnel aircraft in each of these categories have been reported in the 1 iterature. Data obtained aboard 4 propeller-driven planes (C-123, C-130, C-133 and 377-PG), 2 turbojets (KC-135A and $\mathrm{NC}-135)$ and 4 helicopters (H-37, CH46, CH45 and HH43B) were presented in sections 4.1 and 4.2. Examination of figures 4.1 through 4.9 shows that the air transport data have been presented in several different formats. The use of various forms of acceleration versus frequency diagrams makes it difficult to establish a single predictive model for the entire environment. However, it was noted in the literature that broad-band 


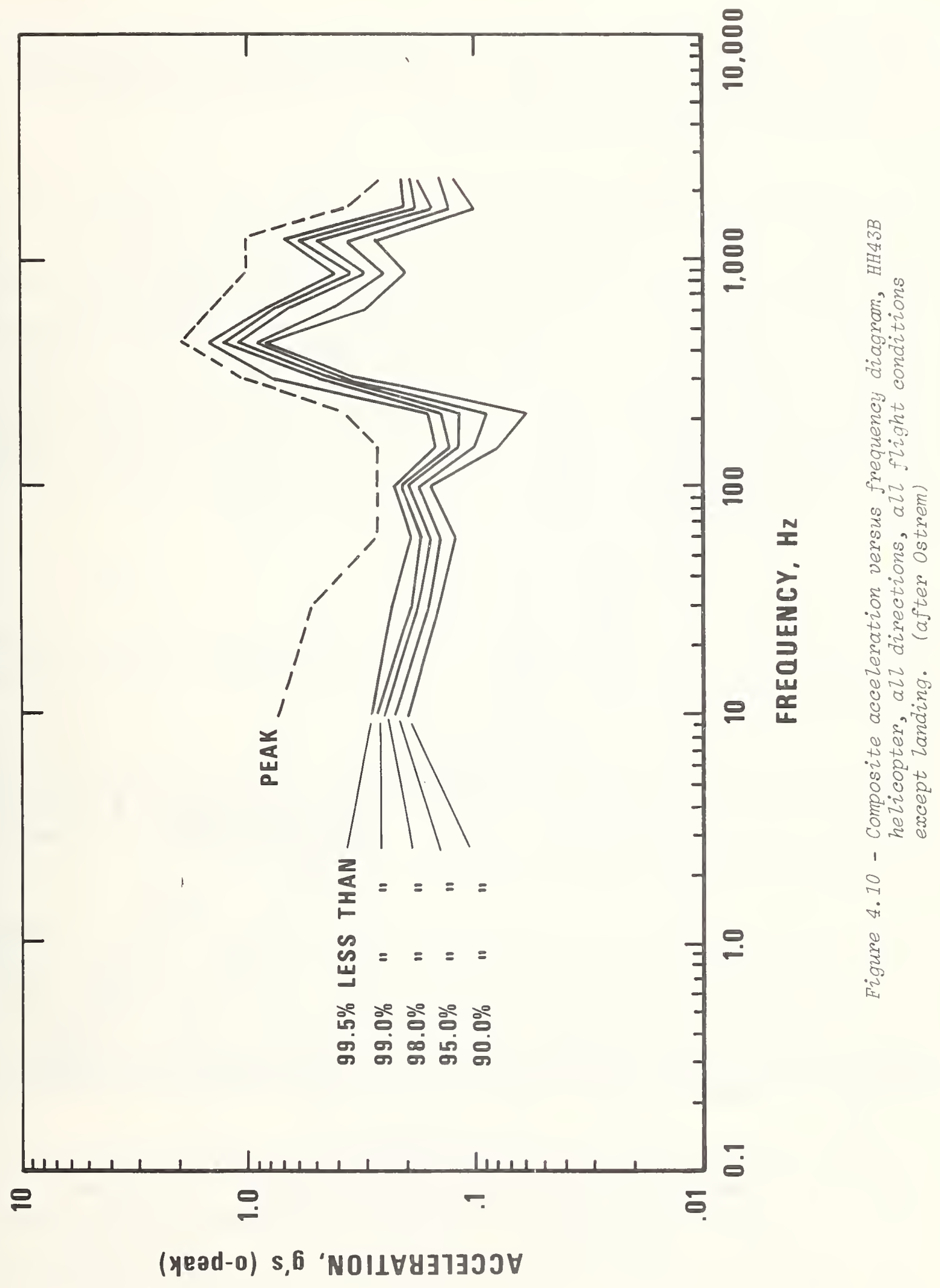


random excitation with peaks distributed approximately in a Gaussian manner, was a component common to the three classes of aircraft. Based on this observation, a common format was established for presenting the test data. The 99 percent level of zero-to-peak accelerations was selected for summarizing the various data.

The data presented in figure 4.6 for the. NC-135 turbojet were used to establish a scaling or multiplying factor for the root-mean-square data in figures 4.1 through 4.5 and

figure 4.8. Properties of the Standard Normal curve were used to calculate $g_{r m s}$ (i.e. the sample standard deviation for a zero mean transformation process) values for the frequencies shown in figure 4.6. At each selected frequency, a value of the ratio $\mathrm{g}_{0.99} / \mathrm{g}_{\mathrm{rms}}$ was computed. Then an average value was computed from the set of ratios. The average value of the ratio, which was 3.5, was applied as the multiplying factor to the $g_{\text {rms }} v a l u e s$ given in figures $4.1-4.5$ and figure 4.8. It is acknowledged that the scaling factor derived in this manner is dependent on the period over which the observations are made. Nevertheless, it is felt that the use of 3.5 as a multiplier provides a reasonable estimate of the 99 percentile accelerations. The transformation formula is as follows:

$$
\mathrm{g}_{0.99(\mathrm{o}-\text { peak })}=3.5 \times \mathrm{g}_{\mathrm{rms}}
$$

The directional summaries are presented in figures 4.11, 4.12 and 4.13. Thus, the ordinate of each diagram is $99 \%$ level acceleration $\left(\mathrm{g}_{\mathrm{o}}\right.$-peak $)$ and the abscissa is the center frequency of the various frequency bands.

Figure 4.11 presents the summary diagram for the C-123, C-130, C-133 and 377-PG aircrafts. The directional curves are composites obtained by enveloping the maximum $99 \%$ value of $g_{\text {o-peak }}$ at the indicated frequencies. Typical of the aircraft environment, the vertical direction predominates over most of the frequency range.

Figure 4.12 presents the summary diagram for the KC-135A and NC-135 turbojets. Composite curves have been plotted for both the vertical and lateral directions. It is recommended that the values given for the lateral direction be used for the longitudinal direction, due to the close agreement between the two directions. Comparison of figures 4.11 and 4.12 reveals that the acceleration magnitudes obtained from propeller-driven airplanes are higher at all frequencies than those produced by turbojets.

A summary of helicopter data obtained from cargo aircraft is presented in figure 4.13 . It should be noted that the data from the HH43B were not included in the directional composites because this aircraft is not a likely carrier of shelters. Examination of figure 4.13 shows that there is no clear predominance of any one direction. By comparing figure 4.13 with figures 4.11 and 4.12 it is seen that the acceleration amplitudes are highest for the helicopter cargo area, over the entire comparable frequency range. 


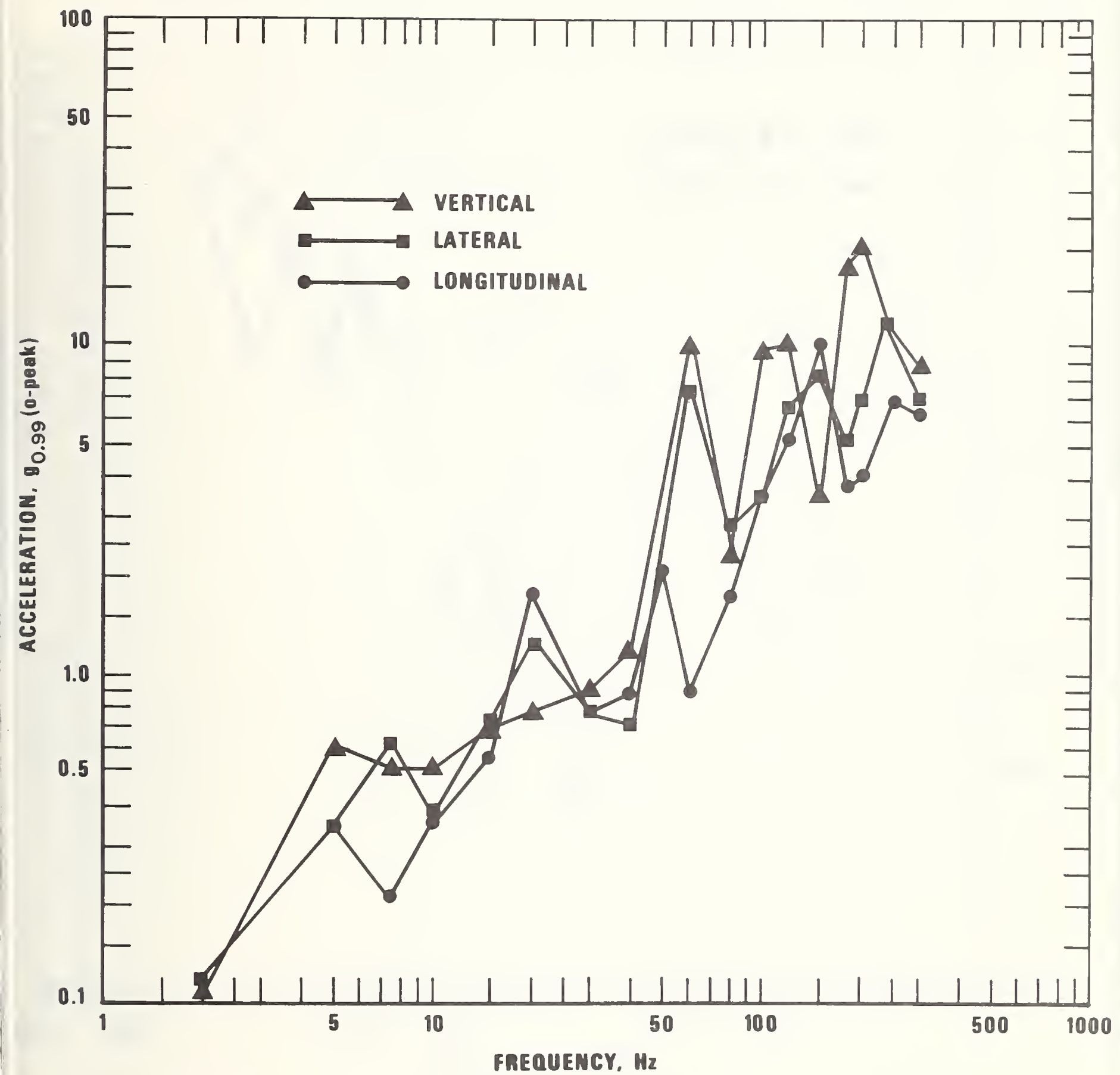

Figure 4.11 - Composite aircraft acceleration versus frequency diagrcon, 99\% level, C-123,C-130,C-133 and 377 PG propeller planes, directional. 


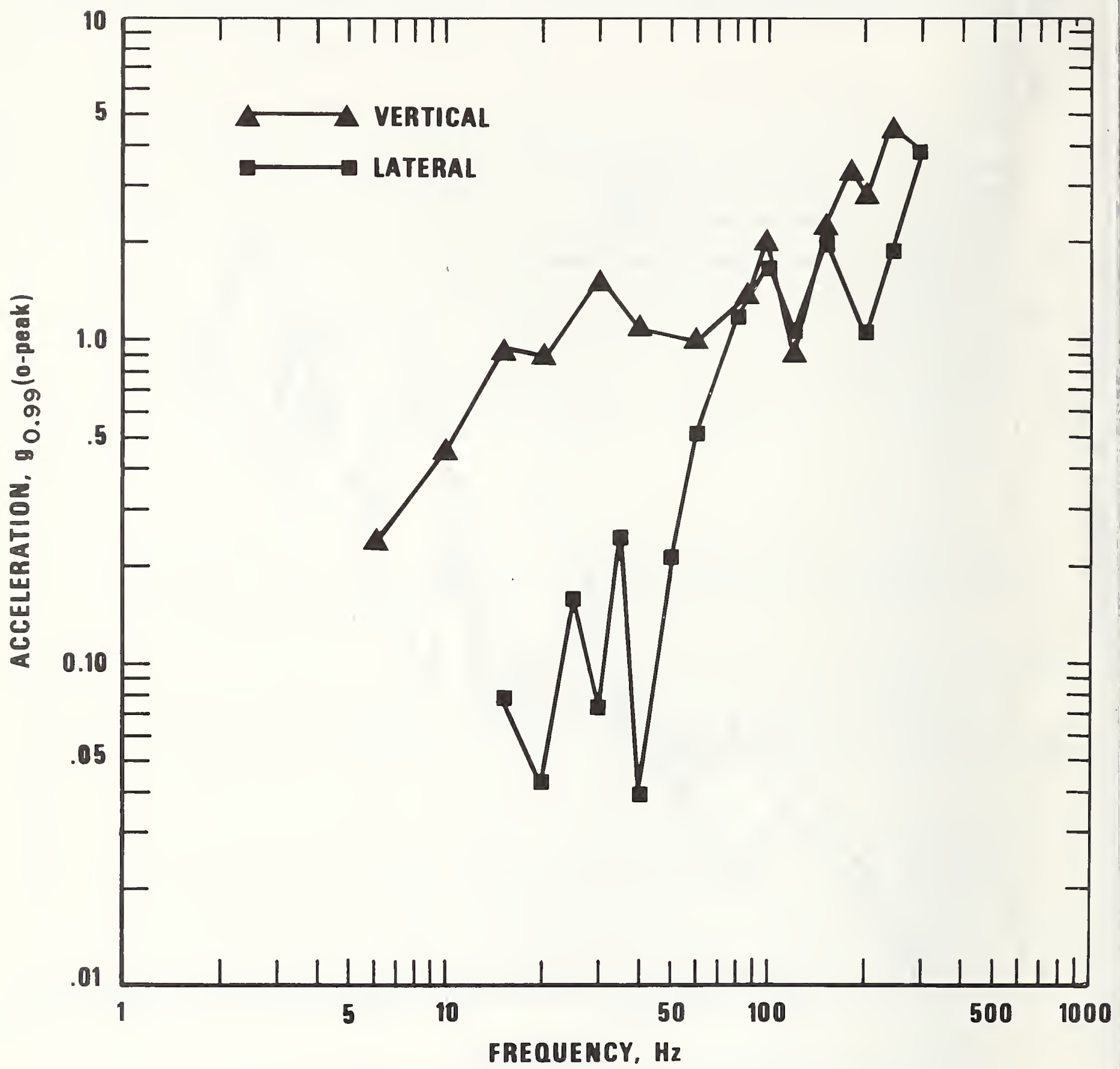

Figure 4.12 - Composite aircraft acceleration versus frequency diagram, 99\% level, $N C-135$ and $K C-135 \mathrm{~A}$ turbojets, vertical and lateral directions. 


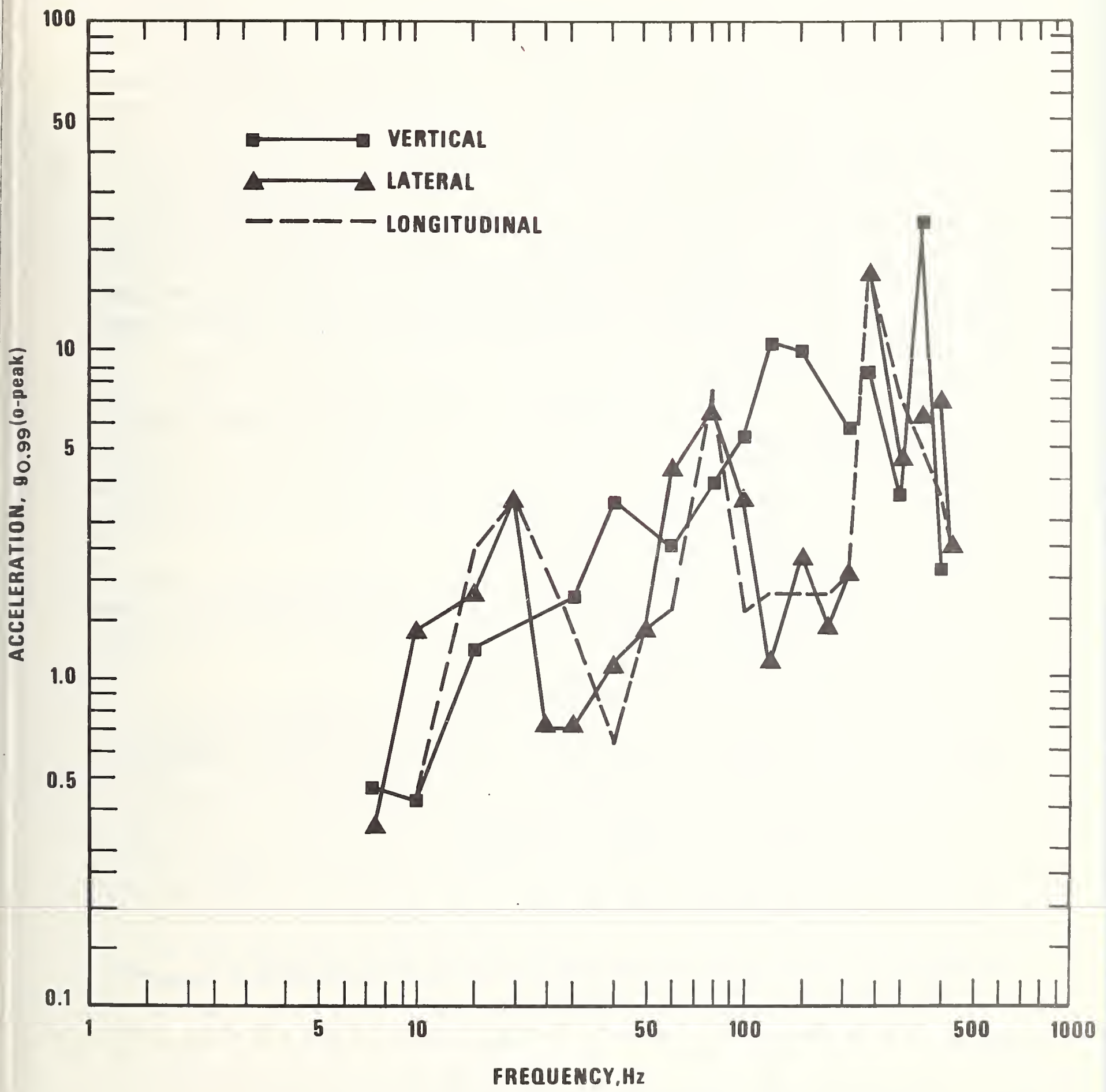

Figure 4.13 - Composite aircraft acceleration versus frequency diagram, 99\% level, $\mathrm{H}-37, \mathrm{CH} 46, \mathrm{CH} 47$ helicopters,
directional. 
The summary data presented above can be used independently or collectively in the prediction of air transport dynamic forces. An equivalent static force can be established for either of the three classes of carrier, when the design/analysis operation is narrow in scope. The critical design frequencies would be based on the known or estimated natural frequency of the shelter or shelter component. When the design/analysis considers the entire air transport mode, the absolute maximum 99\% level can be obtained by comparing the respective ordinates at the designated frequencies. It shculd be noted that the predictive models presently do not include excitations resulting from landing any of the three classes of aircraft. The composite diagrams could change as a result of incorporating data obtained from the landing event. Also, no information is included for the case of cargo suspended beneath the fuselage of a helicopter. ANSI MH5.1[19] should be referred to when this mode of transportation is a likelihood.

It is possible to predict acceleration amplitudes for other designated percentiles by using the following formula:

$$
g_{p}=g_{0.99}-\left(z_{0.99}-z_{p}\right) \frac{g_{0.99}}{3.5}
$$

where $\mathrm{g}_{\mathrm{p}}=$ The acceleration amplitude at percent level $\mathrm{P}$,

$\mathrm{g}_{0.99}=$ The $99 \%$ acceleration amplitude obtained from figures 4.11-4.13,

$\mathrm{Z}_{0.99}=$ The standard normal variable for $\mathrm{P}=0.99$

and $\mathrm{Z}_{\mathrm{p}}=$ The standard normal variable for percent level $\mathrm{P}$.

For example, the determination of the $90 \%$ level vertical acceleration for a frequency of $30 \mathrm{~Hz}$, for helicopter transport is as follows:

$$
\begin{aligned}
& g_{0.90}=1.75-(2.326-1.282) \frac{1.75}{3.5} \\
& g_{0.90}=1.75-0.52=1.23
\end{aligned}
$$

The value of 1.75 for $g_{0.99}$ was obtained from figure 4.13 , while the values of $Z_{0.99}$ and $\mathrm{Z}_{0.90}$ were obtained from table A-2 of Reference 21 . 


\section{HANDLING ENVIRONMENT}

A mobile shelter will generally experience handling loads at different stages of its useful life. For example, there is a sequence of handling events which may occur between the point of manufacture and a place of temporary storage. The dynamic environment incident to handling shelters results from two different classes of excitations. First, normal handling excitations are those produced by such terminal activities as stacking, crane hoisting, forklift transfer, jacking, towing and pushing. These excitations are deterministic in that they are primarily dependent upon the dynamic characteristics of the handling device. However, the normal handling environment cannot be adequately predicted because the available data pertaining to normal handling operations are scarce. As will be discussed below, the only documented handling vibrations found were obtained in a test involving forklifts. The second class of excitations is produced by rough handling activities such as accidental dropping, collisions and expedient handling practices. Because these handling excitations are largely dependent on human elements, the dynamic environment is non-deterministic. Predictive models in this handling mode are non-existent. However, judiciously observed handling instructions and procedures can significantly limit the severity of this source of loading.

5.1 Normal Handling Excitations - Three operations which comprise a large portion of the normal handling activities for shelters are: (1) lifting at various terminal points, (2) placement during stacking and (3) short transport by handling devices such as forklifts.

5.1.1 Lifting Inputs - Depending upon the type and location of the terminal point, shelters may be lifted by a range of machines, including forklifts, cranes, mobilizers, straddle carriers and side loaders. The dynamic input from these types of handing devices are generally characterized by intermittent $\underline{\text { I }}$ transient inputs of relatively low amplitudes, for normal conditions. Furthermore, although the dynamic forces resulting from lifting are repeated a number of times during the life of a shelter, their cumulative effect on a shelter's fatigue life is considered to be insignificant by comparison with the effect of transportation and field service loads. The basis for this conclusion is the fact that normal lifting events caused relatively low dynamic load magnitude. Thus, the absence of shock and vibration data incident to lifting is not critical to establishing design criteria. Furthermore, the acquisition of data from lifting experiments should receive relatively low priority in a transportation and handling test program.

\subsubsection{Placement During Stacking - Shelters are often stacked two-high or three-high} for storage purposes. The bottommost shelter should be capable of withstanding the inertial forces generated by the second and third tier shelters. No data are available

7I Intermittent infers a single occurrence "or irregularity in occurrence. For example: the response caused by railcar coupling or a truck crossing railroad tracks. 
to provide a basis for predicting the dynamic environment experienced by containers and shelters during stacking. However, ANSI MH-5.1 [19] requires that a downward "Design Load Factor" of 2.0 be applied in an equivalent static force analysis to account for the impact loads. The use of a load factor of 2.0 may be somewhat conservative in that the normal practice for accounting for suddenly applied loads requires a factor of 2.0 only for elevator support design.

\subsubsection{Short Transport by Handling Devices - Short distance transportation of shelters} may be accomplished by a number of handlers including forklifts, cranes amd mobilizers. Trucks are also used as short transport carriers. In addition, shelters may be towed and pushed at prior to being stored, transported over longer distances or erected. The dynamic environment caused by short-distance moving activities has not been adequately described. The only handling device for which data were found was the forklift. Gens [20] reported on the results of a study conducted to determine the dynamic loads imparted to cargo during transfer by four different industrial forklift trucks. The forklifts ranged in capacity from $20001 \mathrm{~b}$ (907 kg) to $70001 \mathrm{~b}$ (3175 kg). Another test variable was the type of tires mounted on the forklifts. Both pneumatic and solid rubber tires were used. Three-directional vibration measurements were made at the base of the handling cradle. The dynamic environment was characterized as consisting of high-amplitude discrete (i.e. transient) excitations superimposed on a background of low-amplitude pulses. Thus, the three-direction data were reduced in the form of shock spectra. Envelopes of the response spectra for each type of forklift truck are shown in figure 5.1 [20]. Note that the diagrams are presented for a damping ratio of 0.03 . Examination of figure 5.1 shows that accelerations in the vertical direction are, in general, the highest. Due to the relatively small amount of vibration data obtained for forklift operations, no prediction of the dynamic environment should presently be undertaken. Because the response amplitudes shown in figure 5.1 are relatively high, future transportation and handling research programs should assign high priority to measuring shelter responses during forklift transport.

\subsection{Abnormal Handling Excitations - Dynamic inputs from abnormal handling events are}

inherently non-deterministic. These events are caused by human error, accident or expedient procedures and, therefore, they have not been extensively documented. A statistical basis for predicting abnormal handling loads does not presently exist. The state-of-the-art consists of simulating accidental and rough handling events in standardized test methods. For example, shelters are commonly subjected to a drop test in which one end of the unit is dropped 51 in $(1.3 \mathrm{~m})$ onto a well compacted surface. This test simulates the accidental drop from the cargo bed of a M-35 truck. After conducting the test the specified number of times, acceptance is dependent upon compliance with damage criteria. Several other test procedures are available for simulating other abnormal handing events. 


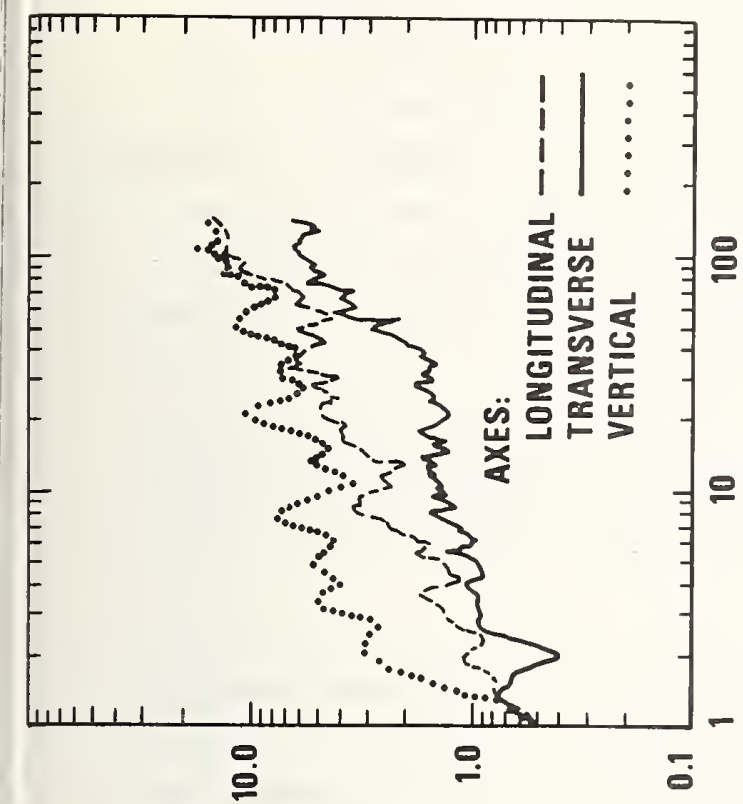

(פ) JSNOdS 34

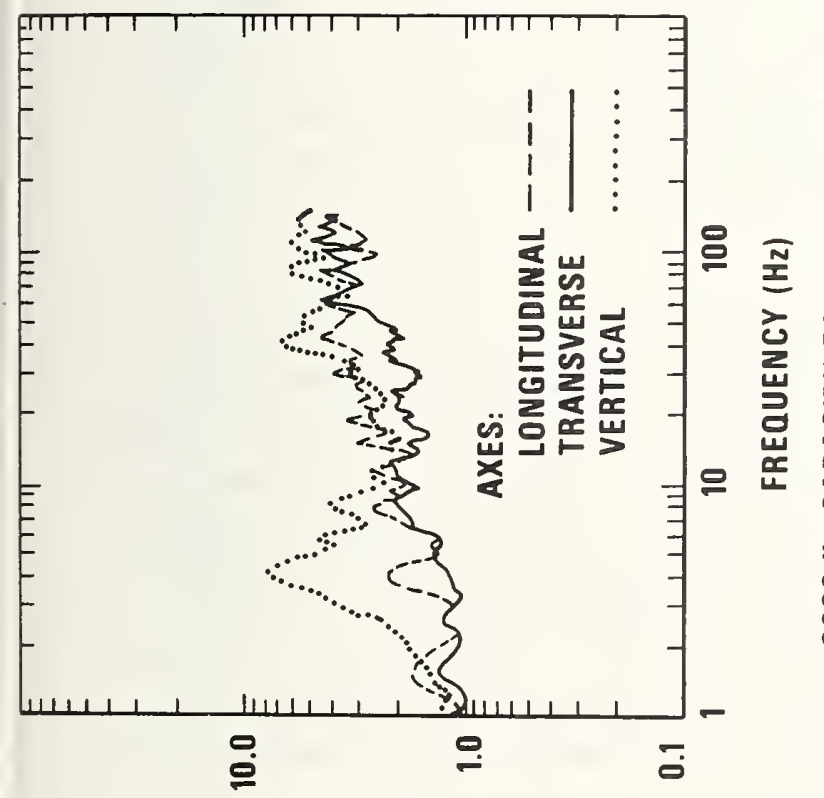

(פ) JSNOdSJY

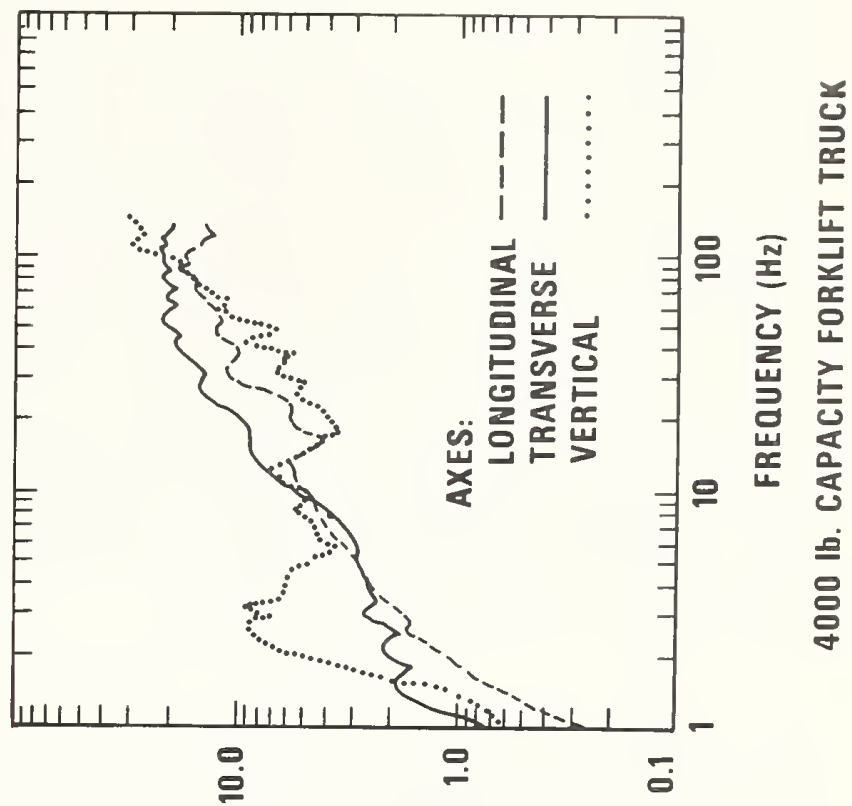

(פ) JSNOdSJY

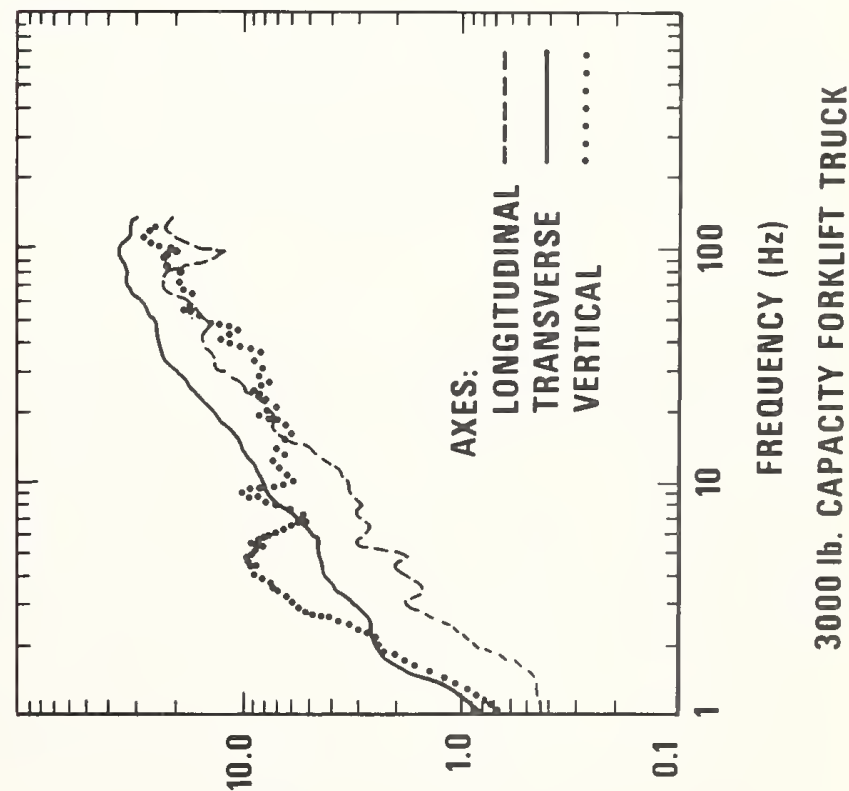

(פ) JSNOdSIY 
Both expandable and rigid shelters are required to resist loads caused by equipment, furnishings, occupants, snow, ice, wind and thermal gradient during field service. Snow, ice, wind, thermal and gravity loads imposed during storage must also be considered in shelter design. In the case of expandable shelters, their conformation during storage may be considerably different from their expanded outline while in service. The designation of design loads to account for human occupancy, furnishings and equipment is relatively uncomplicated because design load tables are readily available and the loads are invariant with the locale of shelter deployment. On the other hand, snow, ice and wind loads are complicated by being geography dependent. Also, these environmental loads are dependent upon the geometry of the structure, the nature of the terrain surrounding the structure and the degree of exposure to wind. The above-mentioned sources of service loads will be discussed in the following paragraphs.

6.1 Gravity Loads - The weights of materials, constructions and fixed equipment used in shelters are generally known quantities. Therefore, the design dead loads will be defined for both the storage and erected conditions. The floor live loads should be predicted on the basis of the intended use or occupancy of the shelter. The maximum load which will probably occur at least once during the shelter's useful life should be used in the design. Furthermore, the minimum uniformly distributed floor live loads should conform to Table I of AFM 88-3, Chapter 1 [22] and Table 1 of ANSI A58.1-1972 [23]. Where applicable, a concentrated load of $2000 \mathrm{lbf}(8896 \mathrm{~N})$ should be applied on any area, $2 \mathrm{l} / 2 \mathrm{ft}(0.76 \mathrm{~m})$ square, to produce the maximum stress condition.

6.2 Snow and Ice Loads - Shelter roofs should be designed to support the snow and ice loads listed in Table II and shown on the isoline map (Figure 2) of AFM 88-3, Chapter 1 [22]. Reference should be made to paragraph 4.d of AFM 88-3 for specific design requirements. It should be noted that the uniform load values presented in Reference 22 are based on statistical analyses of extremes of ground snowpack for a 25-Year Mean Recurrence Interval. For structures built solely for use in the continental United States, Figure A7 of ANSI A58.1-1972 [23] should be consulted. The snow load values given in Reference 23 can be used as a guide for establishing values for other parts of the world. To account for loads which may be imposed during maintenance and repair, the roof design load should in no case be less than 20 psf $\left(958 \mathrm{~N} / \mathrm{m}^{2}\right)$.

6.3 Wind Loads - While transportation and handling loads are likely to govern the design of field shelters, the structures should be analyzed for wind pressure resistance. Structural elements such as the walls and roof must be designed to resist localized wind pressures. Also, the shelter structure and its tie-down system must resist uplift, sliding and overturning. The state-of-the-art in wind load design of lowrise buildings is to compute 
external and internal pressures which are the products of the effective velocity pressure and pressure coefficients. The general formulation for wind pressure is as follows:

$$
p=q_{e} c_{p}-q_{i} C_{p i}
$$

where $\mathrm{q}_{\mathrm{e}}=$ Effective velocity pressure for external pressure,

$c_{p}=$ External pressure coefficient,

$\mathrm{q}_{i}=$ Effective velocity pressure for internal pressure,

and $\quad \mathrm{C}_{\mathrm{pi}}=$ Internal pressure coefficient.

The effective velocity pressure is a function of the basic wind speed for a given site.

The appropriate basic wind speed needed for computing the effective velocity pressure can be obtained from tables and maps which have been constructed for various mean recurrence intervals. Wind load provisions in AFM 88-3, Chap. 1 [22] should be used to obtain the design wind loads. The basic wind speeds can be obtained from Table II and Figure 1 of AFM 88-3, Chapter for locations in the United States and overseas.

6.4 Thermal Loads - The design of field shelters must consider the effects of temperature changes in addition to the effects of the service loads mentioned above. Temperature gradients through the thickness of structural elements may cause significant forces and deformations when the elements are restrained from expansion and contraction. Although the thermal forces are not classified as dead or live loads, they are additive to other field service loads. To establish the design loads caused by temperature changes, it is first necessary to quantify temperature differentials which may result from various environmental conditions.

The design temperature differential is taken to be the difference between the temperatures of the exterior and interior faces of the structural elements. The problem of defining the temperature differential for field shelters is caused by a lack of data regarding surface temperatures on the exterior faces of the shelters and a lack of information as to the profile of the temperature gradient for typical shelter constructions such as foam and beam and honeycomb-core sandwich panels. During the useful life of most shelters the inside ambient temperature will remain relatively constant, having only small deviations from normal room temperature. Hence, the interior ambient temperature can be considered a reliable estimate of the interior surface temperature. On the other hand, the exterior ambient conditions are almost continuously changing. Furthermore, exterior conditions are dependent on seasonal characteristics and on the variation in environmental conditions with locale. The factor of air temperature variation notwithstanding, statistical data on the maximum and minimum daily temperatures can be obtained from local weather bureaus and the Environmental Data Service (of the National Oceanic and Atmospheric Administration) in establishing exterior ambient conditions. The problem lies in the fact that the surface temperature may differ substantially from the ambient temperature. The surface temperature 
depends of wind and solar radiation effects and on the thermal properties of the sandwich panels. No data were found regarding the heat conduction characteristics of sandwich panels typically used in field shelters.

Considerable study is warranted in the area of heat conduction through wall and roof elements of shelters to establish models of thermal gradients for various environmental conditions. Then, upon defining the boundary restraint conditions for the structural elements, the induced thermal loads can be specified. In this way, the shelter analysis can consider thermal loads in combination with the other service loads.

6.5 Combination of Field Service Loads - The above-mentioned field service loads should be combined in accordance with section 4, ("Combination of Loads") of ANSI A58.1 [23] to establish the most unfavorable design conditions. 
It is recognized that a cycle of shelter use includes a number of possible transportation and handling activities which may affect the shelter's design. The concept of a cycle of shelter use has been illustrated in figure 1.3. Toward the objective of developing a comprehensive design criteria, a study of the dynamic environment produced by transportation and handling events was conducted. A literature search was performed to obtain test data resulting from measuring the dynamic response of cargo decks on trucks, trains, airplanes and helicopters in their respective modes of transport. The dynamic environment produced by typical military cargo carriers was of particular interest in the search because it is expected that military carriers will generally be used to transport shelters. The underlying premise of this activity was that the various loadbed responses could in turn be used as forcing function inputs in shelter design analysis. Also considered in the study were the forces incident to normal and abnormal handling activities and those produced while the erected shelters are in service. In view of the fact that shelters may be deployed in many parts of the world existing military and nonmilitary design load standards have been referenced for guidance in the selection of applicable snow and wind load values.

It was found that representative shock and vibration data for some transportation events were well documented and directly applicable to the stated objective. However, for several other transportation events and most handling operations the dynamic load data were either non-existent or insufficient. Summaries of the areas of sufficient and insufficient data are presented in the following paragraphs.

7.1 Areas of Sufficient Data - Sufficient shock and vibration data have been reported to describe the dynamic environment for railroad, road and fixed-wing aircraft transportation modes. Measurements obtained from the cargo area of several military helicopters have also been well documented. The data have usually been presented in the literature in the form of acceleration versus frequency diagrams. For continuous vibration excitations the results have been presented in several forms: cumulative probability distribution diagrams, root-mean-square acceleration versus frequency curves and zero-to-peak accelerations versus frequency curves. Cargo bed responses to shock excitations have been presented in the form of shock spectra and composite diagrams derived from enveloping spectra for different events.

Representative acceleration versus frequency diagrams have been presented in this report for commercial flatbed trucks, cargo trains, propeller-driven and turbojet airplanes and helicopters which transport the cargo inside the aircraft. Some data are also presented for four different industrial forklifts. The various transportation modes and handling operations are discussed independently to permit flexibility in the process of combining various loads. 
It is recommended that the acceleration magnitudes obtained from the diagrams be used in an equivalent static force analysis. The frequencies at which the design accelerations are selected are dependent upon the fundamental frequencies of the various elements (i.e. walls, floor and roof) of the shelter. The acceleration versus frequency curves have generally been presented for the three orthogonal axes of the carriers. Insufficient research has been performed to resolve the questions of how to combine the loads acting in three directions. Therefore, the load combinations assumed in section 6.2 of ANSI MH5.1 [19] provide the bases for the following recommendations. It is recommended that the equivalent static vertical load (accounting for inertial and gravity loads) be uncoupled from the horizontal loads and be considered as acting singly in all transportation modes. The equivalent static lateral and longitudinal design loads should be applied simultaneously with the dead load (i.e. gravity load) of the shelter.

7.2 Areas of Insufficient Data - It is recognized that shelters may be transported for relatively short distances while being suspended beneath cargo helicopters. At this writing, the frequency of occurrence of cable-supported shelter transport is unknown. But, it is felt that a comprehensive design criteria should account for the shocks and vibrations produced by this mode of cargo transport. However, sufficient vibration measurement data does not exist to quantify the dynamic loads applicable to shelters supported outside helicopters. Since helicopter transport provides the most severe environment for air transport, design load data should be developed for this case.

It was found that there is a scarcity of information regarding shocks and vibrations produced in the cargo areas of airplanes and helicopters during landing. Some data obtained for turbojet airplanes indicate that there is a low probability $\left(10^{-3}\right.$ ) of exceeding $1 \mathrm{~g}$ acceleration during landing. When compared with acceleration amplitudes produced by such events as take-off and climbing, landing accelerations appear not to govern the design load for shelters transported via turbojets. However, there is insufficient evidence to conclude that landing is inconsequential to the dynamic environment of other classes of cargo carriers. Therefore, future vibration measuring programs involving airplanes and helicopters should include landing as a test event.

Although it was observed in the literature search that various transportation studies had included acceleration measurements on various parts of military trucks (e.g. transmission housing and rear axle), insufficient data exist on cargo bed accelerations for military cargo trucks. Trucks are likely carriers for short and medium transport of shelters. As noted in Chapter 3, normal road conditions range from stretches of smooth blacktop to surfaces containing a number of dips and bumps. Abnormal conditions such as that created when a truck drives entirely on a rough shoulder should also be considered. While well documented data exist for commerical trucks traversing various normal and abnormal road conditions, future programs should include typical military cargo trucks such as the M-35 and $\mathrm{M}-55$. 
As indicated in figure 1.3, handling is the most frequently recurring event in the use cycle of a shelter. This fact notwithstanding, handing operations are the least documented events covered in this study. No dynamic load data were found for rough handing activities such as accidental dropping and collisions. However, this insufficiency is not considered critical to shelter design provided safe handling practices are prescribed and observed. There is also a scarcity of applicable data pertaining to normal handling activities such as lifting, placement during stacking and short transport by handing devices. Since lifting operations generally produce low amplitude accelerations for relatively short time periods, the absence of quantitative data is not critical in shelter design criteria. The absence of dynamic load data for placement during stacking can be compenstated for by using the design load factor of 2.0 that is recommended in ANSI MH-5.1[19]. With regard to short transport by handling devices, further study is needed to establish design load values. A study involving four types of industrial forklifts provides the only documented description of dynamic environment resulting from this handling event.

Finally, as the fundamental frequencies of the shelter's structural elements will determine the accelerations used in the equivalent static force analysis, it is essential to know the frequency magnitudes for various types of shelter construction. This information is needed before any of the data presented above can be used. At present such information is not avallable. This deficiency should be addressed by experimentally determining representative fundamental frequencies for both honeycomb core and foam and beam core sandwich panel construction. 


\section{LIST OF REFERENCES}

1. Foley, J. T., Gens, M. B. and Magnuson, C. J., "Current Predictive Models of the Dynamic Environment of Transportation," The Journal of Environmental Sciences, Jan./Feb., 1973, pp. 18-28.

2. Gens, S. G., "Rail Vehicles," Chapter 45, Shock and Vibration Handbook, Vo1. 3, McGraw-Hi11, pp 45-21 to 45-39.

3. Gens, M. B., "The Rail Transport Environment," The Journal of Environmental Sciences, July/August, 1970, pp 14-20.

4. Ostrem, F. E., "A Survey of Environmental Conditions Incident to the Transportation of Materials," Report PB-204-442, General American Transportation Corporation, Niles, Illinois, October, 1971.

5. Simmons, L. C., and Shackson, R. H., "Shock and Vibration on Rail Movement of Freight, Shock, Vibration and Associated Environments, Bulletin No. 31, Part III, U.S. Naval Research Lab., Washington, D.C., Apri1, 1973, pp. 94-101.

6. Anon., "The Railroad Environment - A Guide for Shippers and Railroad Personnel," Technical Research Department, New York Central Railroad, Co., 1966.

7. Ostrem, F. E. and Rumerman, M. L., "Shock and Vibration Transportation Environmental Criteria," Report MR 1262-1, Genera1 American Research Division, Niles, Illinois, Sept. 1965.

8. MIL-STD-810C, Military Standard Environmental Test Methods," Wright Patterson Air Force Base, Ohio, March, 1975.

9. Foley, J. T. and Gens, M. B., "Environment Experienced By Cargo During Normal Rail and Truck Transport-Complete Data," Report SC-M-71-0241, Sandia Laboratories, Albuquerque, New Mexico, August, 1971,318 pp.

10. Foley, J. T., "Normal and Abnormal Environments Experienced by Cargo on a Flatbed Truck," Report SC-DR-67-3003, Sandia Laboratories, Abuquerque, New Mexico, Feb. 1968.

11. Foley, J. T., "Normal and Abnormal Dynamic Environments Encountered in Truck Transportation," The Shock and Vibration Bulletin, Bulletin 39, Part 6, U.S. Nava1 Research Lab., Washington, D. C., March, 1969, pp. 31-45. 
12. Foley, J. T., "The Environment Experienced by Cargo on a Flatbed Tractor-Trailer Combination," Report SC-RR-66-0677, Sàndia Laboratories, Albuquerque, New Mexico, Dec. $1966,155 \mathrm{pp}$.

13. Hunter, P. A. and Fetner, M. W., "An Analysis of VGH Data Collected from One Type of Four-Engine Turbojet Transport Airplane," NASA TN D-5601, National Aeronautics and Space Administration, Jan. 1970.

14. Schlue, J. W. and Phelps, W. D., "A New Look At Transportation Vibration Statistics," Shock and Vibration Bulletin, Bulletin 37, Part 7, U. S. Naval Research Lab, Washington, D. C., October 1967, pp. 19-37.

15. Webb E. L. and Kann, A. J., "Vibration Measurements on the KC-135A Airplane During Ground, Take-Off and Flight Conditions with J57 P-43W Engines, "Report on Test No. T6-1255, Structural Test Unit and Flight Unit, Boeing Airplane Co., Seattle, Washington, January 1958.

16. Harley, R. A., "Impromptu Vibration Data Acquisition with the ELI-31 Recorder," 1967 Proceedings, 13th Annual Technical Meeting, Vol. I, Institute of Environmental Sciences, April, 1967, pp. 83-93.

17. Gens, M. B., "The Dynamic Environment of Selected Military Helicopters," The Shock and Vibration Bulletin, Bulletin 42, Part 1, U. S. Naval Research Laboratory, Washington, D. C., January 1972, pp. 153-161.

18. "U.S. Rotary-Wing Aircraft," Aviation Week and Space Technology, Vol. 94, No. 10, March 8, 1971, p. 76 .

19. American National Standard, "Basic Requirements for Cargo Containers, MH5.1-1971, American National Standards Institute, New York, N. Y., 1971.

20. Gens, M. B., "The Dynamic Environment on Four Industrial Forklift Trucks," The Shock and Vibration Bulletin, Bulletin 45, Part 4, U.S. Naval Research Laboratory, Washington, D. C., June 1975.

21. Natrella, M. G., "Experimental Statistics," National Bureau of Standards Handbook 91, National Bureau of Standards, Washington, D. C. August 1963.

22. Department of the Air Force Manual, AFM 88-3, Chapter 1, "Load Assumption for Buildings," Department of the Air Force, September 1966.

23. American National Standard, "Building "Code Requirements for Minimum Design Loads in Buildings and Other Structures," ANSI A58.1-1972, American National Standards Institute, New York, N. Y., 1972. 
NBS-IIAA (REV. 7.73)

\begin{tabular}{|c|c|c|}
\hline $\begin{array}{l}\text { U.S. DEPT. OF COMM. } \\
\text { BIBLIOGRAPHIC DATA } \\
\text { SHEET }\end{array}$ & $\begin{array}{l}\text { I. I'UHALIK AIION OR RLI'OORT NO. } \\
\text { NBSIR 77-1254 }\end{array}$ & 3. Recipient's Accession No. \\
\hline \multirow{3}{*}{\multicolumn{2}{|c|}{$\begin{array}{l}\text { 4. Tllil: ANI SUBllil: } \\
\text { Transportation, Handling and Field Service Loads for Air } \\
\text { Mobility Shelter Systems }\end{array}$}} & 5. Publication 1)ate \\
\hline & & July 1977 \\
\hline & & $\begin{array}{l}\text { 6. Performing Organization Code } \\
461.01\end{array}$ \\
\hline \multicolumn{2}{|l|}{ 7. AU'TIIOR(S) } & 8. Performing Organ. Report No. \\
\hline \multirow{2}{*}{\multicolumn{2}{|c|}{$\begin{array}{l}\text { 9. PERFORMING ORGANIZATION NAME AND ADDRESS } \\
\text { NATIONAL BUREAU OF STANDARDS } \\
\text { DEPARTMENT OF COMMERCE } \\
\text { WASHINGTON, D.C. } 20234\end{array}$}} & $\begin{array}{l}\text { 10. Project/Task/Work Unit No. } \\
461-5414\end{array}$ \\
\hline & & 11. Contract/Grant No. \\
\hline \multirow{2}{*}{\multicolumn{2}{|c|}{$\begin{array}{l}\text { 12. Sponsoring Organization Name and Complete Address (Street, City, State, ZIP) } \\
\text { Civil \& Environmental Engineering Development Agency } \\
\text { Tyndall Air Force Base, Florida } 32401\end{array}$}} & $\begin{array}{l}\text { 13. Type of Report \& Period } \\
\text { Covered }\end{array}$ \\
\hline & & 14. Sponsoring Agency Code \\
\hline
\end{tabular}

15. SUPPLEMENTARY NOTES

16. ABSTRACT (A 200-word or less factual summary of most significant information. If document includes a significant bibliography or literature survey, mention it here.)

To fulfill one of the prerequisites for establishing design criteria for military field shelters, transportation, handling and field service load data are presented. An extensive literature search was conducted to determine the magnitude and frequencies of shock and vibration responses produced by railroad, road and air cargo vehicles and by devices commonly used in handling field shelters. Summary data, extracted from field study reports, are presented in the form of acceleration versus frequency diagrams. The acceleration values can be used to compute an Equivalent Static Force input for the design and analysis of shelter models. The probabilities of occurrence of the acceleration amplitudes generated by the three transportation modes are indicated in cases where data reduction included statistical analyses. Sources of the dynamic load data included flatbed trucks, propeller and jet airplanes, helicopters, railroad flatcars and forklift trucks. Where possible, the shock and vibration data used in presenting the summary diagrams were restricted to that obtained from tests involving military vehicles commonly used to transport shelters. Recommendations are presented for the selection of static design loads to account for gravity, snow, ice and wind effects.

17. KEY WORDS (six to twelve entries; alphabetical order; capitalize only the first letter of the first key word unless a proper name; separated by semicolons) Acceleration; airplanes; cargo; dynanic loads; equivalent static force; gravity load; handling devices; handling loads; military field shelters; probability distributions; shocks, snow load; static load; trains; transportation; trucks; vibrations; wind load.

18. AVAILABILITY X Unlimited

For Official Distribution. Do Not Release to NTIS

Order From Sup. of Doc., U.S. Government Printing Office Washington, D.C. 20402, SD Cat. No. C13

\begin{tabular}{|l|c|}
\hline $\begin{array}{l}\text { 19. SECURITY CLASS } \\
\text { (THIS REPURT) }\end{array}$ & 21. NO. OF PAGES \\
UNCL ASSIFIED & 73 \\
\hline $\begin{array}{l}\text { 20. SECURITY CLASS } \\
\text { (THIS PAGE) }\end{array}$ & 22. Price \\
UNCLASSIFIED & 4.50 \\
\hline
\end{tabular}

X Order From National Technical Information Service (NTIS) Springfield, Virginia 22151 